\title{
ON AN ARCHITECTURE OF ATMOSPHERE
}

by

\author{
Matthew A. Suriano \\ Bachelor of Architectural Science (Honours), Ryerson University, 2012
}

\author{
A thesis \\ presented to Ryerson University \\ in partial fulfillment of the \\ requirements for the degree of \\ Master of Architecture \\ in the Program of \\ Architecture \\ Toronto, Ontario, Canada, 2016 \\ (C) Matthew A. Suriano 2016
}



Author's Declaration

I hereby declare that I am the sole author of this thesis. This is a true copy of the thesis, including any required final revisions, as accepted by my examiners.

I authorize Ryerson University to lend this thesis to other institutions or individuals for the purpose of scholarly research.

I further authorize Ryerson University to reproduce this thesis by photocopying or by other means, in total or in part, at the request of other institutions or individuals for the purpose of scholarly research.

I understand that my thesis may be made electronically available to the public. 

On an Architecture of Atmosphere

Master of Architecture 2016

Matthew A. Suriano

Architecture Program | Ryerson University

\begin{abstract}
In architecture, atmosphere is a term that is used to describe an intangible characteristic that permeates our built environments. The feeling of atmosphere is a direct result of one's perceptible circumstances, which are shaped by what architects design and how they go about designing it. But for a construct that is grounded in the reality of the buildings architects design, there is a clear lack of consideration and discourse on the subject of atmosphere in the design of architecture. As a result, atmosphere in architecture has been relegated to a default atmosphere by architectural processes that focus on the conceptualization of buildings as ideal objects. In order to consider atmosphere in architecture designers must acknowledge in their designs the importance of a building's temporal nature, its effect on one's corporeal presence, and the surrounding environment. This thesis work is an evolving exploration into designing an architecture of atmosphere.
\end{abstract}





\section{Acknowledgements}

Firstly, I would like to thank and express my sincere gratitude to my supervising professor John Cirka, for his patience and guidance through the development of this thesis. His extensive knowledge and approach to design thoroughly enriched my understanding of architecture and this thesis project. Every weekly discussion inspired me to delve deeper and push forward, and for all of this I thank him.

I am also incredibly grateful to Vincent Hui who over the past seven years has been a mentor and who acted as second reader for this thesis. Vince has consistently challenged and pushed me to achieve my goals, a higher standard, and to strive to become better. Without a doubt he has helped shape my academic and professional career, for which I am indebted to him.

I would also like to thank Arthur Wrigglesworth for his contribution and critique of this thesis, which helped it to develop to its final state. To Frank Bowen and all of the DAS fabrication staff I owe a great deal of appreciation for aiding me in the construction of my models and for sharing their extensive knowledge of making.

But most importantly, I must acknowledge the constant love and support of my family, my parents Mike Suriano and Paola Bertoia-Suriano, and brothers Alexander and Michael, who patiently encouraged me every step of the way. Their unwavering belief in me always helps me to keep going. 

To My Family 



\section{Table of Contents}

List of Figures $\quad$ XIII

List of Appendices and Appendix Figures $\quad$ XIX

Preface XXIII

$\begin{array}{ll}\text { Chapter I Defining Architecture } & 0 \text { I }\end{array}$

$\begin{array}{lll}\text { I.I Matter and Energy } & 03\end{array}$

$\begin{array}{ll}\text { I.2 The Architectural Typologies of Atmosphere } & 07\end{array}$

I.3 Body and Mind 09

$\begin{array}{ll}\text { I.4 Diagramming the Atmosphere of Architecture } & 12\end{array}$

$\begin{array}{lll}\text { Chapter } 2 & \text { Architecture's Default Atmosphere } & 15\end{array}$

$\begin{array}{ll}2.1 & 17\end{array}$

2.2 Default in the Typical Design Process 20

$\begin{array}{llll}\text { Chapter } 3 \text { Considering Atmosphere in Architecture } & 25\end{array}$

$\begin{array}{lll}3.1 & \text { Atmosphere Re-defined } & 27\end{array}$

3.2 The Subjectivity of an Authentic Atmosphere 31

Chapter 4 The Expression and Emergence of Atmosphere in Design 35

Chapter 5 Atmosphere on Little Morgan Bay Road 4I

5.I Location and Site Character 4I

5.2 The Atmospheres of Little Morgan Bay 42

Chapter 6 The Architectural Typologies of Atmosphere - Expanded 47

6.1 Atmosphere of Characteristics 48

6.2 Atmosphere in Forces 58

6.3 Atmosphere of Objects 62

$\begin{array}{lll}\text { Chapter } 7 & \text { Designing an Architecture of Atmosphere } & 67\end{array}$

Chapter 8 Atmosphere, Architecture, and Design 91

Post-script $\quad 95$

$\begin{array}{ll}\text { Appendices } & 97\end{array}$

$\begin{array}{ll}\text { Endnotes } & 115\end{array}$

Bibliography 121 



\title{
List of Figures
}

\author{
Figure I What is Architecture? \\ Source: Matthew A. Suriano \\ Figure 2 Intensive and Extensive, Reiser + Umemoto \\ Source: Reiser + Umemoto, Atlas of Novel Tectonics - https://parametricmonkey.files. \\ wordpress.com/2015/0I/reiserumerto_2006_p73.jpg
}

Figure 3 Hell's Gate \#8, Mark Ruwedel - 2008

Source: galleryluisotti - www.galleryluisotti.com/artists/mark-ruwedel/images

Figure 4 Columbia and Western \#3, Mark Ruwedel - 1999

Source: galleryluisotti - www.galleryluisotti.com/artists/mark-ruwedel/images

Figure 5 Devil's Gate \#24, Mark Ruwedel - 2003

Source: galleryluisotti - www.galleryluisotti.com/artists/mark-ruwedellimages

Figure 6 Brion Cemetery, Carlos Scarpa - 1968

Source: Thomas Nemeskeri - https://www.flickr.com/photos/world3/9094833766

Figure 7 Therme Vals, Peter Zumthor - 1996

Source: Helene Binet - http://www.metalocus.es/content/en/blog/20/3-riba-royal-gold-medalwinner-peter-zumthor-conversation-2-videos

Figure 8 Monumento a Sandro Pertini, Aldo Rossi - 1990

Source: http://italianpiazza.blogspot.ca/2009// / /aldo-rossi-monument-to-sandro-pertini.html

Figure 9 The Familiar Objects, Rene Magritte - 1928

Source: $h t t p: / / w w w . w i k i a r t . o r g / e n / r e n e-m a g r i t t e / t h e-f a m i l i a r-o b j e c t s-1928$

Figure 10 Le Modulor, Le Corbusier - 1945

Source: Foundation Le Corbusier - www.foundationlecorbusier.fr

Figure II Diagramming Atmosphere in Architecture

Source: Matthew A. Suriano

Figure 12 Hardware Store, Default Atmosphere - 20 I I

Source: www.fav.me/d38f4y3

Figure 13 Devil's Gate Triptych, Mark Ruwedel - I 996

Source: galleryluisotti - www.galleryluisotti.com/artists/mark-ruwedellimages 
Figure 14 Plato's Cave - Jan Saenredam and Cornelis van Haarlem - 1604

Source: National Gallery of Art - http://www.nga.gov/content/ngaweb/Collection/art-objectpage.62542.html

Figure $15 \quad$ Notre-Dame de Paris, Cathedral Nave - 1877

Source: Cornell University Library - http://library24.library.cornell.edu:8280/luna/servlet/detail/ CORNELL 3 1 741 72 10130005\#

Figure 16 The Weather Project, Olafur Eliasson - 2003

Source: Tate Photography - http://i.telegraph.co.uk/multimedia/archive/01716/ unliever-2003_Ola_I 716544 i.jpg

Figure 17 Bruder Klaus Kapelle Interior, Peter Zumthor - 2005

Source: Pietro Savorelli - http://3.bp.blogspot.com/-lq2FsK3HCaU/VIlppAEVeRI/

AAAAAAAABD4/jYF6bHfOo5k/s /600/capilla_brother_klaus_interior_2.jpg

Figure 18 Blur Building, Diller Scofidio + Renfro - 2002

Source: http://4 I.media.tumblr.com/a6df96bc7e5bbfb2094d5e7b5fI d70cc/tumblr_ nkstl75wPMIscptfiol_/280.jpg

Figure 19 Wanderer Above the Sea of Fog, Caspar David Friedrich - 1818

Source: Tate Modern London - www.tate.org.uk/context-comment/articles/staringcontemporary-abyss

Figure 20 The Holocaust Tower, Jewish Museum Berlin, Daniel Libeskind - 1999

Source: Studio Libeskind - www.libeskind.com/work/jewish-museum-berlin

Figure $21 \quad$ Circulation Void, Jewish Museum Berlin, Daniel Libeskind - 1999

Source: Studio Libeskind - www.libeskind.com/work/jewish-museum-berlin

Figure 22 Laurentian Library, Michelangelo - 1568

Source: http://news.lib.uchicago.edu/wp-content/uploads/201 I/04/Laurentian_readingroom2. jpg

Figure 23 Snow Storm - Steam-Boat off a Harbour's Mouth, William Turner - 1842

Source: Tate Modern London - http://www.tate.org.uk/art/artworks/turner-snow-storm-steamboat-off-a-harbours-mouth-n00530

Figure 24 Bruder Klaus Kapelle, Peter Zumthor - 2005

Source: Rui Cardoso - http://afasiaarchzine.com/20/3//2/peter-zumthor-8 
Figure 25 Kunsthaus Bregenz, Peter Zumthor - 1997

Source: $h$ ttps://madelineantoinette.files.wordpress.com/2010/05/entrance-hall-peterzumthor.jpg

Figure 26 Site Location, 1054 Little Morgan Bay

Source: Matthew A. Suriano

Figure $27 \quad$ I:2500 - Context Model

Source: Matthew A. Suriano

Figure 28 Site Character

Source: Matthew A. Suriano

Figure 29 Interior Atmosphere, Study No. I

Source: Matthew A. Suriano

Figure 30 Interior Atmosphere, Study No. 2

Source: Matthew A. Suriano

Figure 31 Interior Atmosphere, Study No. 3

Source: Matthew A. Suriano

Figure 32 Interior Atmosphere, Study No. 4

Source: Matthew A. Suriano

Figure 33 Tactile Study No. I

Source: Matthew A. Suriano

Figure 34 Tactile Study No. I, Fastening Detail

Source: Matthew A. Suriano

Figure 35 Tactile Study No. I, Stitching Detail

Source: Matthew A. Suriano

Figure 36 Tactile Study No. 2, Fastening Detail

Source: Matthew A. Suriano

Figure 37 Tactile Study No. 2

Source: Matthew A. Suriano

Figure 38 Tactile Study No. 2, Leather Weave

Source: Matthew A. Suriano

Figure 39 Tactile Study No. 3, Carved Door

Source: Matthew A. Suriano 
Figure 40 Tactile Study No. 3

Source: Matthew A. Suriano

Figure 4l Tactile Study No. 3, Door Lock

Source: Matthew A. Suriano

Figure 42 Light and Materiality Study No. I

Source: Matthew A. Suriano

Figure 43 Light and Materiality Study No. 2

Source: Matthew A. Suriano

Figure 44 Light and Materiality Study No. I, Detail

Source: Matthew A. Suriano

Figure 45 Light and Materiality Study No. 2, Detail

Source: Matthew A. Suriano

Figure 46 Light and Materiality Study No. 3, Screen Depth

Source: Matthew A. Suriano

Figure 47 Light and Materiality Study No. 3

Source: Matthew A. Suriano

Figure 48 Light and Materiality Study No. 3, Detail

Source: Matthew A. Suriano

Figure 49 Facade and Materiality Study No. I

Source: Matthew A. Suriano

Figure 50 Facade and Materiality Study No. I, Charred Surface

Source: Matthew A. Suriano

Figure 5 I I:250 Site and Structural Expression Study

Source: Matthew A. Suriano

Figure 52 I:25 Tectonic Detail Study

Source: Matthew A. Suriano

Figure 53 I:100 Site Massing, View South

Source: Matthew A. Suriano

Figure 54 I:100 Site Massing, Circulation and Procession

Source: Matthew A. Suriano 
Figure 55

Figure 56

Figure 57

Figure 58

Figure 59

Figure 60

Figure 61

Figure 62

Figure 63

Figure 64

Figure 65

Figure 66

Figure 67

Figure 68

Figure 69
I: 00 Site Massing, Lake View

Source: Matthew A. Suriano

I:I Detail Model - Column, Beam, and Decking Structural Assembly Source: Matthew A. Suriano

I:I Detail Model - Decking and Beam Intersection

Source: Matthew A. Suriano

I:I Detail Model - Column and Beam Connection

Source: Matthew A. Suriano

I:I Detail Model, Entrance Door and Exterior Cladding

Source: Matthew A. Suriano

I:I Detail Model, Entrance Door and Door Handle

Source: Matthew A. Suriano

I:I Detail Model - Exterior Cladding and Door Lock

Source: Matthew A. Suriano

I:50 Sectional Model

Source: Matthew A. Suriano

\section{I:50 Sectional Model,View North}

Source: Matthew A. Suriano

I:50 Sectional Model - Section I

Source: Matthew A. Suriano

I:50 Sectional Model - Section I, Entry Bridge

Source: Matthew A. Suriano

I:50 Sectional Model - Section I, Studio Volume

Source: Matthew A. Suriano

I:50 Sectional Model - Section 2

Source: Matthew A. Suriano

I:50 Sectional Model - Section 2, Dwelling Entrance

Source: Matthew A. Suriano

I:50 Sectional Model - Section 2, Exterior Bridge to Studio

Source: Matthew A. Suriano 
Figure $70 \quad$ I:50 Sectional Model - Section 3

Source: Matthew A. Suriano

Figure 7 I I:50 Sectional Model - Section 3, Roof Scupper and Ribbon Window Source: Matthew A. Suriano

Figure 72 1:50 Sectional Model - Section 3, Operable Envelope

Source: Matthew A. Suriano

Figure $73 \quad$ I:50 Sectional Model - Section 4

Source: Matthew A. Suriano

Figure 74 I:50 Sectional Model - Section 4, Interior Screen and Exterior Transition Source: Matthew A. Suriano

Figure 75 I:50 Sectional Model - Section 4, Exterior Deck

Source: Matthew A. Suriano

Figure $76 \quad$ I:50 Sectional Model, Procession and Rhythm

Source: Matthew A. Suriano 


\section{List of Appendices and Appendix Figures}

Appendix A Orthographic Drawings

Site Plan, Floor Plan, Sections, and Elevations

\begin{abstract}
Figure A I I:300 Site Plan
Source: Matthew A. Suriano
$\begin{array}{lll}\text { Figure A } 2 & \text { I:250 Floor Plan }\end{array}$
Source: Matthew A. Suriano
Figure A 3 I:250 West Elevation
Source: Matthew A. Suriano
Figure A 4 I:250 South Elevation
Source: Matthew A. Suriano

Figure A 5 I:250 East Elevation

Source: Matthew A. Suriano

Figure A $6 \quad$ I:250 North Elevation
Source: Matthew A. Suriano

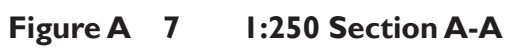

Source: Matthew A. Suriano

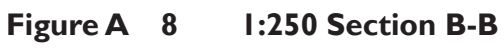

Source: Matthew A. Suriano

Figure A 9 I:250 Section C-C

Source: Matthew A. Suriano 
Appendix B

Dwelling at 1054 Little Morgan Bay Road

Figure B I Perspective Drawing No. I

Source: Matthew A. Suriano

Figure B 2 Perspective Drawing No. 2

Source: Matthew A. Suriano

Figure B 3 Perspective Drawing No. 3

Source: Matthew A. Suriano

Figure B 4 Perspective Section A

Source: Matthew A. Suriano

Figure B 5 Perspective Section B

Source: Matthew A. Suriano

Figure B 6 Perspective Drawing No. 4

Source: Matthew A. Suriano 
Appendix C

The Characteristics of Atmosphere

Figure C I Preliminary Drawing Study, Spatial Study No. I Source: Matthew A. Suriano

Figure C 2 Preliminary Drawing Study, Spatial Study No. 2 Source: Matthew A. Suriano

Figure C 3 Preliminary Drawing Study, Spatial Study No. 3 Source: Matthew A. Suriano

Figure C 4 Preliminary Drawing Study, Spatial Study No. 4 Source: Matthew A. Suriano 



\section{Preface}

Beginning the journey of architectural education as a first-year undergraduate student in 2008, the notion of atmosphere had already entered into the collection of concepts I considered in relation to architecture. At the end of my first semester of study I was assigned the task of responding to the seemingly simple, but deceivingly complex, question: "What is Architecture?" [Figure 1]. My response included the following:
"More than simply an empirical science, architectural design possesses the ability to evoke emotion, create atmosphere, and give definition to a space. From the beautiful to the brutal, the classical to the modern, the celebration of glory to the commemoration of tragedy, architecture retains the ability to express the entire spectrum of the human experience".

Even at this early stage of my education, I had identified atmosphere as a critical characteristic of architecture. While I still consider atmosphere central to any definition of architecture, in reflecting on my earlier answer I wonder whether I had fully understood the concept of atmosphere and its definition at that time. Atmosphere's omnipresence as a by-product of our built world is evident even if we cannot precisely define it. Just like I had recognized atmosphere as a key component of architecture, for many designers and those who consciously interact with the built environment, the notion of atmosphere engendered by the spaces that surround them is a prevalent one. Atmosphere is a term which everyone inherently understands and 
the inability to precisely define it does not equate to a lack of awareness that it exists.

It is this pervasiveness of atmosphere in our architecture, but also the lack of meaning and general understanding of the term, that has drawn me to this study and which will be the focus of this thesis. In this regard, the thesis will not be an attempt to decompose atmosphere into a scientific formula; rather it is a body of work that seeks to understand the concept in its entirety, to comprehend this single word, its ramifications on architectural design, and what it means to work with atmosphere in designing architecture. 
December $2^{\text {nd, }} 2008$

For: Prof. John Cirka

\section{ASC 103 The Built Context}

What is Architecture?

Matthew Suriano

What is architecture? For something that we interact with everyday, in a very real and physical sense, the definition of architecture seems to remain extremely illusive. At its basis, I believe, it can best be analyzed with respect to two major traits. At first, architecture seems most perceptible in its physical, empirical form. The many buildings which we come across in our daily interactions with the surrounding environment demonstrate the material quality of the practice. These structures are the product of a design process whose objective is to create functional spaces suited to accommodate the needs and purposes of people who come across them from both the inside and the outside. Like a musical symphony or most pieces of art work, architecture has a definite structure. Therefore, as a discipline, it also includes all aspects that go into composing the form. Purpose, geography, forces (either structural or natural), geometry, materiality, and light all have roles in creating a structure's form while submitting to its functionality. The considerations of these many aspects, both aesthetic and functional, lead to a second tenet of architecture as a form of art and artistic expression. More than simply an empirical science, Architectural design possesses the ability to evoke emotion, create atmosphere, and give definition to a space. From the beautiful to the brutal, the classical to the modern, the celebration of glory to the commemoration of tragedy, architecture retains the ability to express the entire spectrum of the human experience. However, good architecture requires a balance between these two characteristics. Like a musical composition, a design must borrow from the imagination and harmonize it in accordance with the practical constraints of its tools and instruments. 



\section{I}

\section{Defining Atmosphere}

Atmosphere. A term of glowing generalities that carries with it a vague and abstract yet highly valued meaning. It is a word that is also often used to express a state without offering supporting details. Nonetheless, it is a term that seems to be universally understood and liberally used. Yet defining the word atmosphere presents a challenge, which is made even more difficult when attempting to contextualize its meaning in relation to architecture. Celebrated Argentinean writer and poet Luis Borges, in the first of his 1967 lectures at Harvard University titled 'This Craft of Verse', illustrates the complexity of defining concepts in which there is a vague yet shared understanding. In his discussion Borges describes the difficulty of comprehensively defining the concept of poetry, a subject of which he is an authority. Borges states,

"We know it [poetry] so well that we cannot define it in other words, even as we cannot define the taste of coffee, the colour red or yellow, or the meaning of anger, of love, of hatred, of the sunrise of the sunset, or of our love for our country. These things are so deep in us that they can be expressed only by those common symbols that we share. So why should we need other words?"2

In spite of this inherent conflict, Borges then goes on to provide a definition of poetry that he believes may be good enough for a dictionary, however he expressly acknowledges that such an attempt is feeble, crude, and unable to capture the 
complexity of his own art. Similar to Borges' struggle to define poetry, a definition of atmosphere in relation to architecture is limited in its ability to summarize the full understanding of this concept; any definition falls short of capturing the understanding of atmosphere that one innately comprehends but at the same time has difficulty describing.

However, in order to begin to contextualize atmosphere in architecture, one can say the following about it in an architectural context: atmosphere surrounds us and yet also emanates from objects; it is present at both a meteorological and local level; it is the combination of intensive and extensive properties; ${ }^{3}$ and it is perceived both physically and emotionally. Yet like many of the descriptions of atmosphere found in architectural texts, these characterizations of atmosphere by no means equate to a definition. Rather the statements are simply a series of observations attempting to capture the fullness of the term.

When discussed, the concept of atmosphere is often considered either in terms of qualitative descriptions or preceded by qualifying adjectives. As a result, atmosphere is not often used or considered as a noun or a thing. Noting this, architectural theorist Mark Wigley, in the 1998 issue of architectural journal Daidalos, states, "[by] definition, [atmosphere] lacks definition" and thus the ambiguity of the concept allows it to elude the discourse of architecture in both practice and theory. ${ }^{4}$ Wigley's sentiments in relation to the discussion of atmosphere in architecture have remained true and are evident when scanning the dialogue found in architecture schools, academic journals, and the work of architectural practitioners. For such an omnipresent part of the built environment that architecture creates, there is a clear lack of consideration and discourse on the topic of atmosphere. Thus, in response to the ambiguity of atmosphere (as noted by Wigley) and in order to continue exploring atmosphere, this thesis will put forward a primitive definition of atmosphere while accepting the description's limitations. In a similar manner to Luis Borges' unpolished and, as he himself admits, feeble attempt to define poetry, it should be understood that this definition of atmosphere does not capture the multiplicity of the term but rather provides context for the development of a larger understanding.

The term atmosphere can relate to two distinct concepts. First and foremost atmosphere is generally used to define the gaseous layer that surrounds our planet. While this notion of atmosphere is the commonly interpreted meaning of the term, it does not directly relate to the discussion of atmosphere in the context of architecture. The second and more suited definition of atmosphere in relation to architecture is as follows: 
Atmosphere (noun) - the pervading sensation of a tone or ambiance in/of a place, space, or object ${ }^{5}$

Despite the fact that this definition summarizes the notion of atmosphere in relation to architecture, the simplicity of the description only prompts further questions, such as what defines an atmosphere as a thing, how is atmosphere perceived, what effect does a consideration of atmosphere have on the design of architecture, and what affect is there in one's perception of architectural space.

I.I Matter and Energy: It is not clear in the initial and simple definition of the term provided above what defines atmosphere as a thing, a noun. Atmosphere, in this initial description, is characterized as an intangible ethereal sensation that one perceives in the physical world and through the things which occupy the physical world. For many, this perceived intangible sensation is a result of the environment one is in and the things one experiences that are then understood and perhaps verbalised as feelings, moods, and sensations. Yet, while this intangible thing (atmosphere) is generally understood in the context of one's own perception, its true nature is rooted in the physical environment that engenders the individual perceptions in the first place. Thus, what is essential to defining an atmosphere is what also defines other things in the world. That is of course the combination of matter and energy. We can approach this in an architectural context as surface and environment, the material and immaterial.

Stepping back from viewing atmosphere through the lens of architecture, at the most basic level matter and energy are the elemental core of the physical world and consequently the basis of one's own perception of it. The ability to understand matter as the essence of one's perception of atmosphere is more easily understood due to its material basis in comparison to the notion of energy. Matter is more noticeable and perceivable than energy when considering what comes to define a place, space, or object. What distinguishes matter from energy in its perceivable characteristics is that matter creates distinctive and defined tangible boundaries that are legible as both visual and tactile barriers. ${ }^{6}$ In the current human condition the way one perceives the world has come to privilege and depend on the optical, tactile and other senses. As a result there is a focus on matter as the delineator of space or things, yet energy also play a large role in one's perception of things and places.

In contrast to matter, energy is not a material thing that forms boundaries. Rather, energy is an immaterial entity that for the most part escapes the sense of 
vision, but not the sensation of touch and some of the other senses. None the less, energy - although more difficult to comprehend - is equal to matter in determining and defining one's perception of atmosphere. It is important to note here that this concept of energy is distinct from the popular understanding of energy as a source of power (such as electromagnetic energy, hydroelectric energy, solar energy, etc.). Energy, in the present sense, is a definer of spatial boundaries; not through distinct and defined boundaries like matter, but through transitional zones of energy fields and flows [Figure 2]. ${ }^{7}$ These fields and flows of energy are what one may refer to as non-visual environments that are constantly present in our surroundings. Whether noticeable or not, the forces of energy affect conditions such as temperature, sound, and pressure that contribute to shaping the perception of architectural space. Furthermore, the interaction between energies and material substances (such as wood or water) contribute to other non-visual forces, such as smell or humidity, which also affect one's perception of an environment. While not as obvious as matter, energy, as it is filtered through the senses, is just as important of a contributor as matter to a perceived atmosphere.

Matter and energy are fundamental in defining atmosphere because they are the generators of the phenomenal boundaries of human perception. Together they come to form the foundation of our perceptible circumstance, as one exists in relation to the world and the things within it. While matter and energy are, in the context of atmosphere, the basis of what one perceives, it should be noted that these entities in their pure form do not create an atmosphere. This fact is most noticeable in the natural world that surrounds us. Nature's various types of environments are a result of the combination of matter and energy, yet it cannot be said that every natural setting or individual landscape has a perceptible atmosphere. Rather, it is the result of what matter and energy come to form in the world that, in relationship to one's own perception of an environment or the objects in it, defines and determines an atmosphere. The work of American-Canadian landscape photographer Mark Ruwedel clarifies this point. Ruwedel's photographs of Western American and Canadian landscapes [Figures 3-5] focus on the narration of geological processes found where matter and energy meet. ${ }^{8}$ In the process of taking these photographs the atmosphere of these environments are also captured. It is the unique condition of the scale of the land, the decay of matter, the understood forces of nature, as well as the celestial quality of water vapour in the air, that in these particular environments combine to create the atmosphere captured through Ruwedel's camera lens. Without doubt there were other locations not considered worthy of Ruwedel's focus because

Figure No. 2 
Matter

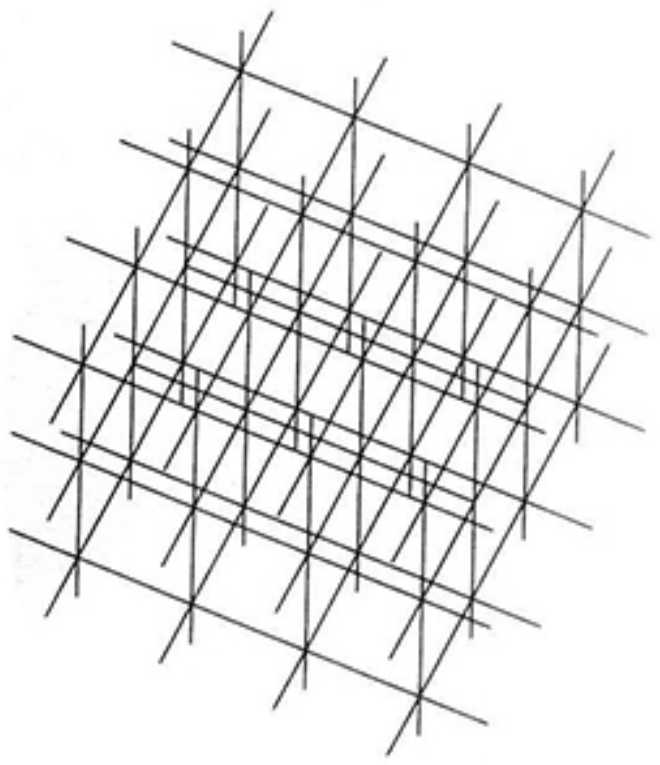

Scalar System

Extensive

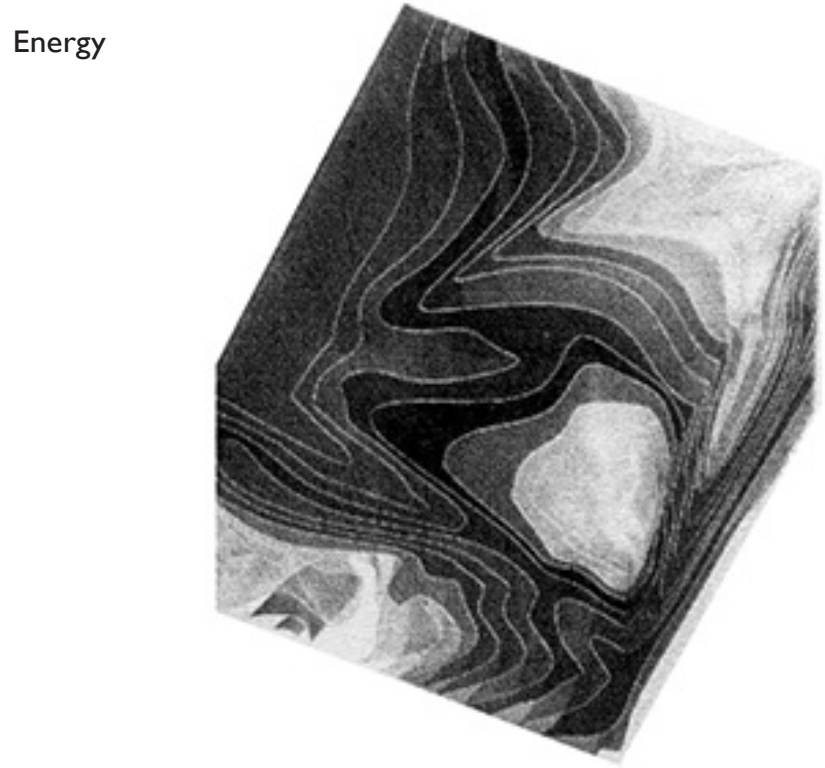

Gradient Field

Intensive 


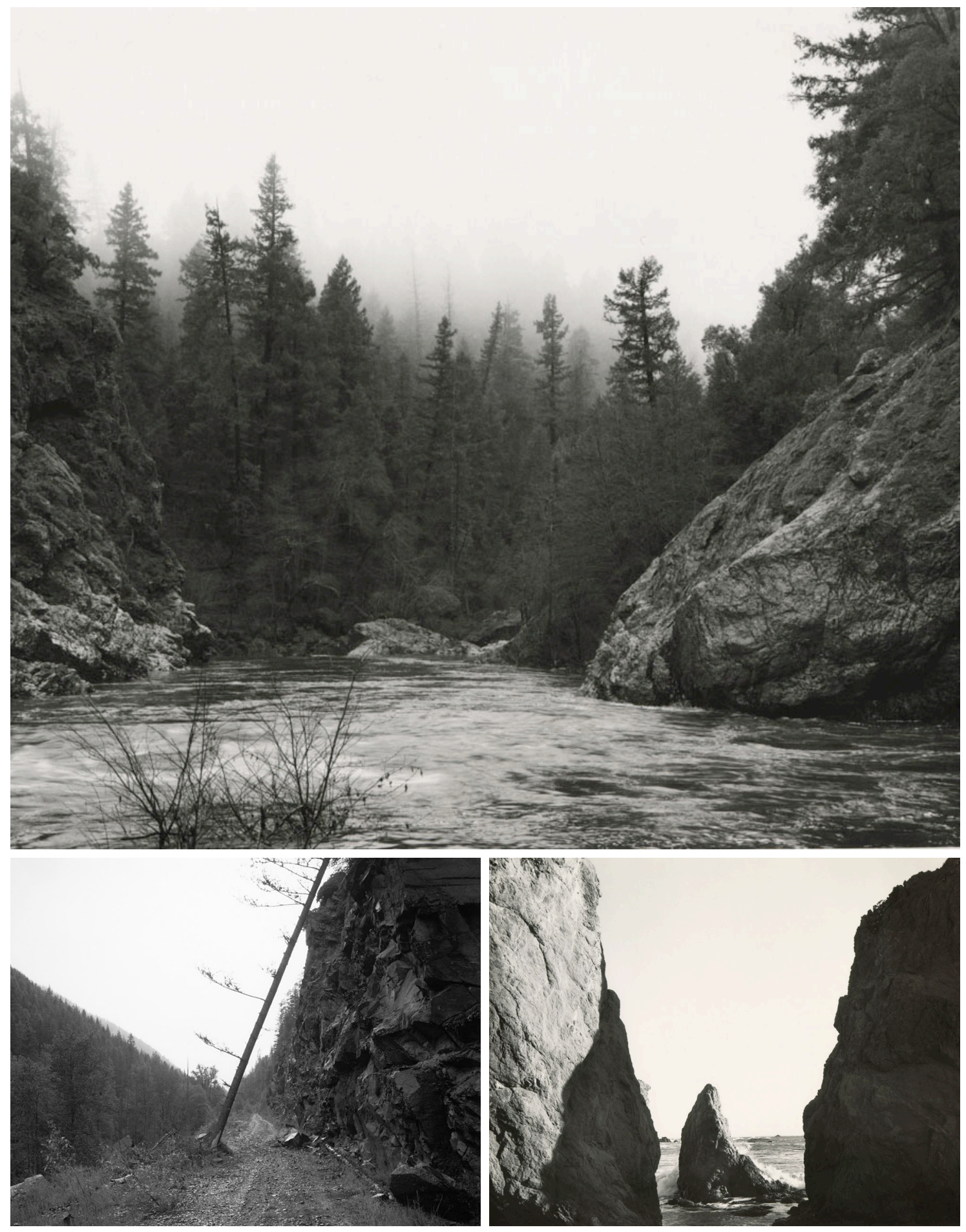


Figure No. 3

Hell's Gate \#8

Mark Ruwedel

Figure No. 4

Columbia and Western \#3

Mark Ruwedel

Figure No. 5

Devil's Gate \#24

Mark Ruwedel not all matter and energy come to form those intense atmospheric conditions he so purposefully sought to capture.

I.2 The Architectural Typologies of Atmosphere: In nature, the conditions of matter and energy that come to define an atmosphere are the direct result of specific temporal environments and topological features of the earth that have developed over thousands of years. In contrast to this natural process, the atmosphere relating to the built object of architecture is a direct result of matter and energy that has been shaped by designers into spaces and objects. While atmosphere is a product of both the natural and designed circumstance, the distinction in the process between a naturally evolved and consciously produced environment is important in developing an understanding of the relationship between design and atmosphere. In nature, matter and energy come to form their own environments and potential atmospheres. However, what is it about matter and energy that is considered when designing or understanding an architecture of atmosphere?

Three distinct categories of atmosphere in architecture form when reflecting on this question. These categories have in various capacities been investigated by both architectural practitioners and theorists working on the topic of atmosphere, but have not been characterized in the three following groups. The three categories are: firstly, Atmosphere of Characteristics, which is directly related to matter; secondly, Atmosphere in Forces, which is associated with energy; and lastly, Atmosphere of Objects, which is the result of compounding matter and energy. Each of these categories relating to atmosphere are associated with properties that are considered in the process of architectural design and affect the way an architect approaches the shaping of matter and energy to create atmosphere.

In the category Atmosphere of Characteristics it is the consideration of matter that is selected and shaped by the architect while bearing in mind architectonic considerations such as materiality and texture, light and shadow, shape and form, and scale and proportion [Figure 6]. On the opposite end of the spectrum, Atmosphere in Forces is the attention focused on energy and its effect on architecture through aspects such as temperature, sound, humidity, and smell, which all contribute to shaping one's sensorial perceptions of a space or object [Figure 7]. In between matter and energy is the category of Atmosphere of Objects, which focuses on the reaction between the energy of forces and the characteristics of matter that alter a material's state. In design, this category is often associated with the recognition of a material's decay and the weathering of buildings [Figure 8]. The categories presented here have far reaching implications on the approach of design with respect to atmosphere 

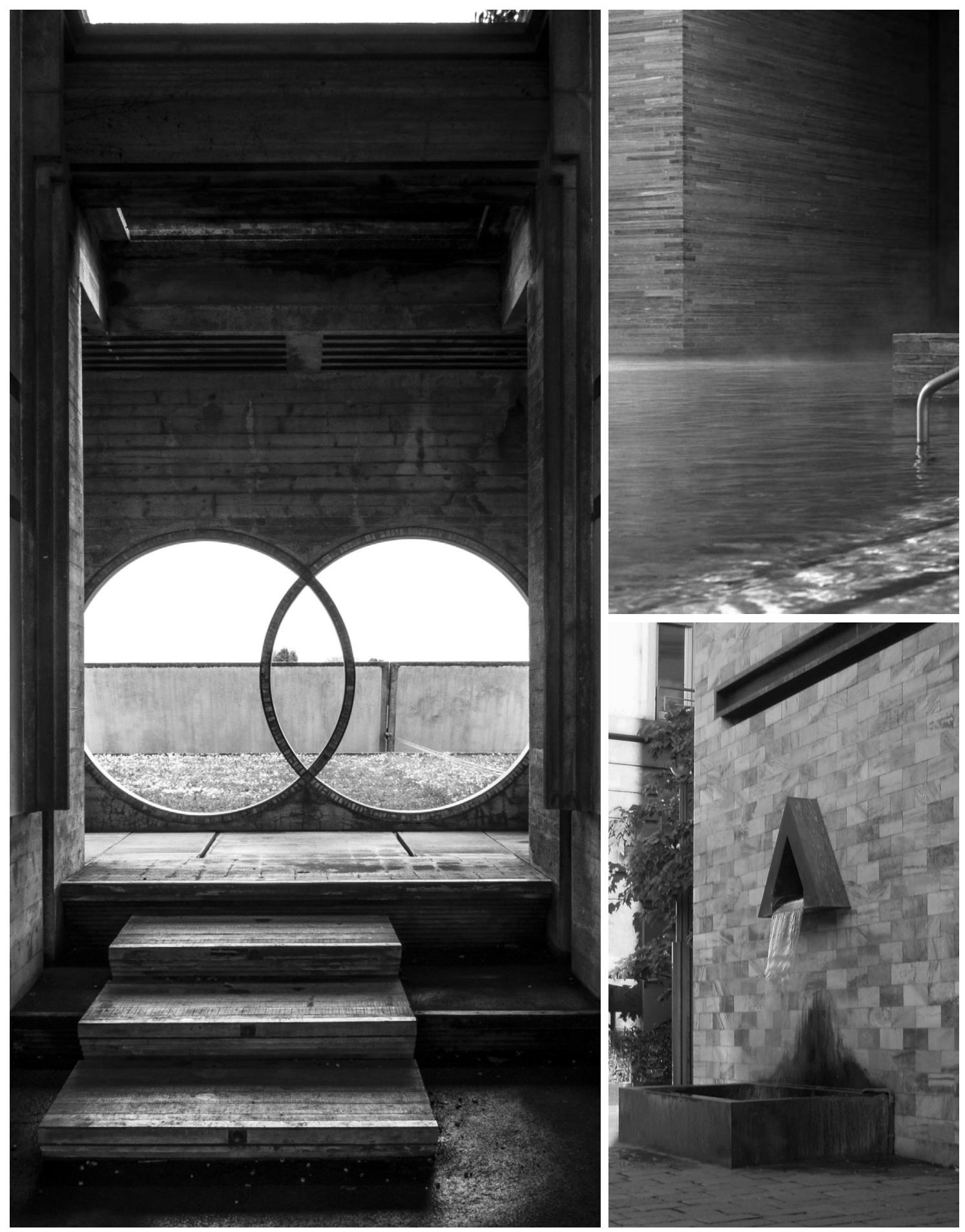
Figure No. 6

Brion Cemetery

Carlos Scarpa

Figure No. 7

Therme Vals

Peter Zumthor

Figure No. 8

Moumento a Sandro Pertini Aldo Rossi and will be further discussed, explored, and presented in later chapters. It is in one's perceptions of the physical world, and in this case the properties of these categories, that atmosphere is made present.

I.3 Body and Mind: As a tangible circumstance of matter and energy, atmosphere can only be comprehended in one's perception of the physical world. This is to say that, although one may understand the notion of atmosphere through a memory, it is not a concept that one can have a priori knowledge of. Rather, specific atmospheres must be experienced temporally.

Atmosphere is perceived in a temporal moment, experienced physically through the body while simultaneously constructed in one's mind. This duality between an individual's own consciousness and the actual physical realm inhabited by that individual as a material being is a necessary friction that sparks the essential elements for the experience of atmosphere. While the mind's cognitive function creates an emotional response to everything that it perceives, it is the resulting relationship between exterior physical objects and one's consciousness which results in a person's ability to comprehend the existence of an external world and, at the same time, that individual's own place in that world.

Despite this duality between the physical and the conscious, a recognition and experience of atmosphere cannot be achieved with those parts working separately but requires both elements to function in synthesis. This notion is emphasised by the French phenomenological philosopher Maurice Merleau-Ponty who observed:

"My perception is not a sum of visual, tactile, and audible givens: I perceive in a total way with my whole being: I grasp a unique structure of the thing, a unique way of being, which speaks to all my senses at once".?

While Merleau-Ponty does not explicitly express it, he implies in this statement that the process of perceiving the world with his "whole being" is not a considered choice. Rather this 'total experience' (a concept encapsulated in the German term gesamterlebnis) is the result of a subconscious engagement of all senses with the surrounding world [Figure 9].

The thought process in shaping one's judgement of space works extremely quickly without time for cerebral thought. ${ }^{10}$ Swiss architect Peter Zumthor, who is notable for his theory on atmosphere and uses it as a guiding principle in his architectural practice, expands on this point. In relation to how one interprets the 
perceivable world Zumthor suggests that:
"Something inside us tells us an enormous amount straight away.
We are capable of immediate appreciation, of a spontaneous emotional response, of rejecting things in a flash. That is very different from linear thought, which we are equally capable of...". ${ }^{11}$

It is possibly because of the speed at which environments are interpreted that there is a misuse of the term atmosphere. When atmosphere is perceived, the ability to comprehend and communicate an awareness of that atmosphere is limited by the understanding of the term atmosphere. Lacking a definable meaning, atmosphere acquires definition in its affiliation to other concepts. ${ }^{12}$ At the lowest level of consideration, atmosphere is used as a term that qualifies a description of an environment or is preceded by qualifying adjectives. An example of this is if one said, 'The aggressive and formal atmosphere of the room was unpleasant'. At a high level of comprehension the notion of atmosphere is understood and coupled with further concepts describing the perception of spatial experience in the concepts of liminality, beauty, and the sublime, among others. It is in the characterization of atmosphere at this highest level and in the shared core concepts of these terms that a true reading of atmosphere begins to emerge.

The Familiar Object Rene Magritte

The importance that one's body and mind play in perceiving atmosphere in architecture cannot be understated. Atmosphere deriving from the material and temporal world is only felt and understood through one's corporeal presence and mental cognition of an environment. For German philosopher Gernot Bohme, the body and its existence in the world also play a central role in an understanding of atmosphere. Bohme states that to experience and perceive atmosphere one must be physically present in an environment. He associates this fundamental understanding of atmosphere with the Roman architect Vitruvius' famous saying that man is the measure of architecture, although for Bohme this statement holds a different connotation than was originally intended. ${ }^{13}$ Bohme's notion alters the Vitruvian perspective declaring man's body central to architecture. Vitruvius saw the body as the standard measure of building proportions. However, in Bohme's use of the concept he suggests that the human body is the fundamental measure of architecture as it is an instrument which absorbs and considers the architectural quality and the atmosphere of its temporal environment. ${ }^{14}$ Bohme's reflection on Vitruvius' Figure No. 10 statement is a departure from a long tradition of architects who have interpreted 
this famous saying as a proportional metrical device, such as French architect Le Corbusier and his Modular Man [Figure 10]. In Bohme's reinterpretation the focus is not on the anthropometry of man in relation to architecture, rather human beings are the measure of architecture because their physical and mental presence evaluates it. This idea is central to understanding how atmosphere is perceived and by that logic how it may begin to be considered in the design of architecture.

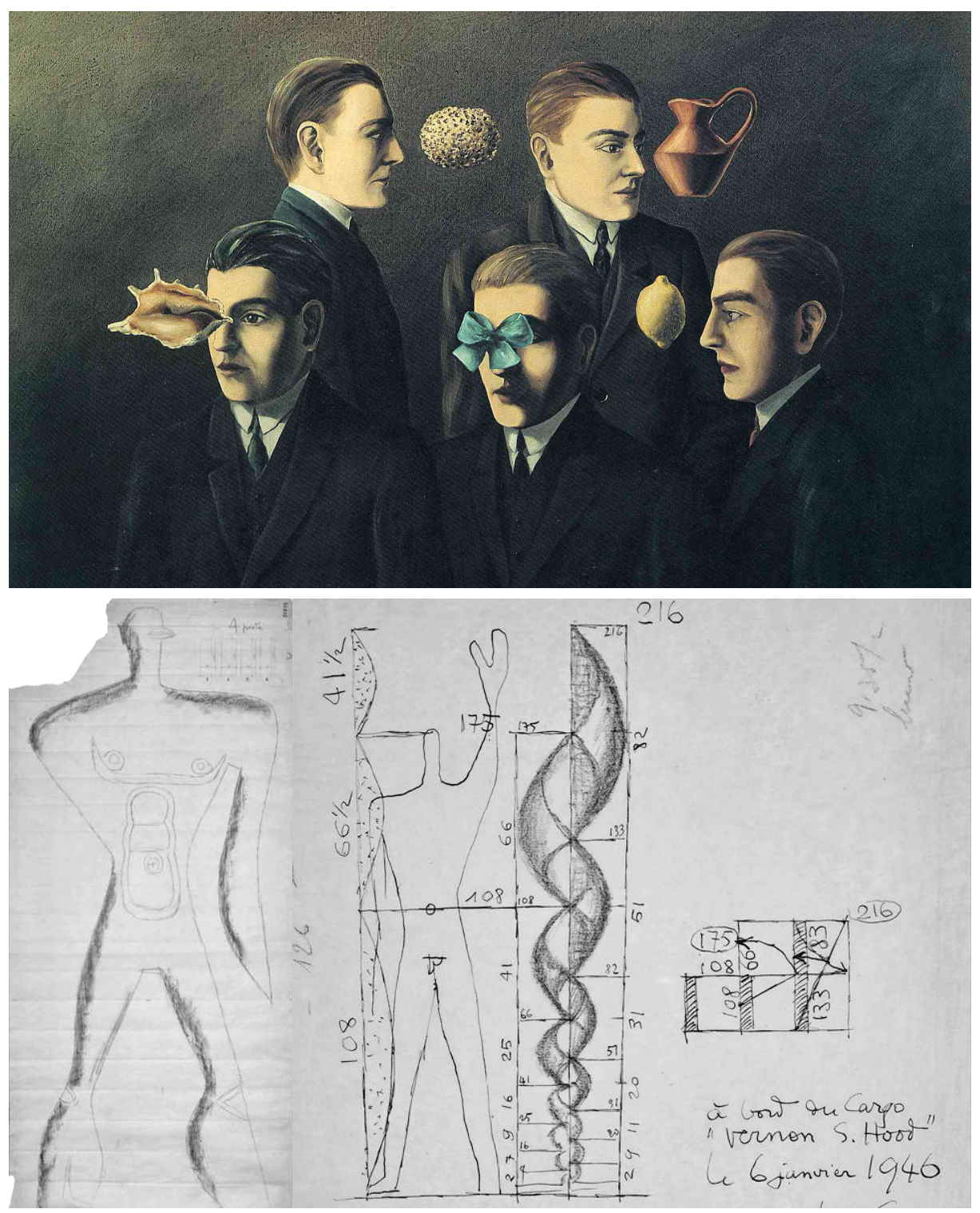


I.4 Diagramming the Atmosphere of Architecture: The discussion thus far has sought to clarify and outline the context of an architecture of atmosphere. In hopes of summarizing the discussion above, in order to capture the complexity of the term as well as move forward in this study, the following illustration [Figure 11] charts how and in what way atmosphere, as previously defined as a tone or ambiance of a place, space, or object, is characterized in architecture and perceived by people. The illustration which can be read from both top and bottom and develops from the initial definition of atmosphere to encompass the concepts of matter and energy, the architectural categories of atmosphere and their resulting properties, the role one's body and mind play in perceiving atmosphere, and one's cognitive understanding of atmosphere as things like the sublime or liminality. At the centre of both the topdown or bottom-up reading of the illustration is the properties of design that relate to the architectural categories of atmosphere. These properties are the architect's domain in relation to their ability to characterize an environment and its atmospheric dimension. Together the three architectural categories of atmosphere and their corresponding properties define both the physical object and its perception in places, spaces, or objects. Thus the way these properties are considered in the design of architectural spaces and objects directly affects their atmosphere.

Figure No. II 
pervading sensation of a tone or ambiance in/of a place, space or object

\section{Atmosphere}

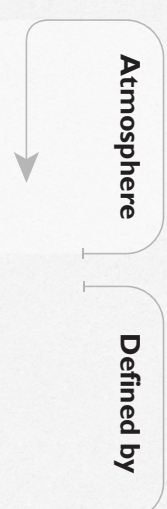

\section{Matter}

material

surface

4 A
Energy
immaterial
environmen

$1 A$ $\forall \vee$

atmosphere of

Objects

\section{Characteristics}

$\checkmark$

materiality \& texture

scale \& proportion

weight \& mass

light \& shadow

shape \& form

warmth \& coolness

tectonic \& stereotomic

interior \& exterior

objects \& space

proximity \& distance..

\section{A}

weathering

material state...

temperature

smell

sound

pressure

humidity

wind

gravity...
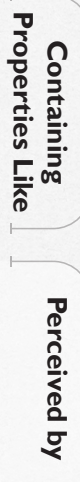

$$
\begin{gathered}
\text { presence } \\
\text { whereness } \\
\text { haecceity } \\
\text { liminality } \\
\text { sublime } \\
\text { coherence } \\
\text { threshold } \\
\text { beauty... }
\end{gathered}
$$

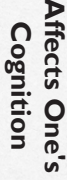

Atmosphere

pervading sensation of a tone or ambiance in/of a place, space or object 



\section{2}

\section{Architecture's Default Atmosphere}

For most architects the concept of atmosphere is one that is often overlooked and neglected in their architectural projects. Yet atmosphere becomes present in the built world even in the absence of its intentional consideration in the design of architecture. As one experiences the world and the architecture in it, the potential to perceive atmosphere in all environments becomes apparent. Christian Borch, in his essay "The Politics of Atmospheres: Architecture, Power and the Senses", emphasises this point. While discussing the atmosphere that one may sense in various environments he states, “...every encounter with architecture contains the possibility that we are being seized by its atmosphere, even if some atmospheres are felt more intensely than others". ${ }^{15}$ In this statement Borch makes a critical point that is often overlooked when considering atmosphere in architecture, namely, that in all architecture there is the possibility for an atmosphere even when there has been no external hand consciously seeking to develop it. In this context, one stumbles upon atmosphere as an incidental part of the built world.

In one's experience of various environments, this type of atmosphere can be noticed even in the most unlikely of places. Take for example the utilitarian structure of a big-box hardware store [Figure 12]. This building type is built for maximum efficiently in both its layout and in its material composition. Long aisles lined with shelving form functional spatial arrangements while durable and maintenance free material such as concrete floors and a steel structure are economic choices for building materials. While it is obvious that creating an atmosphere is not the intent of this building, it becomes readily apparent that this structure contains at some modest level of intensity an atmosphere. The scale of the space, the glowing 


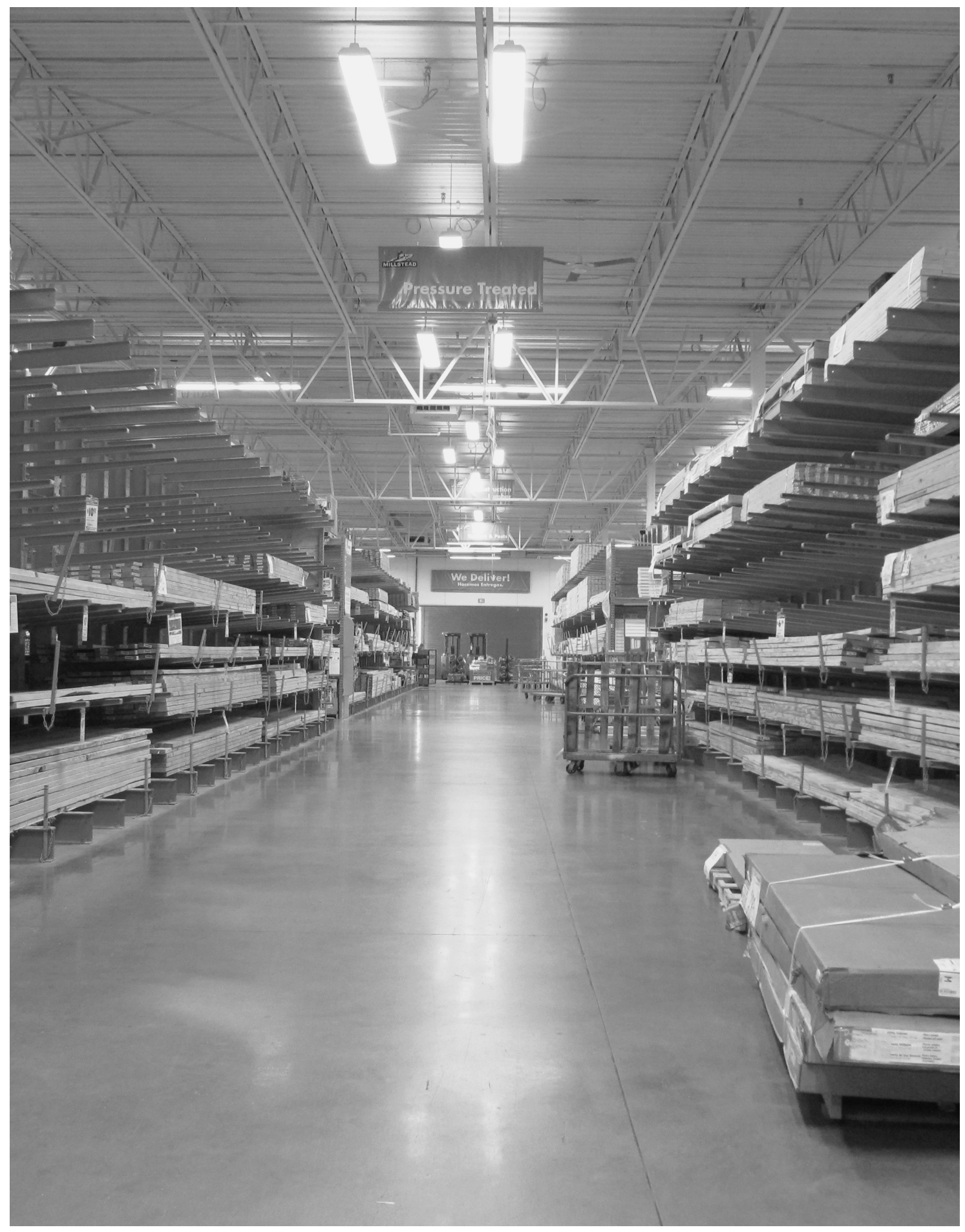


lights of the ceiling, the reflection of light on the floor, the muted colours, and the smell of lumber stocked on the shelves all contribute to a reading of atmosphere in this space regardless of whether it has been considered or not. The absence of considering the atmosphere of this architectural space results in a condition where an atmosphere by default emerges. This is an atmosphere that develops as a result of objects being in the world, and our perception and experience of them.

As noted in Chapter One, the architect's ability to affect an architecture of atmosphere is directly related to the architectural properties outlined in Figure 6. All building designs consider properties such as materiality and texture, shape and form, weathering, and temperature, albeit in numerously distinct ways. It is for this reason that Christian Borch points out in the previous quote that in every experience of architecture there is the possibility for atmosphere. But what Borch does not consider is that these inherent atmospheres can only be characterized as a default form of atmosphere, since they exist independently from a focused desire to shape the ambiance of a building and its spaces.

If, in the field of architecture, atmosphere is shaped by the properties in Figure 6, the question then emerges: Why does most architecture produced only contain default atmospheric conditions? A partial reason for this is that the atmosphere of architecture materializes as a by-product of the way architecture is conceived and the process by which it is designed. In the current architectural condition, including contemporary processes and ideology, the approach of most architects to design is often contrary to the way in which an architecture of atmosphere should be considered. That is to say that the current ideals of architecture, the attitude of designers towards the way architecture is conceived and executed in the design process, all affect the passive development of default atmospheres in our built environments.

2.I Default in Architectural Ideals: Ideology plays a critical role in affecting one's approach and sensibility to the world around them and architects are not immune from this fact. The way architecture is conceived, and later perceived, is as much tied to a designer's philosophical outlook as it is to practical conditions of building. While many designers have their own theories or approach to architecture, there are two critical opposing ideologies that predominantly influence an understanding of design and by association atmosphere. These two ways of perceiving the world are rooted in the origins of western philosophy in the works of Greek thinkers Heraclitus and Plato, who both contemplated the concepts of knowing and reason. Plato's Theory of the Forms and the Allegory of the Cave, as 
well as Heraclitus notion of Panta Rehi, the recognition that "all things are flowing", are two understandings of the physical world that have had a large effect in shaping our view of architecture and how it is designed.

The Heraclitean concept of Panta Rebi, expressed in the sentiment that "everything flows", comes from the philosopher's observation that: "You cannot step twice into the same river; for fresh waters are ever flowing in [and] upon you" ${ }^{16}$ This view of the world is based on a temporal understanding of existence, which accepts that all environments are in a constant state of flux [Figure 13]. The river in which the person steps is not the same river as the one they stepped in the first time. As Heraclitus notes, the river itself has changed because it is constantly flowing. Similarly, neither is the person who steps into the river a second time the same person that dipped their foot in before, since, like the river, that individual themselves is constantly changing. ${ }^{17}$ The Heraclitean orientation derives knowledge through an empirical understanding of the world gained by perceiving and sensing Devil's Gate Triptych Mark Ruwedel dynamic environments. In contrast to the Heraclitean notion of Panta Rebi, Plato's theory of the Forms puts forward the notion that the world can be understood through a set of ideal forms. These forms are separate and distinct from the real world which humans actually encounter in their tactile experience of physical environments [Figure 14]. ${ }^{18}$ In Plato's theory, one has an a priori understanding of the true nature of all things around them. ${ }^{19}$ This Platonic view of the world holds that every individual has in their own mind a perfect model of forms which are ideally true, but when these models are manifested in the real world they can no longer be considered ideal. Rather they lose a little bit of their "trueness" or "idealness" ${ }^{20}$ This theory is not based on a temporal, corporeal, or experiential understanding of one's own environment like the Heraclitean view. Instead the world is conceived in the mind and understood as ideal archetypes.

Both the Platonic and Heraclitean philosophies are not consciously considered when one perceives the world and architecture, but they do subconsciously affect one's understanding and approach to it. For many, both philosophies affect their worldly perception dependent on the situation. But the way in which architecture has been traditionally perceived is strongly associated with the Platonic theory of forms and ideals. Historically, the authority of Platonic thinking as it relates to architecture becomes evident in the evolution of architecture from the practice of constructing basic shelters to the creation of buildings with symbolic meanings embodied in their built form. In addition to being vessels of meaning, buildings also Plato's Cave began to be conceived as ideal architectural objects or concepts. Examples of this are 

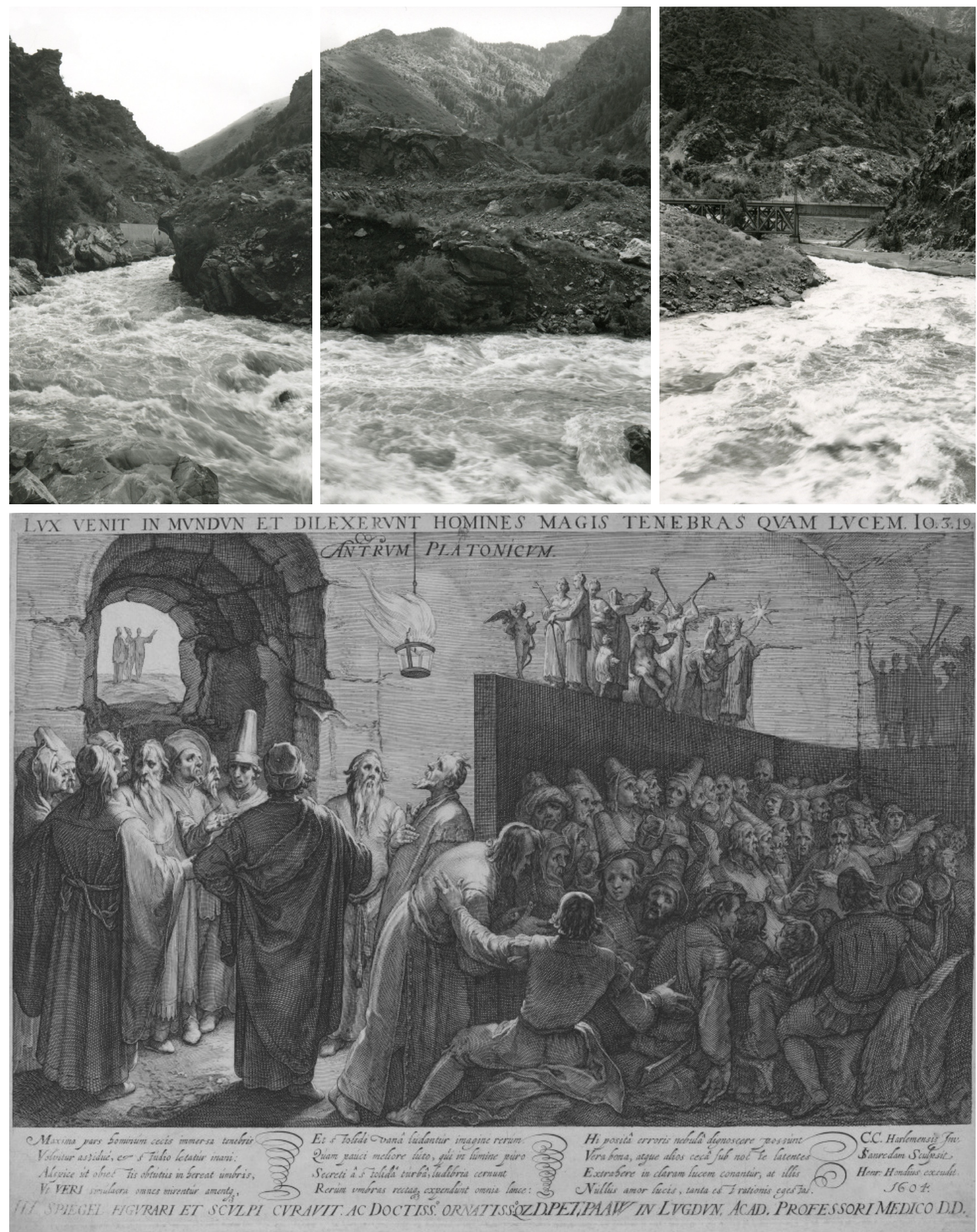
apparent when considering the ancient architectural works of the Egyptian, Greek, Roman, and Christian civilizations. The construction of pyramids, temples, forums, and churches all served practical functions but in their architectural conception each work sought to express the domination and ideology of their respective authorities through the built form. In doing so the notion of architecture transformed from its pure utilitarian purpose to become an expression of ideologies and ideals [Figure 15]. As a result, people's perception of architecture transformed as well. No longer was architecture thought of as a temporal entity, but was considered an ideal object able to represent, instead of just being and functioning in the world.

This tradition of conceiving architecture continued into the renaissance era where the contemporary notion of the architect emerged. Architecture in this period was more literally converted to a form of representation through its means of production. During the renaissance, architecture not only symbolized an ideal concept when it was constructed, but its construction was also idealized in a drawn representation. ${ }^{21}$ Representing architecture in this mode removed the practice one step further from a consideration of the physical and temporal aspects of building and, to a degree, the regard for people in built environments. This way of producing architecture remains true even in the current architectural condition, where the concept of architecture as an ideal object is a prevalent ideology to which many designers unconsciously subscribe.

Ultimately, this neglect of the temporal and corporeal nature of architecture contributes to the creation of default atmospheres. As Gernot Bohme notes, atmospheres are perceptible in the co-presence of a subject and object. ${ }^{22}$ An architecture that is traditionally conceived in the sphere of ideals does not consider the relationship between an individual and building, but more so considers a building as ideal form. A thoughtfulness of atmosphere in architecture is instead conceptually aligned to a Heraclitean view of the world, where architecture considers the physical and temporal presence of the individual body in space and the effect it has on a person's emotional response to it.

2.2 Default in the Typical Design Process: The notion of Platonic ideals has not only influenced the way people and designers perceive architecture, it has also impacted and guided the process by which architecture is designed. A design that is based on a consideration of architecture as an ideal develops in a linear fashion. This process begins with the conception of architecture as an abstract whole and progressively moves towards a detailed resolution at the human scale without a consideration of architecture's atmospheric dimension. Envisaging a 


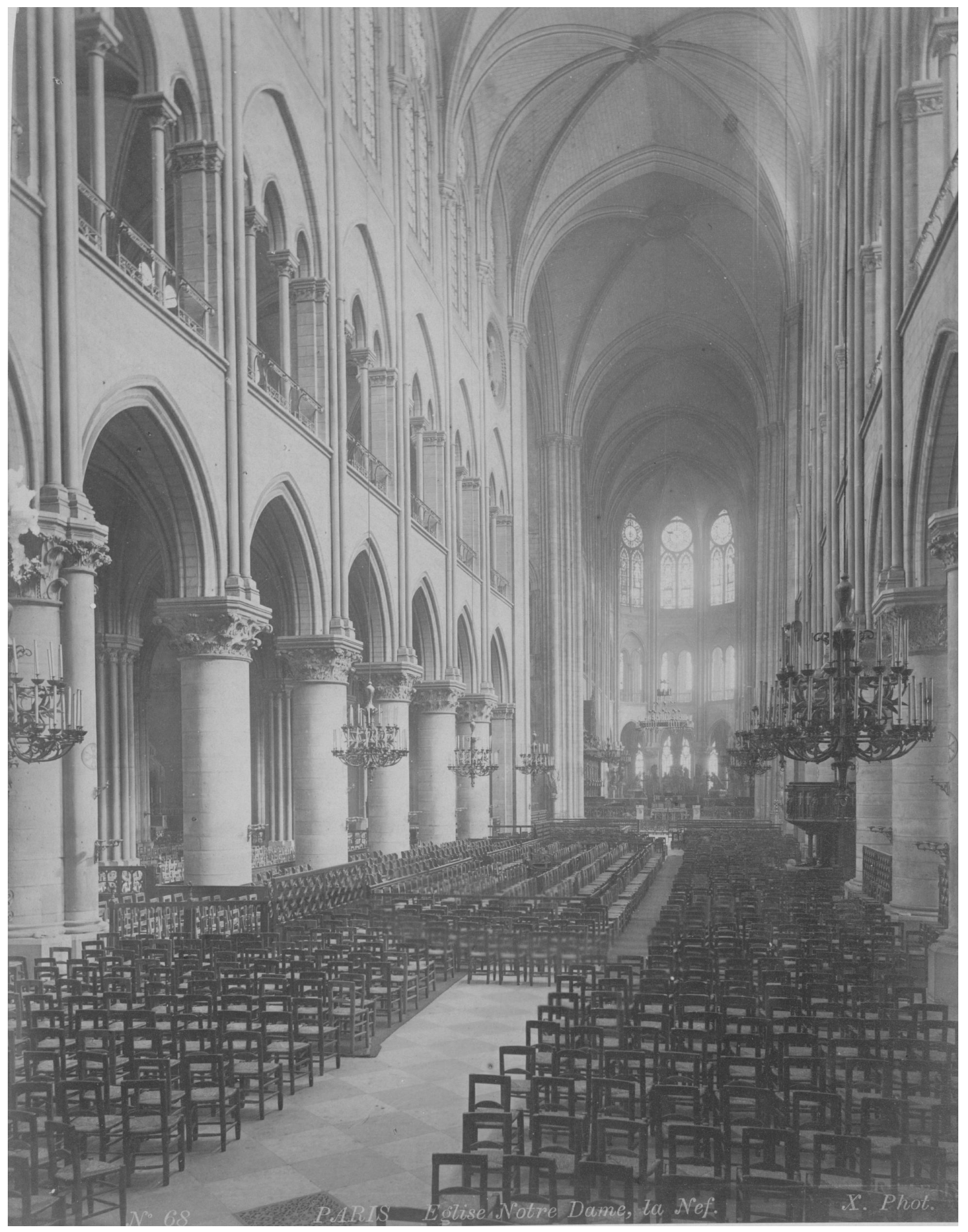


design first from a large conceptual whole to a refined series of architectural details is a way of working that has traditionally characterized the architectural profession. Evidence of this established method of working is apparent when examining three distinctive architectural periods of the past century. Michael Speaks, in his essay "Intelligence After Theory", describes philosophy as being the intellectual principal of early 20th century architecture (i.e., modernism), while theory defined the late 20th century architecture (i.e., postmodernism). ${ }^{23}$ The philosophy of modernism was a slow deep knowledge that conceptually drove architecture towards a belief in the truth of emerging building technology and material production. ${ }^{24}$ In the latter half of the century, theory was seen as a fast philosophy and was embraced by a younger generation of architects who responded to their contemporary architectural condition's lack of meaning by referencing historical symbols. ${ }^{25}$ According to Speaks, architecture of the early 21 st century is dominated by intelligence or data, which is noticeable in current parametric design processes. ${ }^{26}$ In all three characterizations of architecture throughout the past century, and even at the present moment, there is a clear focus on conceptual ideals pertaining to technological advancements, artistic expression, and cultural ideology. The focus of these periods have influenced their respective architectural processes, but what characterizes these design approaches is a primary concern for large conceptual ideas at the building scale which drive the design process. It is only after first formulating a conceptual ideal that contemporary architecture then progresses from that abstract concept towards considerations of the tangible reality at the human scale which ultimately affect the perception of atmosphere.

What becomes clearly obvious is that a concern for humanistic quality, if it is a concern at all, has become a minor focus of architectural designers. Yet, as it has already been noted, one's body and cognition, the physicality of the space, and one's emotional response to the built environment is central to the concept of atmosphere in architecture. Furthermore as Finnish architect and theorist Juhani Pallasmaa states in a short essay on the experience of atmosphere in architecture: "Atmosphere emphasises a sustained being in a situation, rather than a singular moment of perception". ${ }^{27}$ This insight into an atmospheric experience highlights the disconnect between atmosphere and the typical architectural design process. The consideration of architecture, first at the building scale which primarily focuses on the expression and embodiment of cultural ideology, is an approach that excludes the temporal factors of one's body being in and experiencing architecture. Thus, our contemporary attitude towards architecture in both the way it is envisioned and 
designed does a disservice to the development of architectural atmospheres. This notion is further described by Pallasmaa, who neatly sums up why contemporary architects neglect factors that affect atmosphere.

"Among architects, atmosphere is judged as something romantic and shallowly entertaining. The serious Western tradition is entirely based on seeing architecture as a material and geometric object through focused vision, whereas ambience is a kind of immaterial 'halo' that the material reality seems to extrude. Ambience is like an invisible fragrance or smell that uses and heightens the sensory experience. Besides, architectural images are usually expected to seek clarity rather than ephemerality and obscurity, a finiteness rather than open-endedness and deliberate vagueness." 28

It is due to the fact that architecture has been traditionally considered in a sphere of ideals, or as Pallasmaa puts it viewed as a "material and geometric object", that default atmospheres have emerged. They are atmospheres that are simply a part of the reality of buildings which were conceived with other intent. While this is the case for much of the default atmospheres in our built world an architecture that embraces atmosphere cannot be seen as something that spontaneously materializes. Instead atmosphere is an ambiance that is often considered and produced by designers in a method that, as Pallasmaa classifies above, confront the immaterial, obscure, and vague characteristics of the temporal and corporeal environment in which one lives. 



\section{3}

\section{Considering Atmosphere in Architecture}

Our modern mode of conceptualizing and producing architecture has often lead to the development of default atmospheres, as was examined in the previous chapter. Although these atmosphere are, at various levels of intensity, ubiquitous in built environments, the focus of this thesis is not on an atmosphere which develops incidentally in our built world. Rather this body of work explores the question of how atmosphere can be imbued in built architectural projects. Atmospheric works of art and architecture by well known designers such as Olafur Eliasson, Diller Scofidio + Renfro, and Peter Zumthor [Figures 16-18] demonstrate that atmosphere can be, and often is, intentionally designed and materialized in built form with varying types of expression. But in order to comprehend how such designers have successfully and deliberately captured atmosphere in their own projects, one must first examine what it means to consider atmosphere in the design of architecture.

As was previously noted, the ability of an architect to affect the atmosphere of their designs is directly connected to the various properties outlined in the illustration Diagramming Atmosphere In Architecture (Figure 6). One cannot doubt that properties relating to architecture such as materiality, scale, light, weathering, temperature, and sound play a significant role in the experience of atmosphere. But as was noted, a consideration of these properties alone still leads to the development of default atmosphere. This is partly due to the way in which such properties are considered. They are thought of as ideals and disengaged from the reality of the temporal environment which they will help shape. Turning again to Figure 6, it becomes evident that the properties of architecture which help to define atmosphere do so by shaping one's perception of space. Thus in part, to consider atmosphere is 

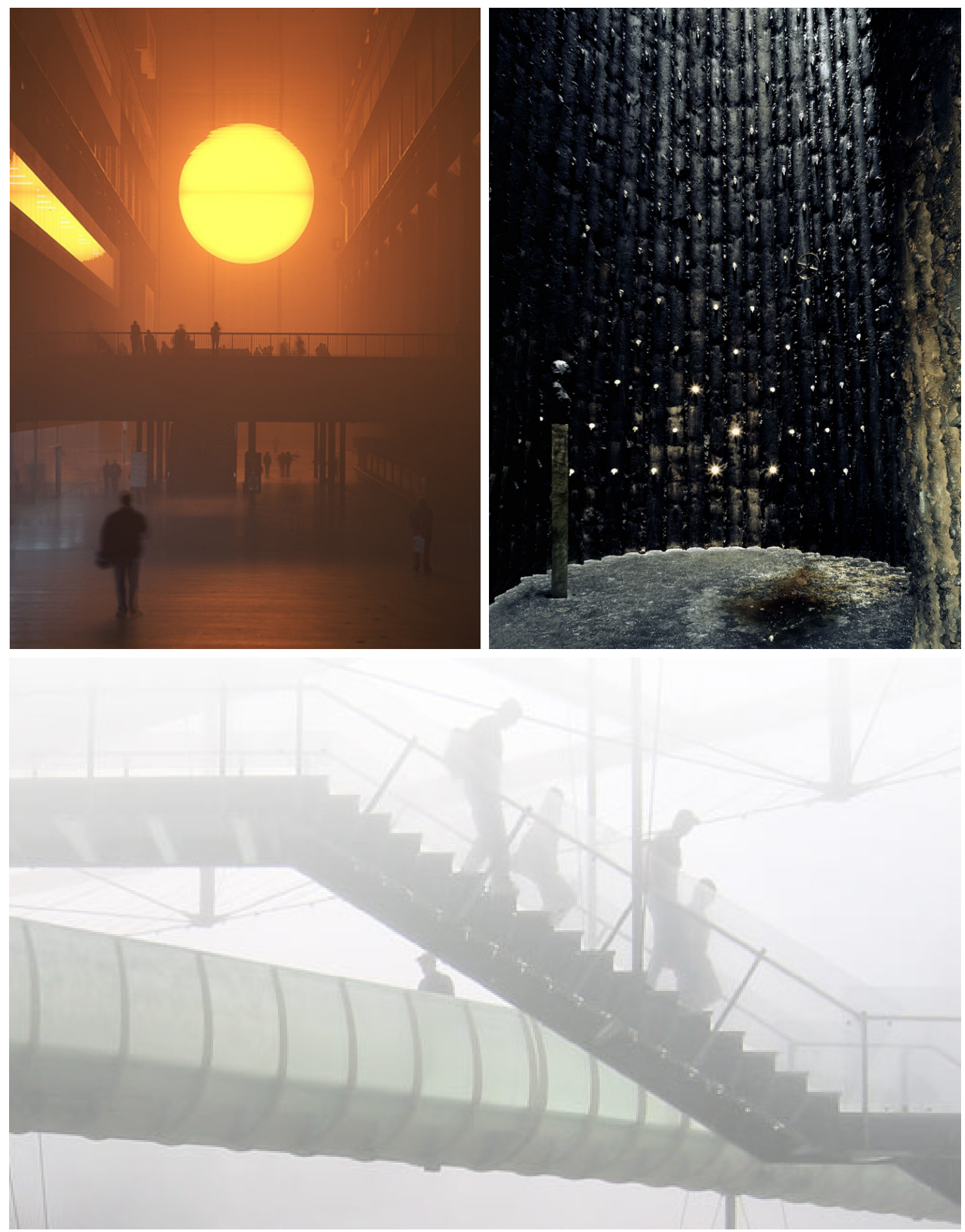
Figure No. 16

The Weather Project

Olafur Eliasson

Figure No. 17

Bruder Klaus Kapelle

Interior

Peter Zumthor

Figure No. 18

Blur Building

Diller Scofidio + Renfro to acknowledge how and what effect architectural properties and spatial conditions have on one's body, mind, and perception, as it is through these means that one's perception and the ability to sense atmosphere functions. As was made evident in Chapter One, Gernot Bohme's reinterpretation of Vitruvius' famous saying “man is the measure of architecture" ${ }^{\prime 29}$ emphasizes the idea that the architectural properties which define an atmosphere are always considered in relation to the temporal and corporeal nature in which people perceive and understand atmosphere.

Yet, in addition to this, a consideration of atmosphere should not solely be confined to one's bodily engagement with space and building, since atmosphere can also be perceived in objects and their relationship to the context in which they are found. As architect Peter Zumthor suggests, an atmospheric work of architecture should "become part of its surroundings", because if it does not it abandons its atmospheric desire. ${ }^{30}$ One's own perception of how things are in relation to the world and themselves is equally important to their own experience of being in architecture. As made apparent in Zumthor's statement, it is not only one's experience of a building and its setting that affects a sense of atmosphere, but also one's ability to understand the object of architecture in relation to its context. Here, one's cognition plays an important role in understanding both the immediate and larger context in which the architecture and one's self are situated.

While it has been demonstrated that an architecture of atmosphere should be considered in relation to one's body, mind, and its surrounding context, how and in what way architecture is considered in relation to these entities is of the utmost importance. As Bohme notes, "[what] counts when designing a space is not what properties [one] seeks to give the objective space, but what sensitivities [one] wishes to create for the space...". ${ }^{31}$ As Bohme suggests, when designing an atmospheric building it is the sensitivities of architectural properties that are considered in relation to the corporeal and building context, and not necessarily the properties themselves which shape the atmosphere of a design. What kind of quality or sensitivity should then be considered in the design of an atmospheric architecture? It is at this juncture that there must be a reconsideration of the initial definition characterizing atmosphere. In this context, atmosphere cannot simply be described as a pervading sensation or tone. This description is too vague and is absent of meaning. A new definition must be specific in answering what type of atmospheric sensation or tone permeates through places and spaces.

3.I Atmosphere Re-Defined: The description of atmosphere initially defined as a pervading sensation of a tone or ambiance in or of a place, space, or 
object was a characterization of the term which lacks sufficient meaning. Although this preliminary definition was left intentionally vague in order to explore the context of atmosphere and develop a larger understanding of the term, the definition has now become limiting in further comprehending the essence of the idea of atmosphere in architecture. While this original definition does well to indicate that atmosphere is predominantly a sensation developed out of one's interactions with places, spaces, and objects, it does not indicate the exact perceived sensation that qualifies an atmospheric experience. Any suggestion of a specific feeling is missing from this definition, but may be found in the language which is used to describe it.

As Bohme so eloquently puts, "[as] an aesthetic concept, atmosphere acquires definition through its relation to other concepts...". ${ }^{32}$ It is for this reason that atmosphere is often discussed and coupled with concepts that describe qualities of objects or spatial experiences. Terms such as liminality, beauty, presence, and the sublime are among countless other words often used to illustrate the sensation one gets when experiencing an atmospheric environment. For example, one may describe the atmosphere of gothic churches as liminal due to the ambiance of their lighting and the beauty of their ornate detail. Thus, in order to describe a feeling of atmosphere, it must be asked: what exact sensation do these other terms describe? The language associated with atmosphere is often used to express an awareness of something that manifests itself in the relationship between one's self, objects, and the environment.

Take for example the concept of the sublime, which is regularly used to portray an atmospheric experience. Described by eighteenth century philosopher Edmund Burke, the sublime is perceived in what he characterizes as terrible or terrifying phenomena that produce a sense of danger. ${ }^{33}$ But at the same time the sublime is also related to the inherent beauty and pleasure associated with a sense of threat. ${ }^{34}$ The concept and sensation of the sublime was a focus in the work of many painters during the Romantic period at the end of the eighteenth century. The painting Wanderer Above the Sea of Fog [Figure 19] by German artist Caspar David Fredrich precisely captures the experience of the sublime and by association the sensation of atmosphere. In the painting a man gazes over mountain ridges while a thick fog blends into the horizon beyond. The fog obscures the valley and forest of trees ahead, while Fredrich's brush strokes of the environment and the man's hair

Figure No. 19 indicate a wild wind tearing through the mountain range. The power and vastness of nature in contrast to the figure of the man highlights his insignificance in relation to the landscape and the power of the physical forces of the natural world. It is in this 


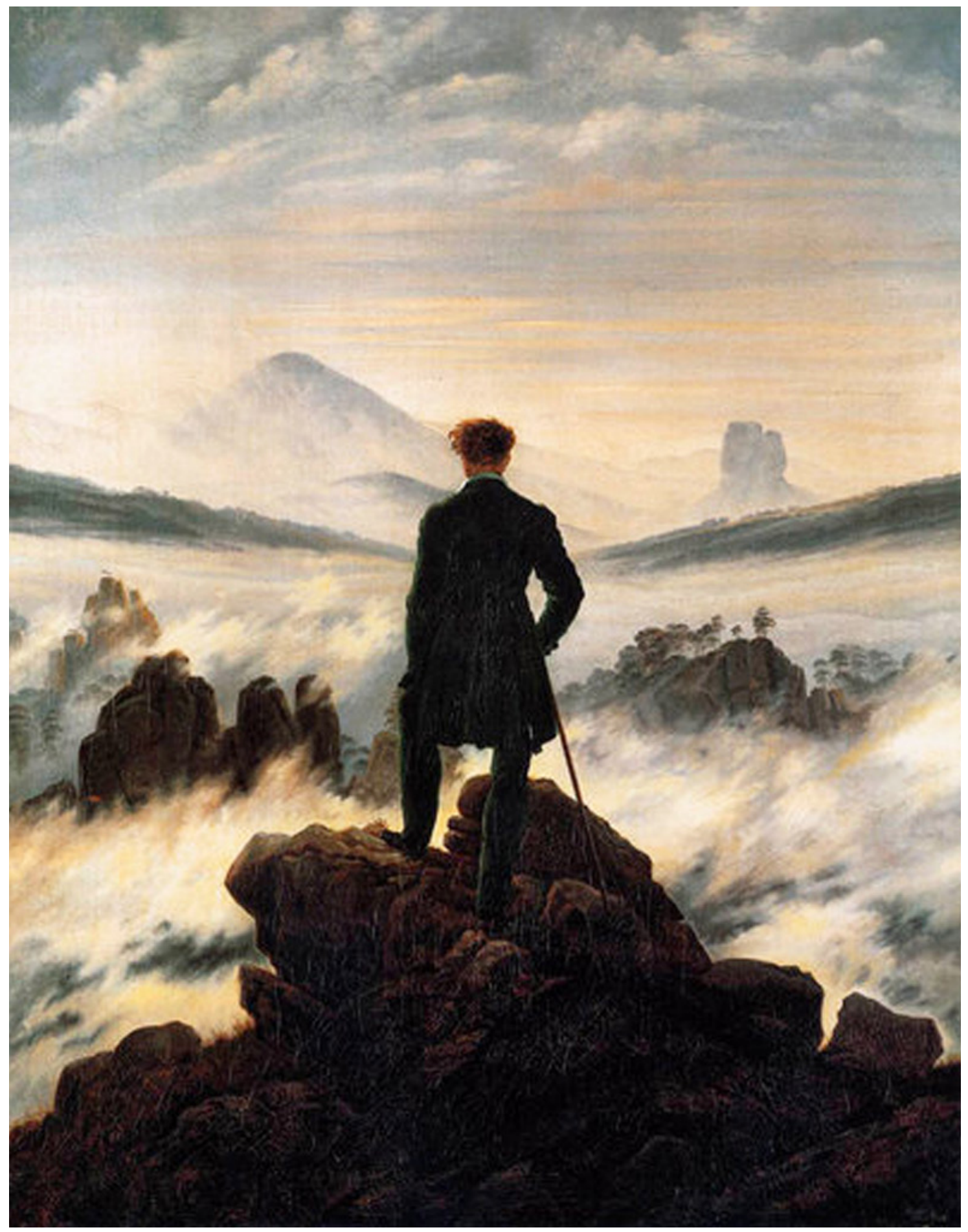


context that the sensation of an atmosphere becomes clear. Atmosphere ultimately is the feeling or consciousness of one's own presence and the presence of things being in an environment. In Fredrich's painting, the atmosphere which one may characterize as being sublime, because of the sensation of fear in confrontation with the power of nature, is really a conscious awakening of the insignificance of one's self being present in this natural environment and the world. Fredrich does well to recreate atmosphere in this painting, as even in its static dimension the dynamic relationship between the temporal environment and one's corporeal existence represented by the silhouette of a man is highlighted.

Expanding on the idea of atmosphere as a conscious recognition of self and objects in the world, Bohme's notion of whereness also attributes atmosphere to an understanding of being. In relation to architectural space, Bohme suggests that a sense of whereness refers to the character of a space that one finds themselves in and further states that: "We sense what kind of space surrounds us. We sense its atmosphere". ${ }^{35}$ Developing on Bohme's concept, a sense of whereness is not just one's ability to sense the kind of space one is in. Whereness, which Bohme believes describes a sense of atmosphere, is ultimately the ability to be aware of being in the world and, in the context of architecture, being in the world through buildings. This notion of being in the world and whereness have developed from the philosophical writings of Martin Heidegger, who in Being and Time discusses at length the concept of Dasein. Dasein, in its original use, indicates a being or existence that a thing has. But Heidegger modified the meaning of the term from its original understanding to describe not just a general being but rather an experience of existence, being present, a being in the world. ${ }^{36}$ Heidegger's notion of Dasein sums up the sensation that one feels when seized by an atmosphere. As architectural theorist Juhani Pallasmaa describes: "It is [the] haptic sense of being in the world, and in a specific place and moment, the actuality of existence, that is the essence of atmosphere". ${ }^{37}$

With this new understanding of the sensation that atmosphere engenders, the term can be redefined to accurately and clearly illustrate its effect on one's experience. This new description of atmosphere is defined as follows: atmosphere Figure No. 20 is the pervading sensation of one's self and objects being in/of a place or space. In creating atmospheric buildings, architects should consider the design of architectural properties that relate to the temporal and corporeal nature of our existence in order to provide a sense of one's self and objects being in the world and of a specific place. Yet even in the thoughtful application of the above principles it must be recognized 
of how they see themselves and the world around them.

3.2 The Subjectivity of an Authentic Atmosphere: Generally what classifies an atmospheric place or space is a shared feeling of atmosphere that is perceived more or less the same regardless of who experiences it. ${ }^{38}$ There are of course many examples of places, both natural and built, that permeate a sensation of atmosphere and overwhelms the feelings of any visitors. Take for instance the Jewish Museum in Berlin designed by Daniel Libeskind. For many visitors to this site there is undoubtedly an atmosphere that is felt in the building's memorial spaces. Visitors are lead through a series of underground halls that transverse void concrete spaces illuminated from above. Rooms focusing on the memory of the holocaust and the exile of Jews from Berlin are first encountered before journeying to the main exhibition spaces [Figures 20-21]. The atmospherics of this building derive from a combination of the architectural quality of the space, but also the context-and collective memory associated with the Jewish genocide during the mid-
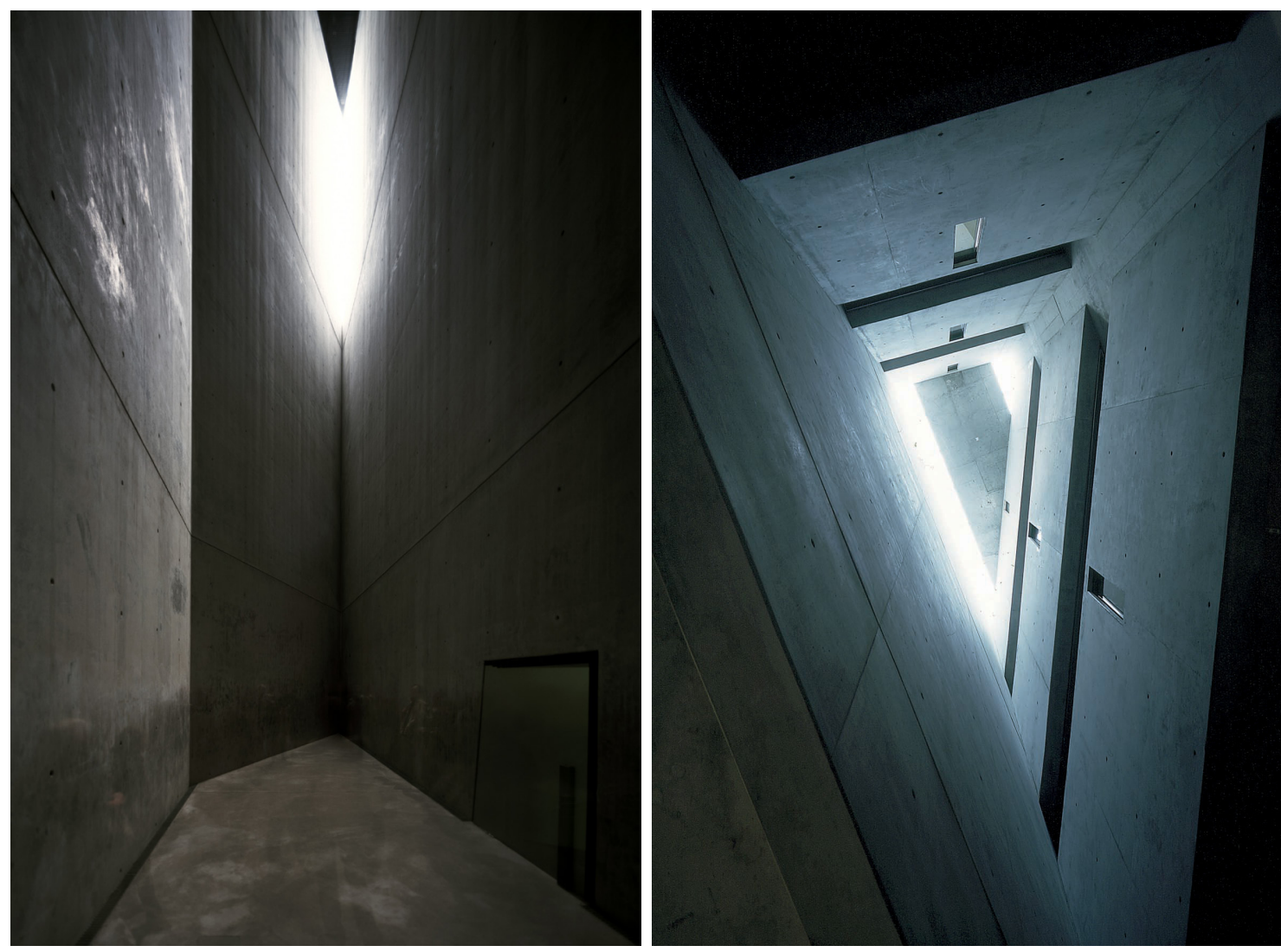
twentieth century. Architectural typologies, such as sacred spaces and museums, are notable in their conscious attempt to enhance the mood that visitors to such places carry with them. As such, these architectural typologies are commonly classified as atmospheric. While these typologies are mostly related to atmosphere, there are many less intense examples of various buildings types that capture the same sensation. The specific historical or sociological contexts of certain buildings, such as memorials or museums, can add to the intensity of atmosphere experienced by visitors to such places.

As much as an environment may evoke a universal feeling of atmosphere, for any particular individual the atmosphere they feel or perceive is always largely a subjective experience. This is due to the fact that, as John Berger stated in his 1972 BBC television series Ways of Seeing: "The way we see things is affected by what we know or what we believe". ${ }^{39}$ Berger illustrates the reality that one's understanding of oneself and of objects in relation to the world is dependent on personal experiences and individual values. Thus, the perception of atmosphere, in its redefined understanding, is based more on one's individual sensitivity, memories, and experiences than a fixed prescribed feeling. ${ }^{40}$ This individual subjective quality of experiencing atmosphere is why even at very minute levels default atmospheres can be perceived in any built space.

The subjective nature of one's perception of architecture and the way in which design shapes the sense of being is a topic discussed at length by Juhani Pallasmaa. His explanation of architecture's role in affecting emotion, which can also be applied to atmosphere, provides:

"Architecture should not specify emotion, but should invite emotion. I often use the example of Michelangelo's Laurentian Library in Florence. I immediately get tears in my eyes when I step into that space. Its melancholia is so powerful. But they are my tears, my own tears. Not Michelangelo's, although his architecture authorises me to expose these emotions. The architecture admits me and authorises me to feel this feeling, which I would otherwise suppress." ${ }^{41}$

What Pallasmaa's example makes clear is that architecture such as Michelangelo's Library [Figure 22] creates the circumstance for people to engage their own emotions, Laurentian Library but architecture itself is not the direct object of these feeling. Rather, architecture 
only has the ability to evoke sensations through an individual's perception and own emotional sensibility. Furthermore, Pallasmaa's statement that architecture should not specify emotion but should invite it, leads to the question of authentic atmospheres. An authentic atmosphere is one which is considered as a thing, that is felt and experienced. In contrast, an atmosphere of inauthenticity is preceded by adjectives which describe and indicate what one should feel. Thus an atmosphere of authenticity is one that does not advocate the feeling of certain emotions, but rather simply allows the individual the ability to feel something through the work. In doing so it can be said that atmospheric architecture is not predetermined in its outcome. Rather, as Pallasmaa once again points out, an "atmospheric experience always centres on your own existential experience, which suggests that atmospheric experience is a much more internalized experience...". ${ }^{42}$ In the design of atmospheric architecture, the work is imbued with considerations that make apparent the temporal and corporeal environment that one is in and, by doing so, evokes the sensation of being present in and part of the building and its context. Yet once the design has been manifested the spirit of the architecture is continuously being contemplated by each individual that experiences it and thus it is in a constant state of rediscovery by each and every visitor.

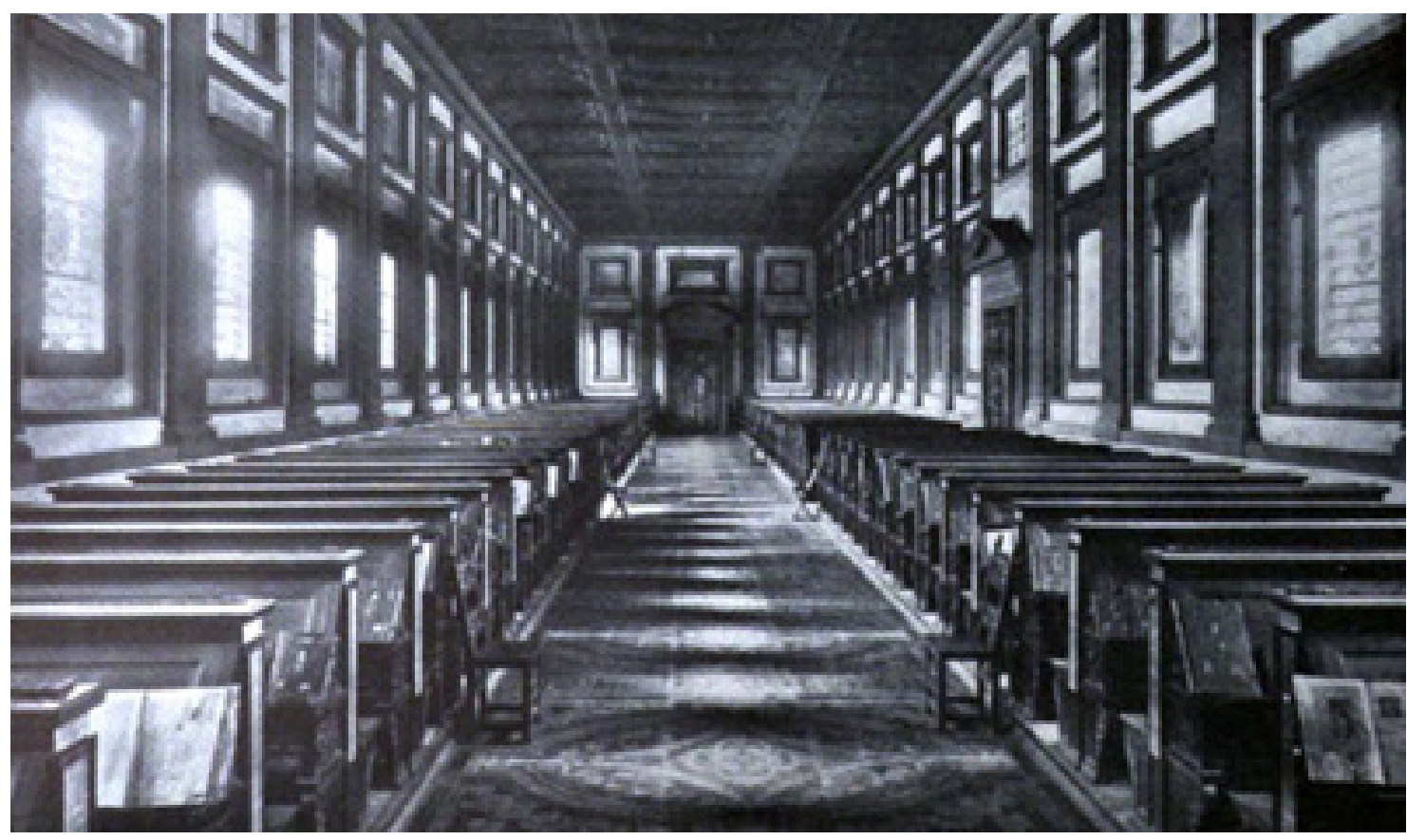





\section{The Expression and Emergence of Atmosphere in Design}

At the beginning of Peter Zumthor's book, Atmosphere, there is a quote by English painter William Turner who in 1844 confides to a leading English art critic of the time (John Ruskin) that, "[atmosphere] is my style". ${ }^{43}$ While Turner's statement suggesting atmosphere is a style could be a contentious point of debate, what is more intriguing about his statement is that Turner has recognized the ability that he could knowingly and consistently produce atmosphere in his work [Figure 23]. In an architectural context, Peter Zumthor's sentiments regarding atmosphere mimic those of Turner, but with fundamental differences in the way a designer realizes atmosphere in their built projects. Zumthor states:

\footnotetext{
"What do we mean when we speak of architectural quality? It is a question that I have little difficulty in answering. Quality in architecture... is to me when a building manages to move me. What on earth is it that moves me? How can I get it into my own work?... How do people design things with such a beautiful, natural presence, things that move me every single time. One word for it is Atmosphere." ${ }^{44}$
}

Like Turner's statement, Zumthor's view acknowledges the ability to materialize atmosphere within his work and the importance that it brings to his architecture. But Zumthor's sentiment, in contrast to Turner's quote, highlights a critical implication of working to produce atmosphere in architecture. For Turner, atmosphere is an effect that he is able to apply to his work, but for Zumthor atmosphere is something 
he hopes to create without the certainty it will be engendered in his buildings. This is why Zumthor questions how he may "get" atmosphere into his own work, while Turner's statement suggests atmosphere is something he already knows how to apply. In Zumthor's work, each building provides a new challenge and design approach to developing an atmospheric architecture. In order to do so, his work must continuously address its changing context, while still considering how his designs affect an individuals perception and the sensation of being that ultimately result in a feeling of atmosphere. In opposition, the paintings produced by Turner are brought into existing without reference to a specific external physical context in mind. Unlike a building that is designed for a certain geographic location, a painting exists on the canvas and not in any particular building or on any specific site. As a result, Turner's 'atmospheric' approach can in the context of painting be a consistent technique applied to his works, since they do not have to respond to an external physical environment. On the other hand, Zumthor's architecture must contemplate the context of the building's site and its use. Therefore, in order to create atmosphere, Zumthor's designs [Figures 24-25], from one building to the next, cannot be stylistically the same like the paintings of Turner.

The difference of how atmosphere is realized in the paintings of Turner and the architecture of Zumthor may be a result of the artists working in separate artistic fields. However, identifying the distinction between both of their approaches helps shape an understanding of how an architecture of atmosphere is designed. An architect's attempt to capture atmosphere through a built form and its spatial experiences is done so by affecting one's perception of how the architecture and one's body belong to and are in the world. Given the changing conditions between one architectural project and the next, in relation to the strong association atmosphere has with context, an architecture of atmosphere cannot be related to a specific predetermined aesthetic approach. Thus, the design of atmospheric architecture is not a prescribed formula. Rather, atmosphere is developed in the mindset and sensibility of an architect's approach to design and their ability to capture a sensation of being within their architecture. To develop a building's atmospheric sensation is a way of working with atmosphere and thinking about architecture.

However, as a product that is infused and tied to the tangible temporal realities of buildings, a consideration of atmosphere in the design of architecture seems a difficult task. This problem is one Mark Wigley discusses. Regarding the design of atmospheric buildings Wigley makes a keen observation that, "[atmosphere] seems to start precisely where the construction stops". ${ }^{45}$ Wigley's comment directly 

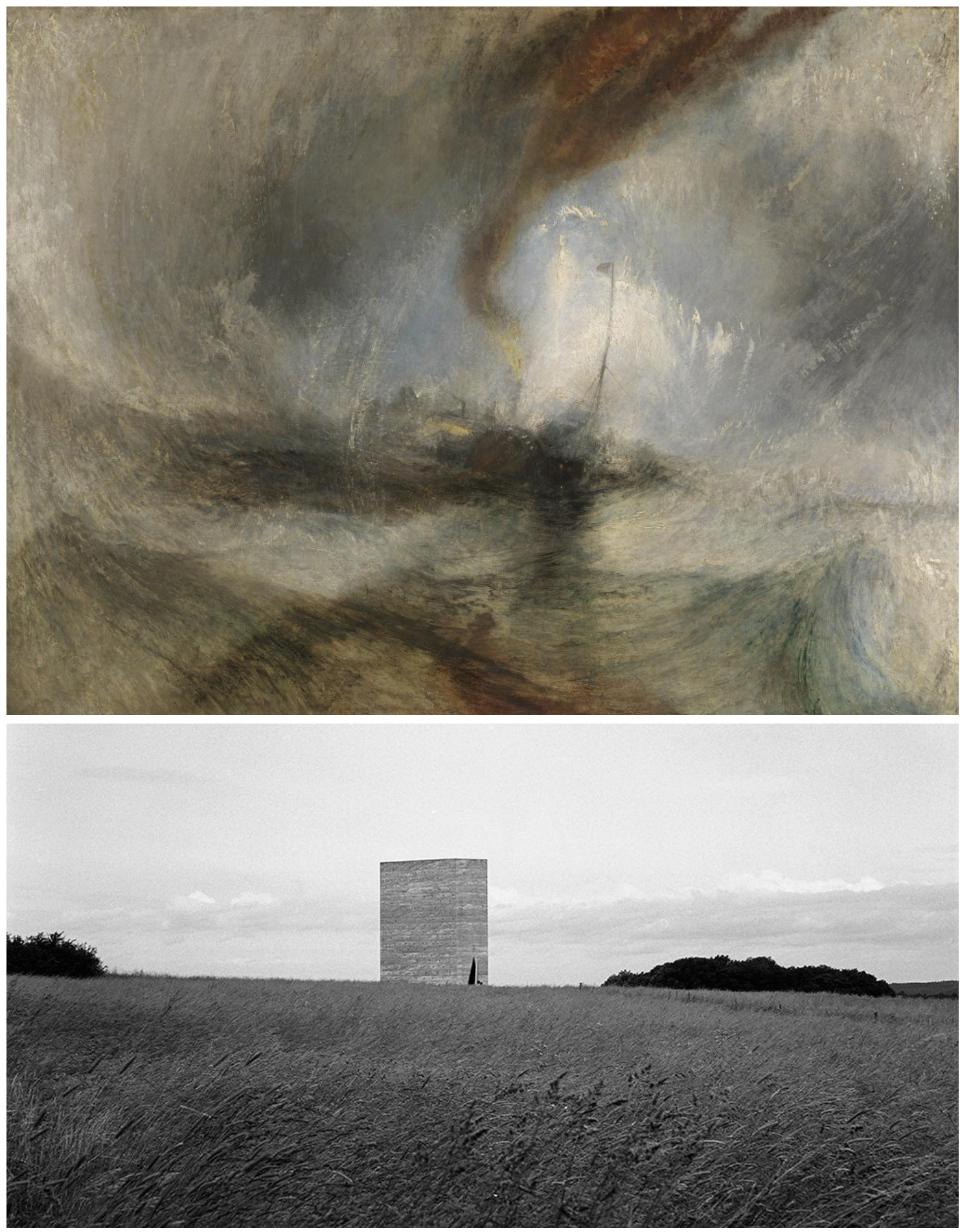
ties the experience and sensation of atmosphere to the temporal world, which he is not incorrect to think while simultaneously doubting whether atmosphere can be predetermined or expected in the design of a building. If design is mainly representational, can a potential atmosphere be determined before the architecture is built? In the same sense that French architect Auguste Perret states "Il n'y a pas de detail dans la construction" (there is no detail in construction) ${ }^{46}$ one can say that there is no atmosphere but those of defaults in the construction of buildings. While atmosphere is sensed in our physical world, the design of architecture sets up the construct which one will engage with and in doing so feel present. Thus, even in the architect's process of representing buildings through drawings or models, the architectural representation still holds the essence and the spirit of the architecture which will be engendered in its built form. A consideration of atmosphere is part of an architectural design process, not in a building's construction.

For many outside the field of design the ability to mentally actualize the built experience of a represented architecture before its construction is a difficult task. However, for those in the practice of architecture, the aptitude to perceive and embody an architectural experience is a learned skill. Many architects have the ability to put themselves in the spaces which they create, feeling and understanding the represented environment as if it was almost physically built. While atmosphere is a physical phenomena experienced by one's body and understood in one's consciousness, at any point in the architectural process, if one is willing to immerse oneself in the work and understand the spirit of the design, one then can begin to appreciate and sense its atmosphere. The following chapters of this thesis will focus on designing an architecture of atmosphere and in doing so invite the reader to immerse themselves in the work, embodying in the mind the designed human experience, and understand the spirit of the architecture. 


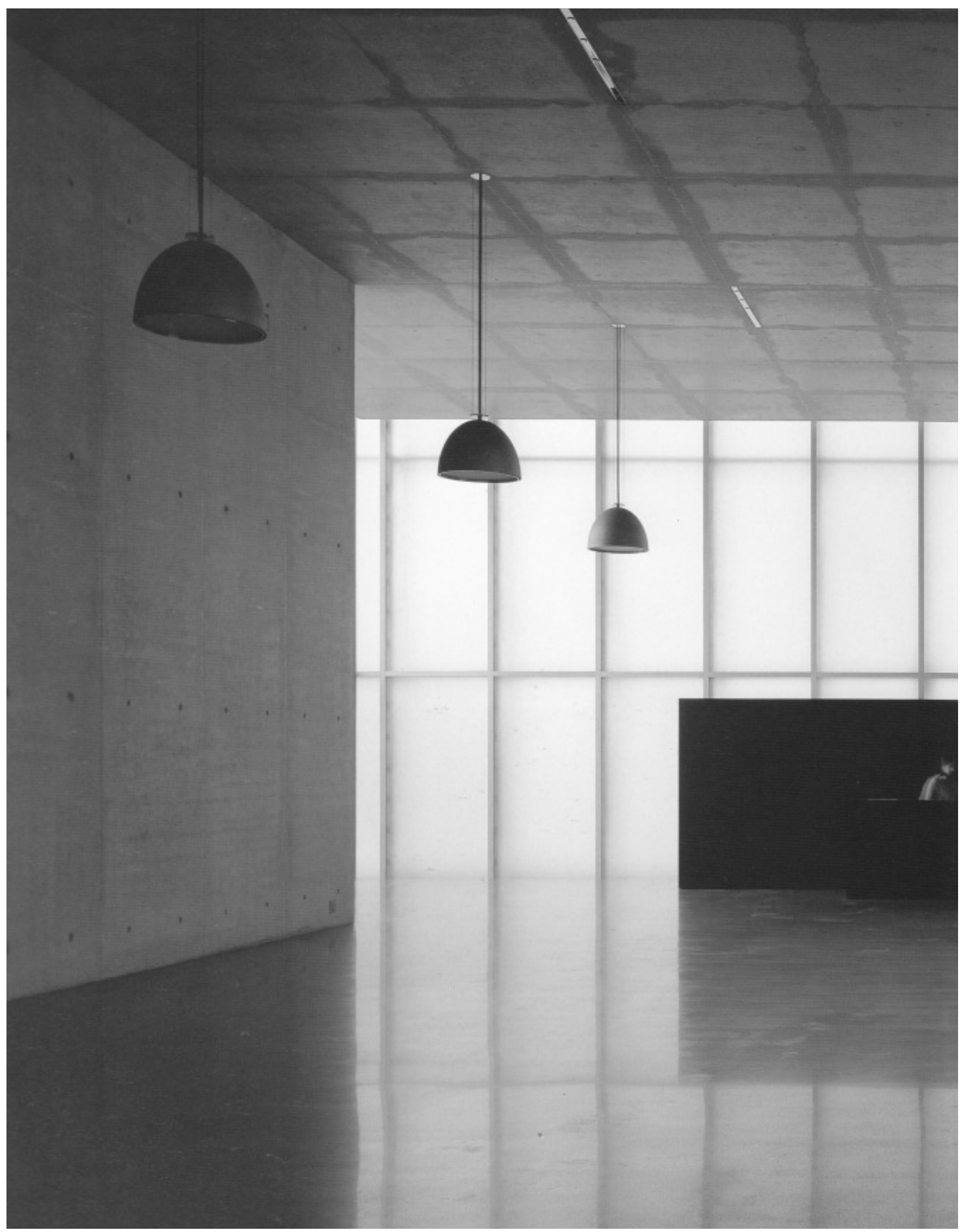





\section{5}

\section{Atmosphere on Little Morgan Bay Road}

In order to explore these notions of atmospheric architecture, the design of a small dwelling on Little Morgan Bay will develop the architectural basis and tenets for this evolving exploration in atmosphere. The dwelling is limited in program and modest in scale in order to focus upon the complexities of designing with atmosphere. It has often been the intimate space of a home that has acted as a typology for architectural exploration. Architectural masters such as Frank Lloyd Wright (Usonian House), Le Corbusier (Villa Savoye), Alvar Aalto (Murratsalo Experimental House), and Peter Eisenman (House I-X), just to name a few, have all used the house as a means of developing their architectural theory. In the same approach the dwelling on Little Morgan Bay will in its process of design embody a way of working with atmosphere and in its final state become demonstrative of this thesis' intent.

5.I Location and Site Character: Located at 1054 Little Morgan Bay Road in Rosseau, Ontario, the dwelling's site is part of the Muskoka Lakes, a popular destination for secondary summer and winter homes of residents in Southern Ontario. Forming part of the inlet of Little Morgan Bay the site is connected to the larger Lake Rosseau that, with the neighbouring Lake Joseph and Lake Muskoka, form what is typically referred to as the Muskoka region. Like many of the properties scattered along the large and smaller Muskoka lakes, the dwelling's site is accessible both by land and water.

The sites character is formed by the Igneous rock formation of the Canadian Shield, which is covered by a thin layer of soil but whose granite stone sporadically emerges from beneath the earth. The region is studded with fresh water lakes that 
were formed by the advance and retreat of the Laurentide Ice Sheet which depressed and scraped out the water basins, shaping the Muskoka region's present landscape. Due to these natural characteristics the sites typography varies approximately 20 meters in height from its North end down towards the lake front. From the water's edge a forest of evergreen trees with dots of deciduous Maple, Oak, Birch, and Ash trees stretch up to the sky. The most prominent florae are the windswept Pine trees whose forms have been shaped by the site's predominantly Western wind and whose needles scatter across the forest floor. Nestled in between the trees are found the vacation homes of many of the area's seasonal residents.

5.2 The Atmospheres of Little Morgan Bay: Regardless of the existence of any dwelling at 1054 Little Morgan Bay Road, the location is contextually rich in natural and atmospheric qualities. But architecture has the ability to enhance or diminish this natural aura of a place and the sensorial experience of being in it. Approaching the design of buildings in such environments Wigley points out that:

"Since the physical context has its own ambiance, the building
is a kind of device for producing a particular atmosphere within
another one. To enter it is to pass from one atmosphere to
another. Architecture is to be found in the relationship between
atmospheres, the play between microclimates. The meeting of
these seemingly ephemeral atmospheres can be as solid as any
building."

Given this fact the design approach will focus on the intersection between the atmosphere of place, the atmosphere of the dwelling, and the intimate experience of architectural spaces. In order to develop the building's atmosphere in this manner a series of exploratory projects relating to the typologies of atmosphere in Figure 6 are dotted along the site and investigated through the design program. These series of design explorations will begin to build a string of spatial experiences that are woven together on the site to create the architectural basis for the thesis project. 

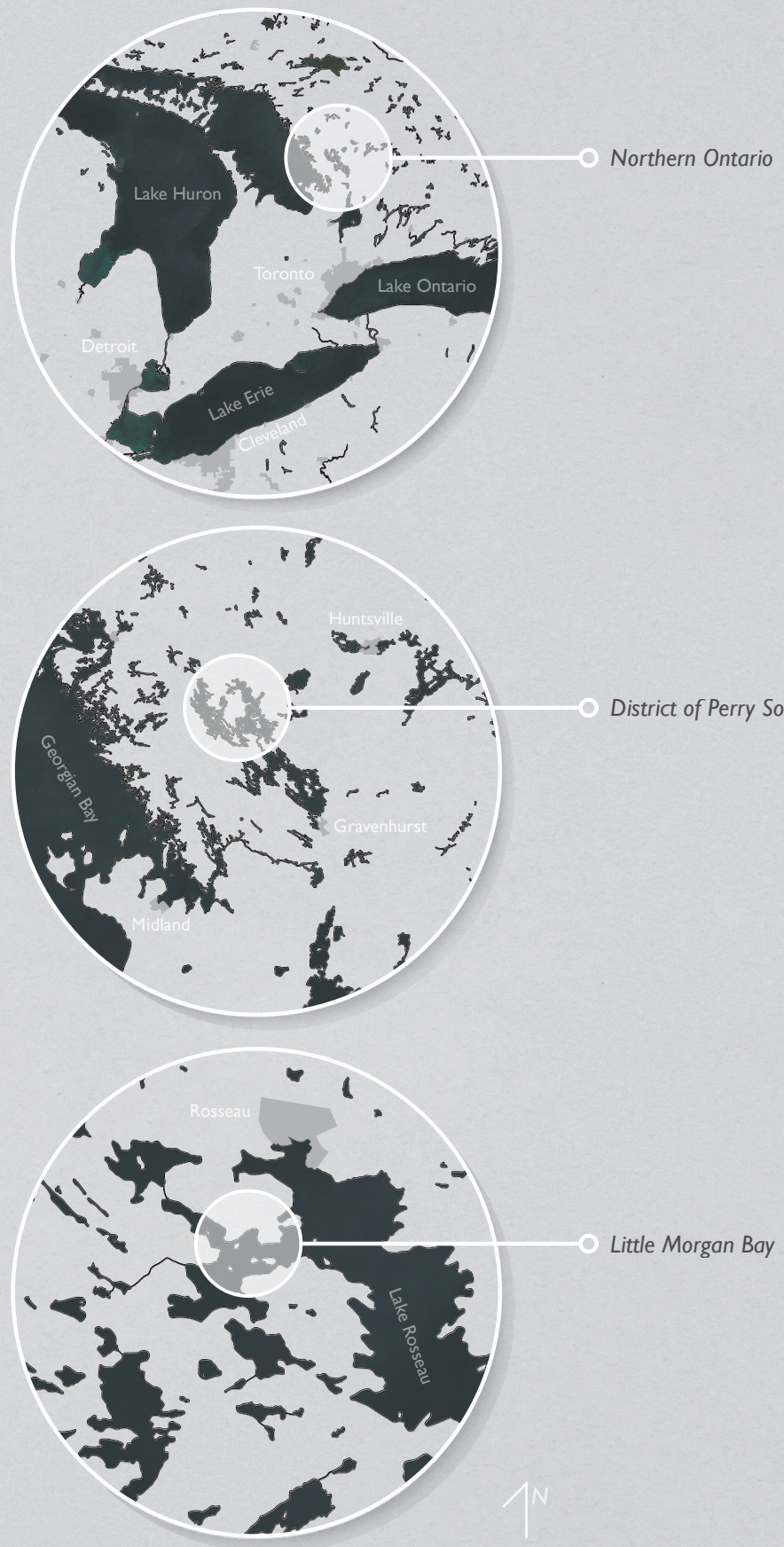


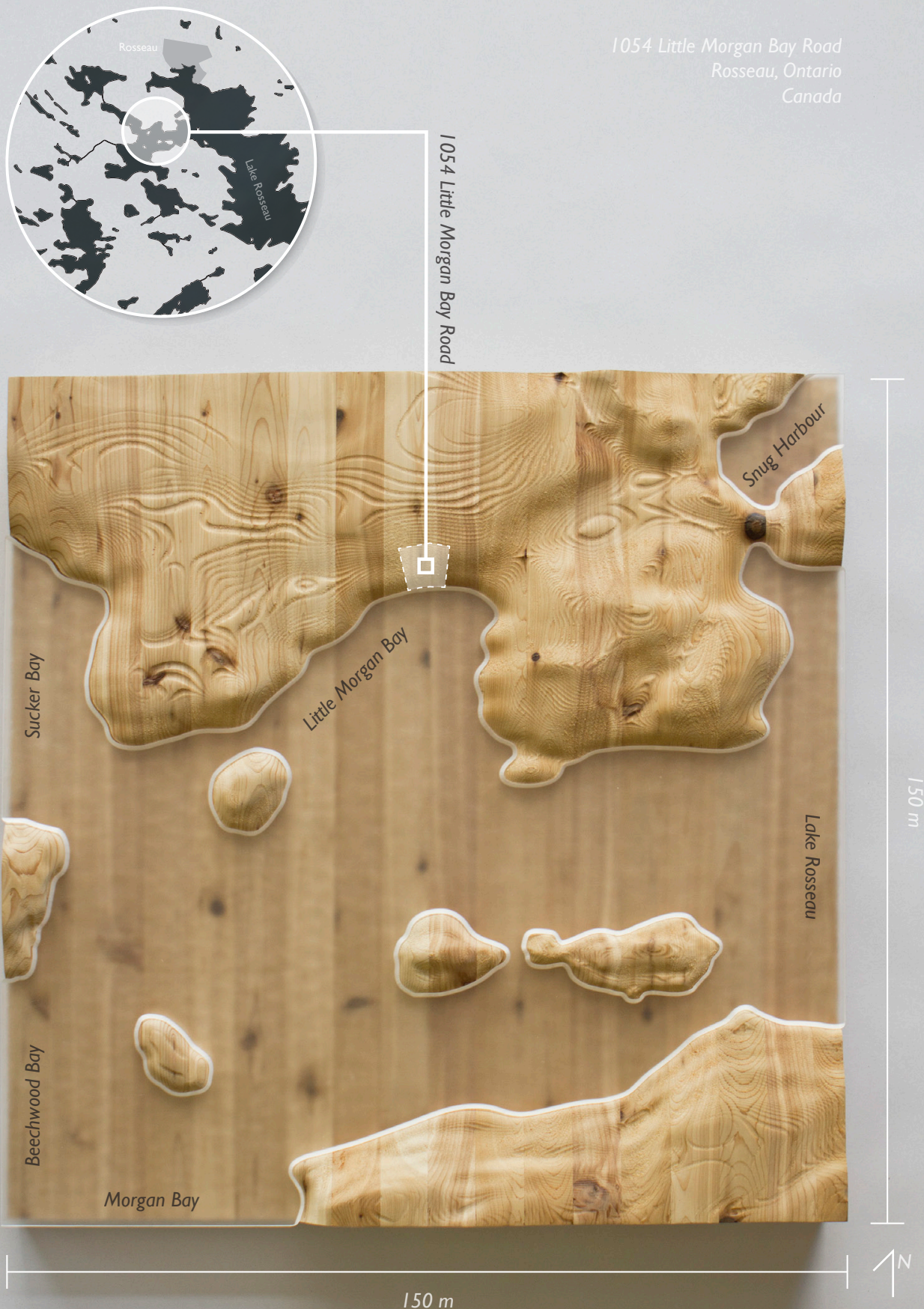




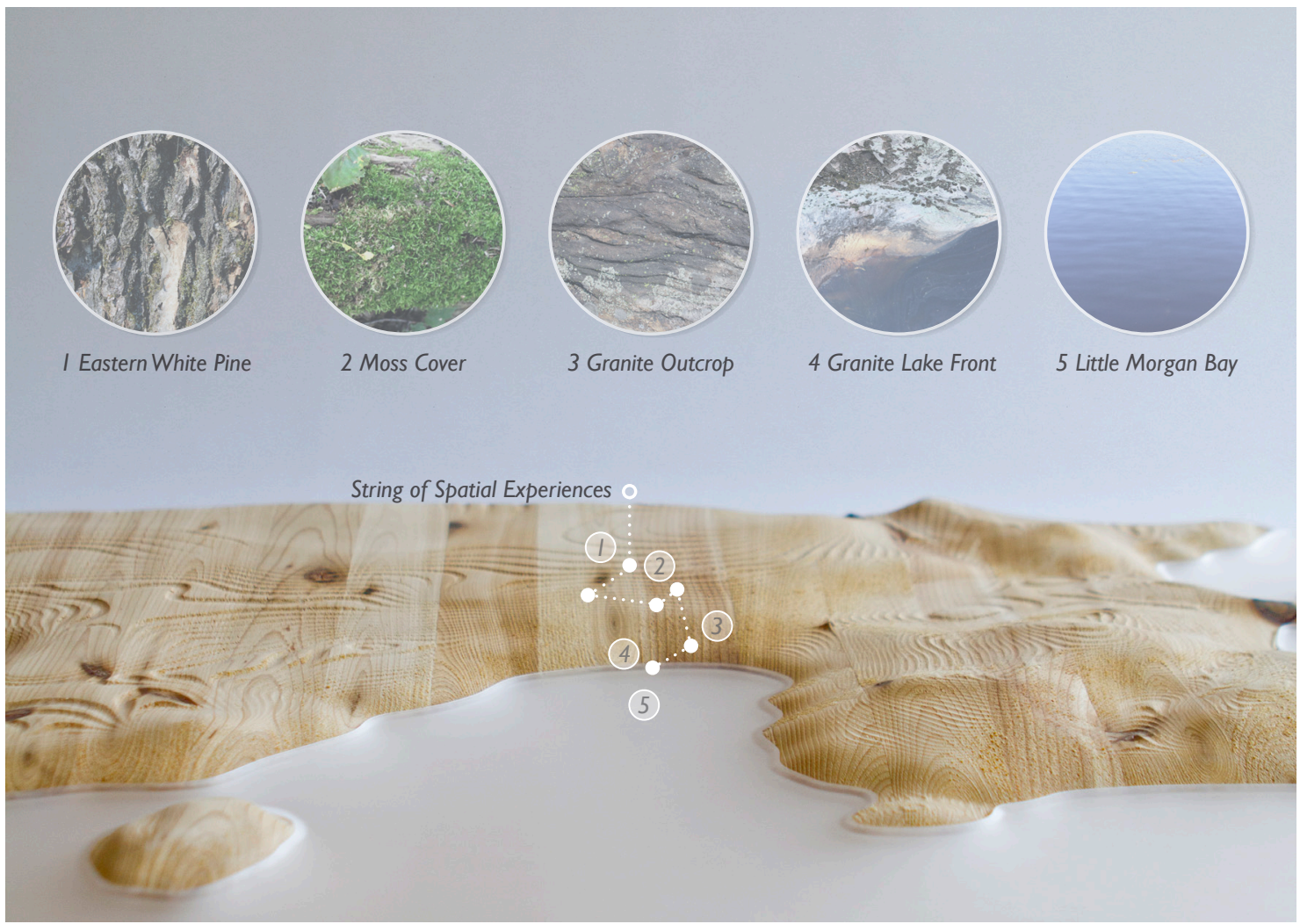

Figure No. 27

I:2500 Context Model

Figure No. 28

Site Character 



\section{6}

\section{The Architectural Typologies of Atmosphere - Expanded}

In this thesis' early considerations on defining and clarifying an atmosphere in architecture, three overarching categories of atmosphere relating to properties of architectural design were identified. The Atmosphere of Characteristics is directly related to built matter, the Atmosphere in Forces is associated with energies found in buildings, and the Atmosphere of Objects are the resulting interaction between matter and energy. Each are groupings of architectural properties that affect the way atmosphere is shaped in a design. As was previously noted in earlier chapters, these typologies of atmosphere along with their associated properties form part of the architect's domain when reflecting upon how an atmosphere is affected in the design of architecture. A consideration of these building properties and the sensibilities which architects imbue in them affect one's perception of objects, space, and a building's atmosphere.

Atmosphere in our physical environment is understood and perceived holistically instead of as a combination of separate entities. However, in order to gain an in-depth understanding of designing with atmosphere, it is necessary that these three categories are explored as individual types. Thus, in the following subchapters the ideas of atmosphere related to characteristics, forces, and objects will be explored further in order to grasp the full implications these typologies have in the design and perception of atmosphere. In addition to the discussion on each typology, the work accompanying these sections will explore the core concepts of the typology and seek to answer what it means to work with and consider atmosphere in the design process. Together these investigations will begin to define the sensibility and built form of the dwelling on Little Morgan Bay. 
6.I Atmosphere of Characteristics: At a fundamental level, the architect's main function is to select and subsequently shape matter to form buildings and spaces. The way matter is formed into architecture, and the sensibilities a designer expresses through it, help to characterize one's perception of space and its potential atmospheres. Architectonic considerations such as materiality and texture, light and shadow, shape and form, as well as scale and proportion, affect the way one perceives one's environment, oneself, and others. Zumthor, discussing levels of intimacy in relation to architecture, notes this fact when discussing the size, dimension, and scale of things. He states:

"Maybe you know a tall slim door that makes everyone who comes through it look great? Or do you know that rather boring one, wider - somehow shape-less? And the enormous, intimidating portal where the person who comes to the door looks good, or proud". ${ }^{48}$

What Zumthor's description of architectural characteristics makes clear is that the way things are designed not only affect one's perception of space but also affects the way one sees themselves, their body, and their being that are constantly in reference to their surroundings.

In aiming to produce an architecture of atmosphere the ability to influence one's perception of oneself and objects being present in a specific environment is critical. But how a designer is able to design architectural characteristics with such a sensation is a question that must first be answered. As architectural historian and theorist Alberto Perez-Gomez declares at the beginning of the book Questions of Perception: Phenomenology of Architecture, "[architecture] is not an experience that words translate later". ${ }^{99}$ Perez-Gomez's statement makes relevant that a true architectural experience, such as sensing a building's atmosphere, is based on a temporal and corporeal experience, and thus these factors should be the focus of designing an atmospheric architecture. Emphasizing one's body in space is essential in allowing one to feel present. As Gernot Bohme states in his essay "Encountering Atmospheres":

"Corporeal feeling allows me not only to feel something, but also to feel how I feel, my sensitive state. Atmospheres are by nature experienced by corporeal feeling, namely by their tendency to 'affect' me, to put me in a specific mood". 50 
Architectural characteristics relating to haptic sensations such as materiality, texture, density, and temperature are the immediate interpretation of designing a corporeal experience. But a corporeal experience also refers to the space of architecture and its scale, proportion, shape, as well as spatial sequence. The form of architecture and the spatial relationships it creates between oneself, its architecture, and its context, can encourage a feeling of being present. As one moves through a building to encounter new and existing spaces, they are engaging their body as well as their mind in a discourse of their own past and future presence, which may emphasize their current state.

Examining the relationship between design and atmosphere by concentrating on the properties relating to the category Atmosphere of Characteristics, the first exploratory study is carried out through the medium of drawing. This initial study's intent is to begin to define the condition of atmosphere at the dwelling on Little Morgan Bay by creating a series of spatial experiences which, dotted along the site, form the architectural basis of the thesis project. In beginning to consider a design approach to developing these atmospheric spaces, the words of German architect August Endell helped to shape the focus of the drawing study. Endell in his book Die Schonheit Der Grossen Stadt states:

"Whosoever thinks of architecture initially always thinks of the elements of the building, the facades, the columns, the ornaments, and yet all of that is of second rank. What is to most effect is not the shape, but its inversion, the space, the emptiness that spreads out rhythmically between the walls, is delimited by them, and that vibrancy is more important than the walls". ${ }^{51}$

Endell's statement encouraged an inversion of a traditional design process. Instead of focusing on the building, the drawn exploration of the dwelling first concentrated on architectural space and its intimate relationship to the body.

The four design studies in this series [Figure 29-32] are all related to a consideration of the interior atmosphere of the dwelling. These drawings focus on several characteristics of architectural space such as materiality, texture, scale, proportion, weight, light, shadow, warmth, construction, proximity, and distance in order to affect the viewers perception of the atmosphere and capture the aura of the building. Each drawing in this series is a re-presentation of the constructed atmosphere of the dwelling insofar as it is the conclusion of this initial design act. 


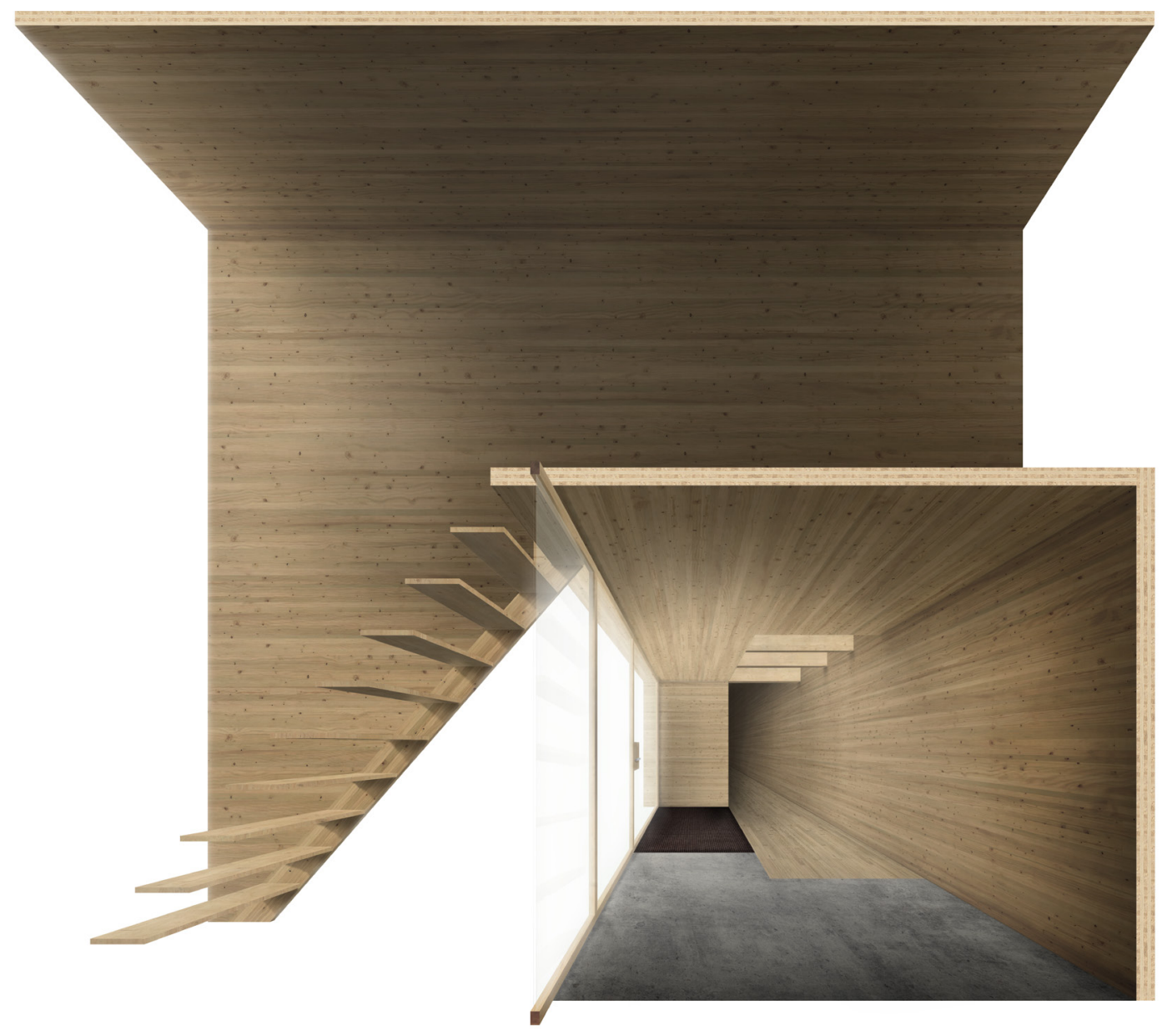

O Study No. I

$\therefore \cdots$
$\vdots$
$\ddots$

Figure No. 29

Interior Atmosphere

Study No. I 


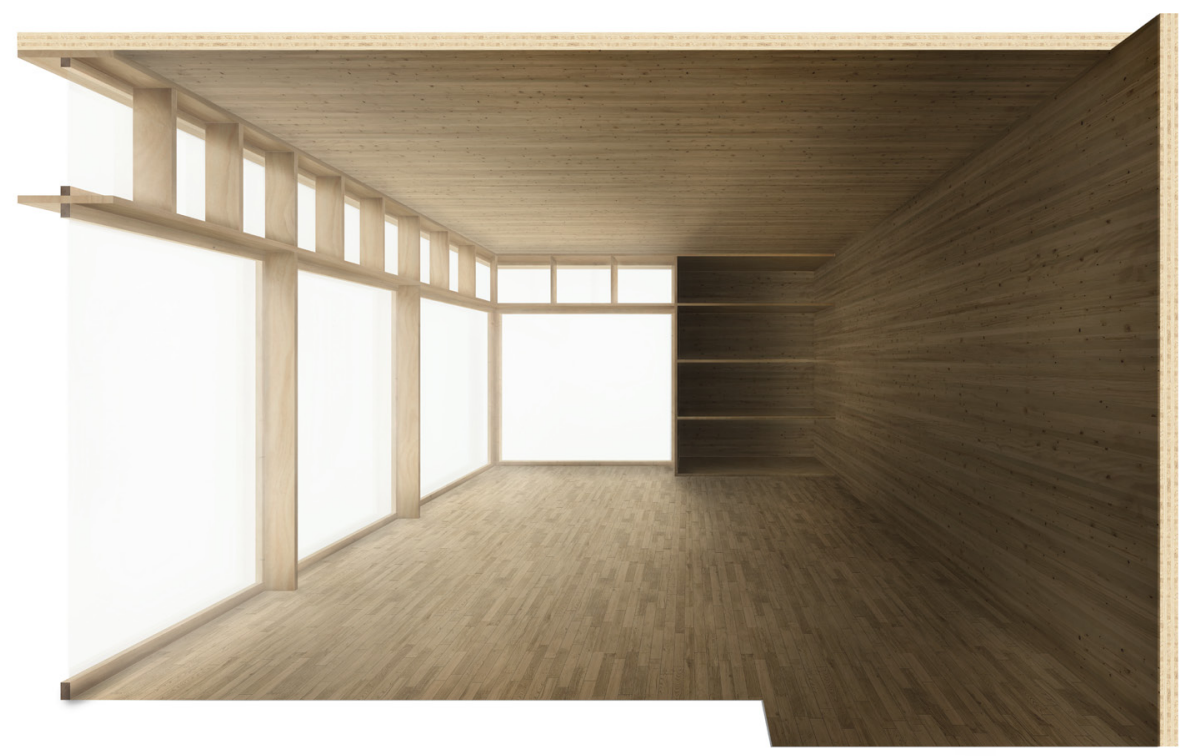

Figure No. 30

Interior Atmosphere

Study No. 2

Study No. 2 ○

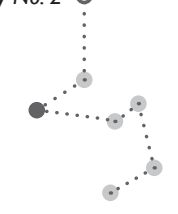




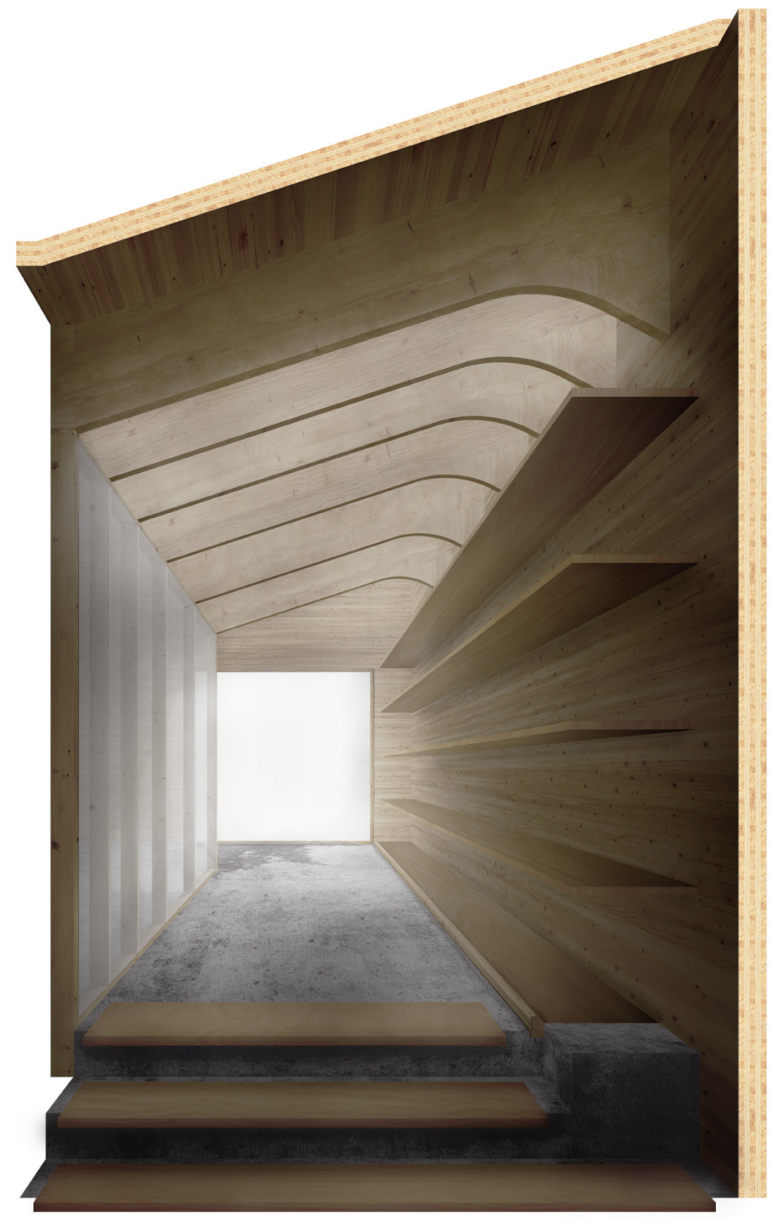

O Study No. 3

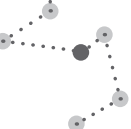

Figure No. 31

Interior Atmosphere

Study No. 3 


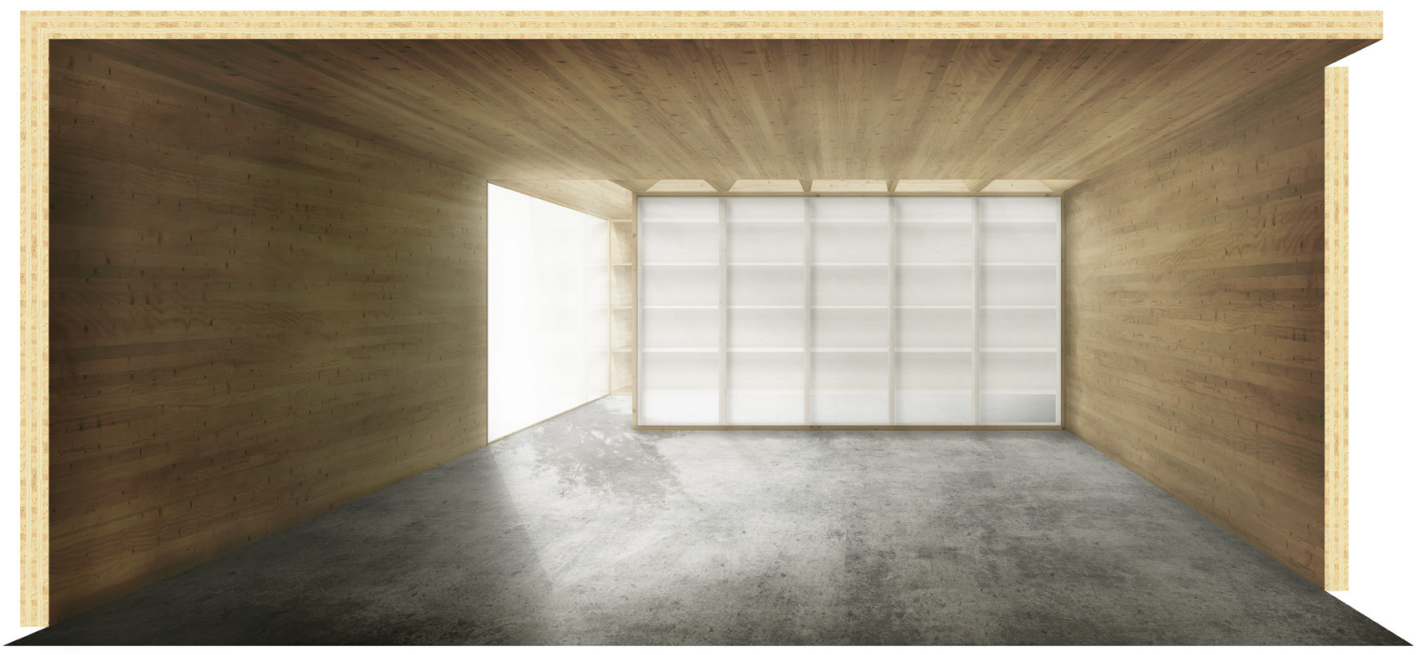

Figure No. 32

Interior Atmosphere

Study No. 4 ○

Study No. 4

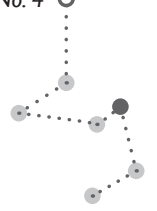


But for the author the drawings are not the desired artifact; rather, moving forward with the design of the dwelling, the Characteristics of Atmosphere which have been developed through this creative process are the intended focus. For example, the use of wood for its natural tactile and visual sense of warmth as well as its reference to the dwelling's context plays a large role in the haptic experience of the architecture. In addition, the quality of light captured in the drawings as well as the overlapping of spatial movement in the designs give prominence to the temporal event of being within the world and specifically these architectural spaces. In relation to viewing the five digitally produced representations it is necessary that they become a framework for a mental reconstruction of space to immerse one's self within the constructed atmosphere.

Moving forward from this initial drawn study, the concentration of the Figure No. 33 work began to further focus on the importance of the haptic in the character of Tactile Study No. I atmospheric architecture. Again, working in a reversed approach to a traditional architectural design process, the second series of explorations centre on the tactile experience of entering the dwelling through the production of three distinct door handles [Figures 33-41]. As Juhani Pallasmaa notes in his text The Eyes Of The Skin, the "door handle is the handshake of the building". ${ }^{2}$ As one of the first tactile components of architecture that is interacted with, the character of a door handle is a subtle introduction into the language and nature of the built form to follow. In the design of the three door handles the experience and sensation of entering is the main consideration. But in addition to this, thought has been given to how the design sensibilities emerging from this exploration could further inform the dwelling's outcome.

An individual's haptic interaction with the materials that construct their built environment initiates both an immediate and direct response which shapes their experience of architectural space. As Peter Zumthor suggests:

"It is well-known that materials more or less extract the warmth from our bodies... So temperature in a sense is physical, but presumably psychological too. It's in what I see, what I feel, what I touch..... 53

Understanding this, Tactile Study No. 1 [Figures 33-35] approached the design of a door-pull in a reflection of this reality. Conceived as a basic circular extrusion, the warmth of the material chosen relates directly to the intimacy of one's touch. 

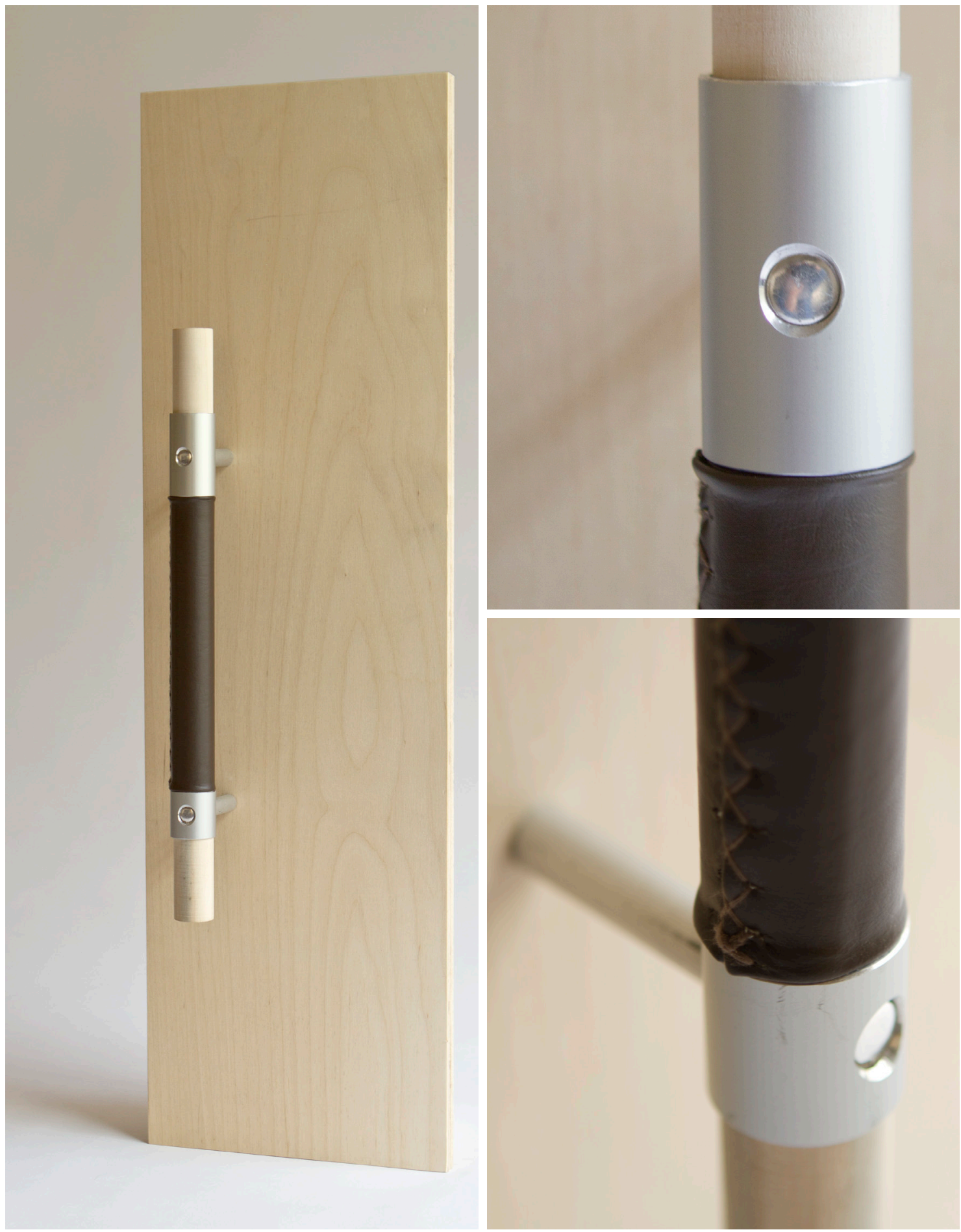
Aluminum collars fastened to a door hold in place a wooden dowel. Where one's hand meets the handle a leather wrapping is secured in place and stitched so that one's finger tips rest upon its seam. Tactile Study No. 2 [Figure 36-38] builds upon this initial investigation and in a similar manner is characterized by its brass collar and wooden support. This study intensifies the tactility of the leather wrapping by weaving circular leather cord around the handle where the woven seam lays within the web of one's palm. In both these studies, the leather handle separates the skin from the cold metal support brackets as well as the hard wood surface and brings to attention one's contact with the warmer textured feeling of the leather. The door handles with their unique seams highlight the sensation of touch and with the warmth of the leather become more akin to a warm receptive handshake (to use Pallasmaa's analogy) rather than an obligatory hello.

Tactile Study No. 3 [Figure 39-41] focuses on the threshold, the tension Figure No. 36

Tactile Study No. 2 between interior and exterior. Created from a block of White Pine, the solid wood Fastening Detail door is carved away so that the hand, when gripping the door handle, is sheltered by the surrounding material. In opposition to this subtractive aspect of the door, the handle is secured in an additive process. The circular dowel which comfortably fits within a hand's grip is embedded three-eighths of its diameter into the wooden door, emphasising its additive construction and its perception as an external element. In the act of entering, one slips their hand into the door and in doing so confronts a liminal state. In this moment, one is simultaneously inside and outside of the dwelling. The door handle emphasizes the threshold of entering where the transitional boundary between interior and exterior is blurred. In doing so, this experience allows one to recognize their own presence, in a moment where one is neither here nor there.

The last series of design explorations relating to the Characteristics of Atmosphere examine qualities of light in space and light on materials. In architecture light has long been an indication of temporality. The movement of light through a space allows one to understand the constant ephemeral environments around them while also highlighting the present moment in time. In addition, light on the surface of objects changes and shapes their appreciable quality. To examine these characteristics a study of three screens [Figures 42-48] was developed with each investigation. Light and Materiality Study No. 1 [Figures 42, 44] begins with a sheet of Baltic Birch plywood. A pattern of liner apertures is made to the sheet material in order for light to stream through and project the positive space of the screen within its surroundings. Over the course of a day the shifting pattern of light in the space alludes to the temporal nature of the surrounding environment.

Figure No. 38

Tactile Study No. 2 LeatherWeave 

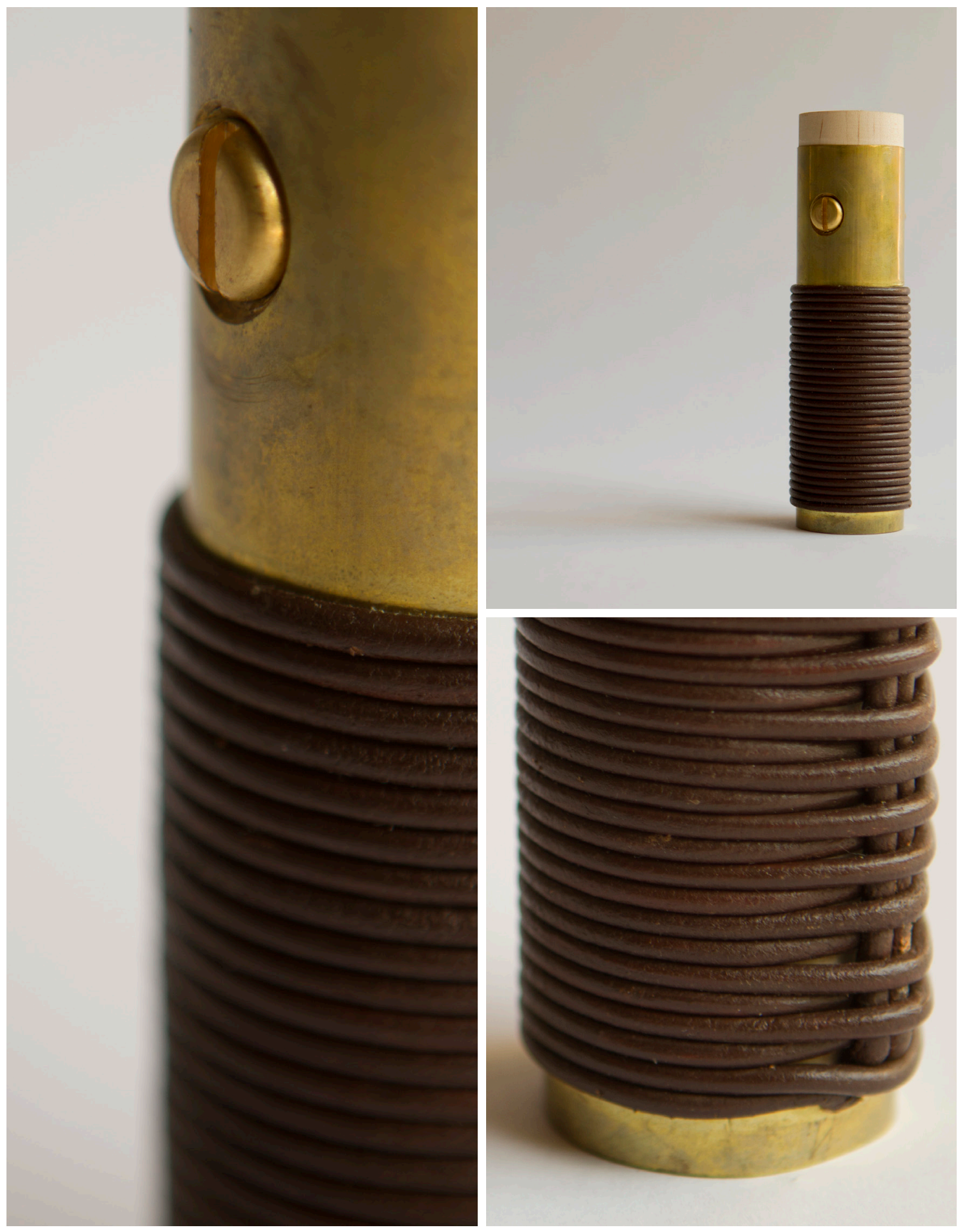
The second examination Light and Materiality Study No. 2 [Figures 43, 45] focuses on the depth of the aperture and the obscuring of the light source. One inch strips of Baltic plywood form the wooden panel in which the apertures are carved out of. While still producing the same effect as the first panel, viewing the second study from the side obscures the apertures. In doing so, this panel creates an ambiguity that allows it to form a liminal presence within the space. Further as one moves past the screen the source of light becomes present. The final study Light and Materiality Study No. 3 [Figures 46-48] builds upon these first two explorations. This third screen is made from a two inch thick composition of White Pine wood in order to accentuate the depth and obscurity of the panels apertures. The openings, cut into the surface, are inset one inch from the top panel so that the linear wood spaces of the vertical apertures are accentuated. The form of the spacing between Figure No. 39 each aperture was designed to allow light to highlight its position and create visual knots within the overall wooden screen. The choice of solid wood provides light the Tactile Study No. 3 Carved Door opportunity to gently bounce off its surface and create a soft glow in the interspatial depth of the panel's apertures. The screen's effect in creating space through light, and highlighting the temporal nature of the world creates a sensation of nowness. In addition, the obscurity of the light source and the glow of light from the aperture shapes a liminal presence within a space. The consequences of the screens' design begin to affect ones perception of atmosphere.

6.2 Atmosphere in Forces: On the opposite end of the spectrum from matter, energy plays an equal role in defining the perceived atmosphere of a building. Forces of kinetic energy affect conditions such as temperature, sound, and pressure, which all contribute to shaping one's perception of architectural space. In addition to this, the interaction of energy and matter, such as water or wood, facilitate the strength of additional non-visual forces like smell or humidity. These forces can be found within any environment architects create and their effects on one's perception of architectural space helps to define an atmospheric condition.

Unlike matter that is easily understood as a delineator of spatial boundaries and which architects mostly engage with, energy is an intangible entity that, for the most part, cannot be seen directly. Rather, forces in the environment are filtered through senses such as touch, smell, and sound. Because forces of energy often escape the visual sense, they are generally not considered in the design of architecture. As architect Sean Lally notes in his book The Air From Other Planets: A Brief History Of Architecture To Come:

Figure No. $4 \mathrm{I}$

Tactile Study No. 3 Door Lock 

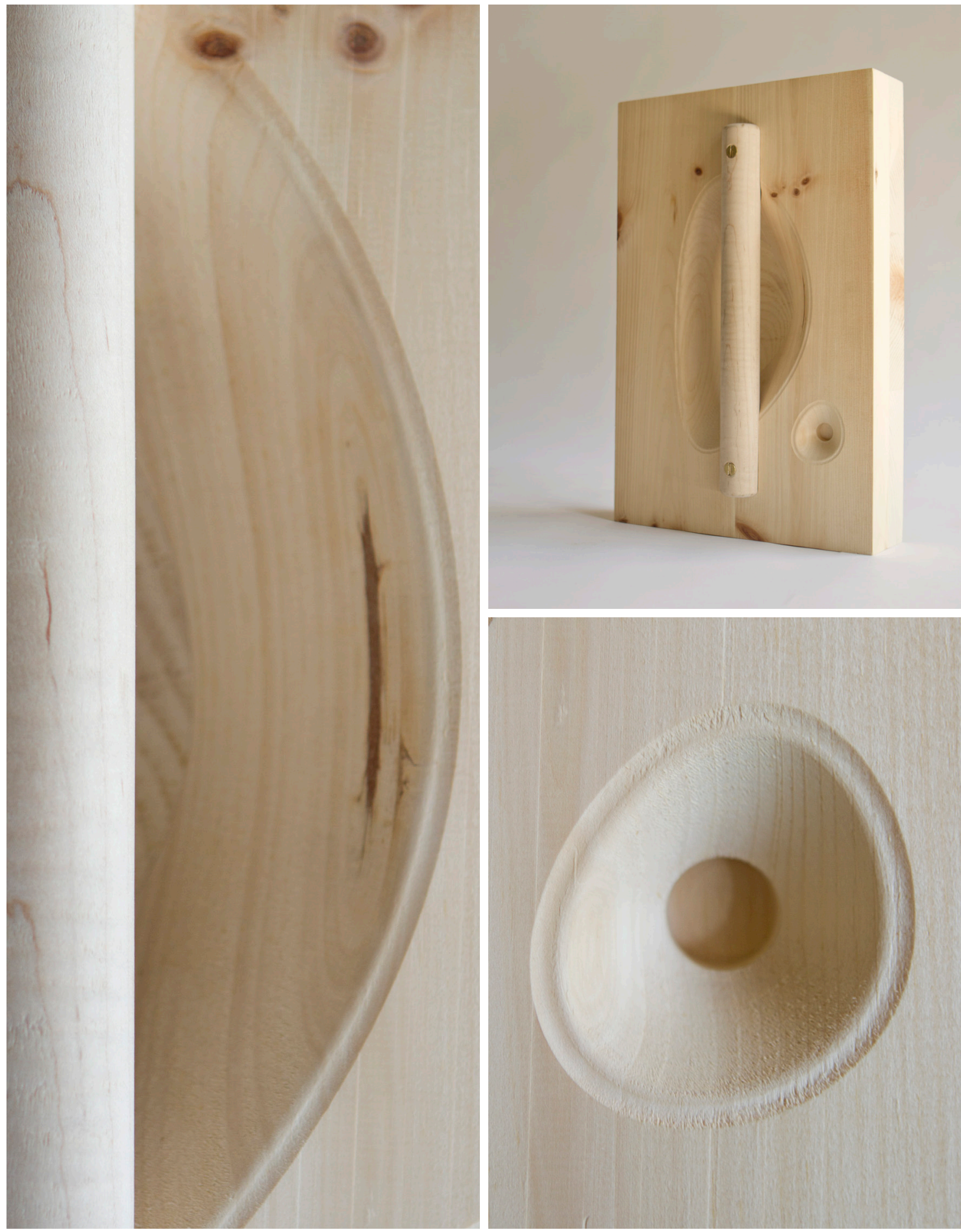
"Architectural innovation in energy is currently judged by how the architect integrates technological devices that reduce energy consumption after a building or site has already been designed not by the capacity of energy to produce the design characteristics of a building". 54

Lally is right in pointing out a lack of attention on the part of designers to consider the characteristic quality that forces of energy produce in their architecture. For example, most architects rely on mechanical systems to control the environmental energy of their buildings. In doing so, architects generally neglect to consider the physical warmth that energy such as sunlight may add to a material and the energy's ability to change the material's perceived characteristic or its ability to create a perceived spatial boundary.

By existing outside of one's visual sense, forces of energy are typically not considered as delineators of spatial boundaries. But this assumption is incorrect. Energy is a definer of spatial boundaries, except not through distinctive and

Figure No. 42 Light and Materiality Study No. I defined surfaces with solid or liquid matter. Instead forces of energy create gradient boundaries that define space through transitional zones of energy fields and flows. ${ }^{55}$ German philosopher Peter Sloterdijk, in his book Terror from the Air, uses the gas warfare of World War I to illustrate the human use of energy forces as a spatial boundary. Discussing the German gas attack on French-Canadian troops at the battle of Ypres in 1915, Sloterdijk notes that the focus of the assault was not on the bodies of the opposing force but rather on their environment. The clouds of chlorine gas revealed that the environment can create a spatial condition. ${ }^{56}$ In the case of Ypres the environmental force and its spatial condition that was created led to death. But the focus here goes beyond the horrors of this conflict. This example emphasizes how the forces in an environment can be distorted and shaped in order to target one's body through their senses and affect the perception of their spatial context. ${ }^{57}$ As a delineator of space the forces of energy and the character in which they have been formed help to shape the atmospheric sensation of one being in, and architecture being of a place, just as much as the physical matter that can be seen.

As Michelle Addington discusses in her essay "The Phenomena of the Non-Visual", how one begins to shape energy and predict its effect is always a difficult task. In relation to the design of buildings, Addington states what "cannot be easily reproduced is the perception or experience of the environment that is always transient, always unique. Defining the surface does not define the environment". ${ }^{58}$ In
Figure No. 44 Light and Materiality Study No. I Detail

Figure No. 45 Light and Materiality Study No. 2 Detail 

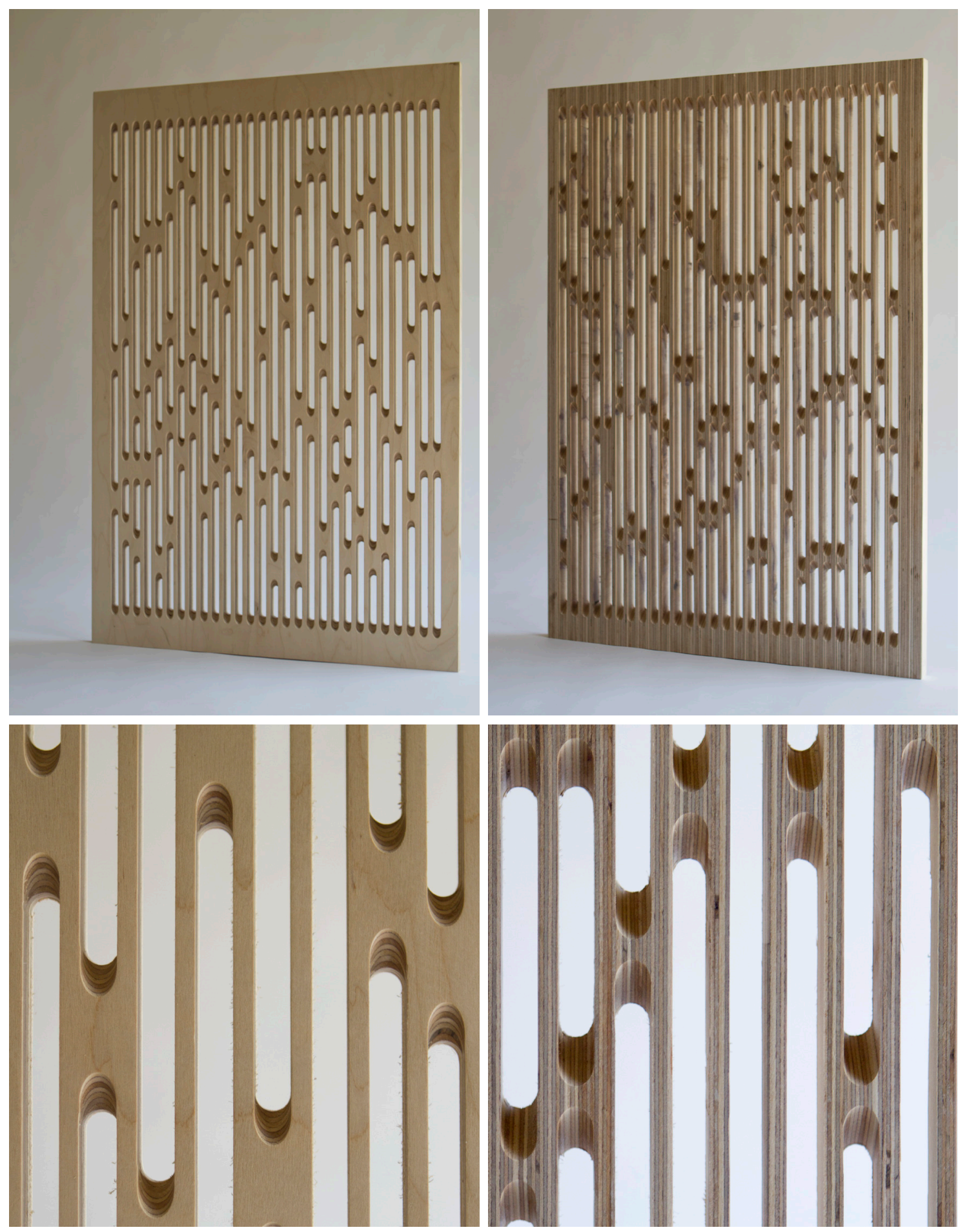
this context exploring the properties relating to the Atmosphere of Forces will be done in the design of the dwelling on Little Morgan Bay. This approach is taken so that the consideration of energy forces becomes directly tied to the design of the dwelling and its environment which the forces are affecting and creating. In the dwelling, a concern for how forces of energy effect the perception of space and create spatial boundaries will be addressed as well as employed to help in developing a sensation of atmosphere.

6.3 Atmosphere of Objects: In Subchapter One and Two of this section atmosphere was discussed in relation to an architect's design of matter and the energy in environments that help shape the perception of space. Situated between these two categories is a condition of atmosphere where matter and energy meet. This condition expressed as Atmosphere of Objects is found in the reaction and relationship between the physical object of architecture and the forces of energy in an environment. Atmosphere of Objects is the effect that energy produces when in contact with matter, altering its material expression. In the design of architecture this category is associated with the acknowledgement of material's decay and the weathering of buildings.

While many designers attempt to stop the weathering and decay of their buildings from external forces in order to preserve their idealized architectural designs, the characteristics that weathering and decay form on buildings contribute to the perception of atmosphere. As architect Jonathan Hill notes in his book Immaterial Architecture, the "[evidence] and experience of decay... indicate the passage of time and fragility of life...". 59 The changing character of architecture under the stress of energy highlights a building's intrinsic temporal nature. In addition to this, one's perception of decay and weathering in architecture builds an awareness that a building is part of the world and as such is susceptible to the imperfections and frailty that define all matter and life. The effect of decay left on buildings from natural forces adds to an architectural atmosphere as it orients one's understanding of buildings beyond their ideal state, and in doing so allows one to consider their own finite existence.

Along with emphasizing the frailty of buildings in temporal environments, the process of weathering also gives architecture a unique sense of place. Architects Mohsen Mostafavi and David Leatherbarrow discuss in their text On Weathering: The Life of Building in Time the relationship between architecture's finished state and weathering. As they note: 'In the process of subtracting the 'finish' of a construction, Light and Materiality weathering adds the 'finish' of the environment". ${ }^{60}$ The 'finish of the environment'

Figure No. 46 Light and Materiality Study No. 3 Screen Depth

Figure No. 47 Light and Materiality Study No. 3 

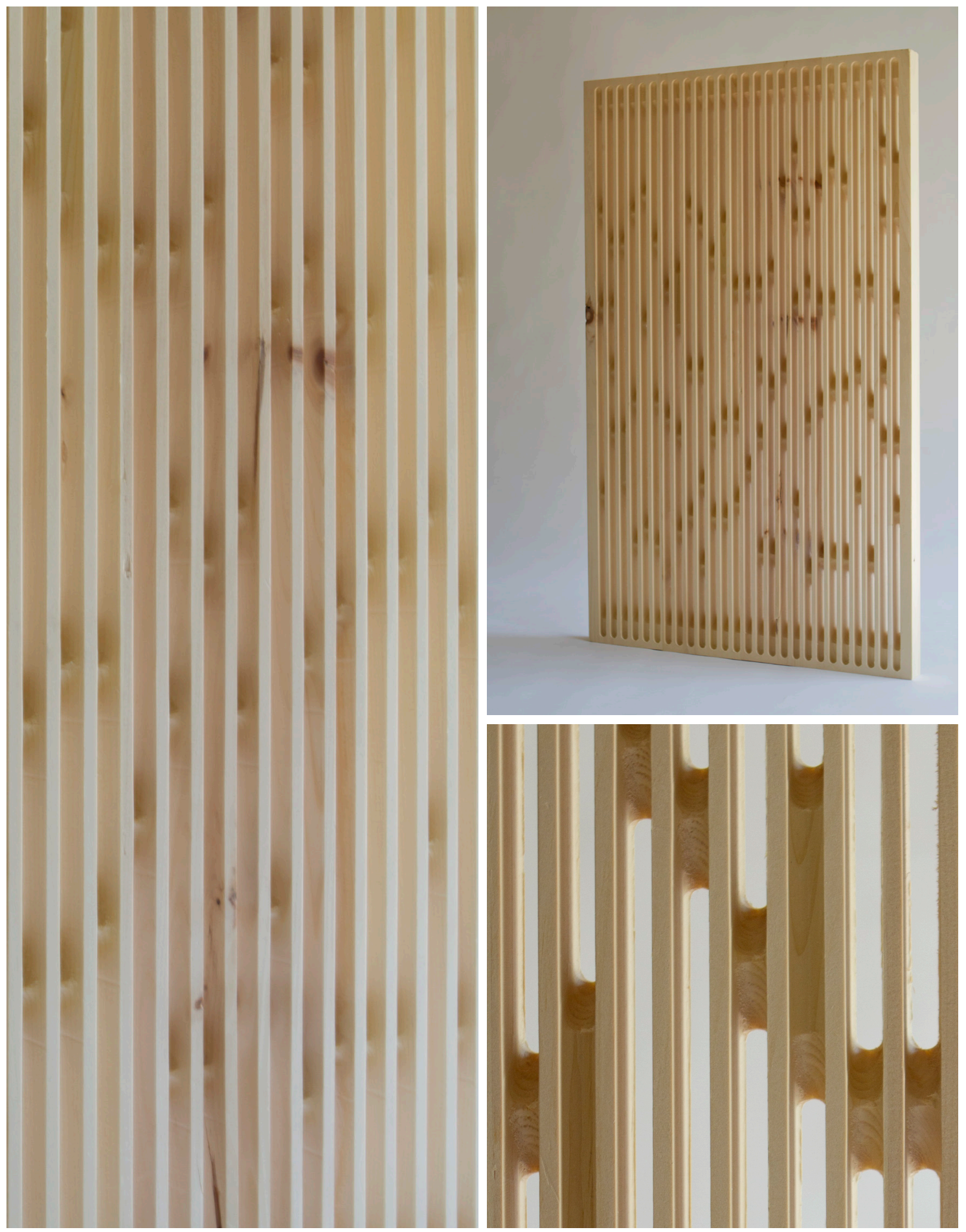
which Mostafavi and Leatherbarrow characterize as weathering is an interesting concept in relation to atmosphere. An environment's finish on a building is unique to its geographical location and climatic context and thus the character of decay on a building is distinctive to its site. In changing the expression of the architecture, weathering roots the building to its location and establishes the architecture as part of the place it is in. In this context, the effect weathering has on the perception of atmosphere is tied to creating a sense of the building belonging to its context. Utilizing this knowledge architects can begin to anticipate, embrace, and design into their projects the decay and weathering of material in order to accentuate a buildings belonging to its context and accentuate the temporality of architecture.

In exploring the concept of Atmosphere of Objects, the design exercise of this subchapter focuses on the exterior cladding and the expression of the dwelling's design. Examining the relationship between matter and energy through the development of the dwelling's cladding the exploratory design first moves past an Atmosphere of Objects association with weathering and decay. Both concepts are considered in the exploration, but as they are extremely slow processes which are directly related to the site's climatic condition their material effects cannot be directly replicated. Thus both concepts are taken into consideration during the design but their effect on the facade becomes a speculative estimate.

Instead of focusing on the hypothetical effect weathering would have on the design of the cladding system, this exploration into Atmosphere of Objects considers the direct change of a materials characteristics with an immediate input of energy. This experiment took form in relation to the Japanese Shou Sugi Ban process of sealing wood for external purposes. Shou Sugi Ban is a process by which Cedar wood is burnt to create a thin layer of carbon that naturally seals the wood and improves its resistance to water, rot, insects, as well as provides increased fire resistance. Exploring this technique, the face of a block of Eastern White Cedar wood is set on fire and charred beyond its surface layer to produce the benefits of the wood noted above [Figures 49-50]. In addition to these beneficial properties of this process, the charred portion of the wood embodies the intensive energy that has gone into its production Facade and Materiality Study No. I to change the physical characteristics of the wood. The charred wood expressing this character indicates its own frailty and develops a poetic narrative of the material's existence.

The end result of the charred wood is a blistering surface with aromatic intensity. Its initial layer becomes flaky with any touch or movement of air causing the detachment of small charred chips to come off while at the same time keeping

Figure No. 50

Facade and Materiality Study No. I Charred Surface 
its integrity. Considered as a cladding system one's touch or natural forces such as rain on its surface will dramatically change the character of the charred wood. To a certain extent the charred surface becomes even more susceptible to the character of weathering but without losing its functional properties. This effect allows the imprint of time and place to be stamped upon the character of the dwelling's facade encouraging the perception of atmosphere.
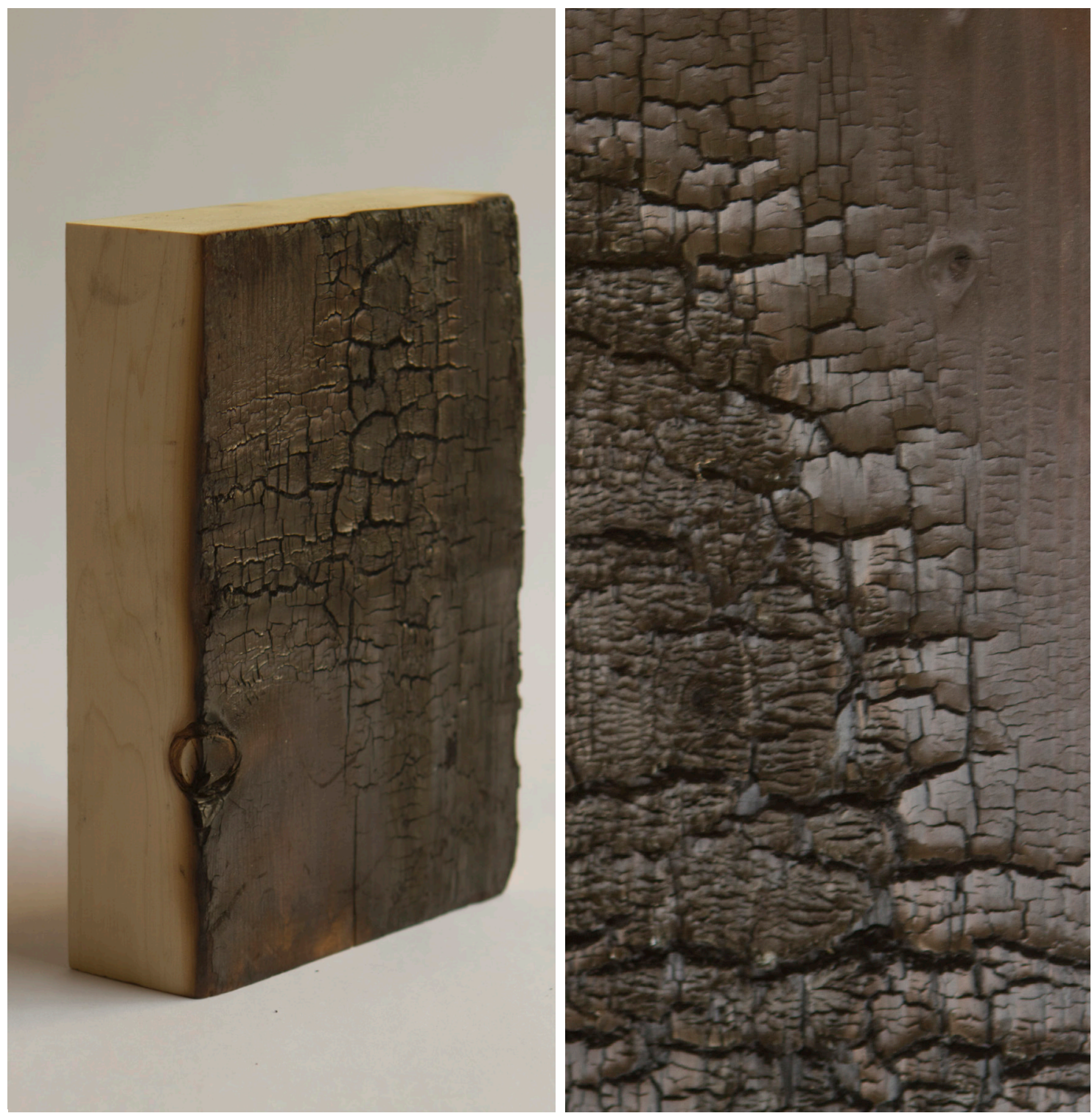



\section{7}

\section{Designing an Architecture of Atmosphere}

Drawing upon the study of atmosphere in relation to architecture thus far, the design of the dwelling at 1054 Little Morgan Bay Road begins to focus on synthesizing atmospheric considerations previously discussed in order to develop its final built form. Integrating the architectural expression and sensibility that was developed in the exploratory studies relating to the typologies of atmosphere, the design of the dwelling begins to move past a consideration of atmosphere that is abstracted from an overall built form. Now, the project progresses by creating the dwelling's atmosphere and architecture by concentrating on traditional architectonic consideration of the building such as architectural space, form, and its immediate surroundings.

The dwelling is sited within a rich context. How the dwelling becomes part of this context and the landscape is essential to rooting the building in its geography and place. As Juhani Pallasmaa so eloquently puts:

"Architecture is essentially an extension of nature into the manmade realm, providing the ground for perception and the horizon for experiencing and understanding the world. It is not an isolated and self-sufficient artifact; it directs our attention and existential experience to wider horizons". ${ }^{61}$

Bearing in mind Pallasmaa's statement, the initial focus of the dwellings design takes form in considering the expression of the building's structure which is rooted in the landscape. Driven by the practical consideration of constructing on the granite of the 
Canadian Shield, the approach to the building's structure is to touch lightly upon the ground. In the site's context this approach meant creating a series of wood columns secured by concrete piles that sit within a natural ridge of the sloped topography [Figures 51]. In Pallasmaa's sentiment, as an extension of nature, the vertical columns are identifiable with the character of the natural setting's rising trees that dot the site and the surrounding context. Practically, the columns form a structural grid in the landscape with bays measuring ten feet in length and eleven feet in depth where the development of atmospheric spatial conditions can begin to form.

Turning to the character of each column's connection to the structural beams that form floor levels and to the concrete footings, an approach to detailing structural connections begins to be considered [Figure 52]. The wood columns are slightly raised above the concrete piles with a metal connection separating the two distinct materials. This separation highlights each element's specific structural capacity and inherent material charter. Floor beams crossing the depth of both structural bays secure all three columns together and on each end slip by the column face extending the movement of the ground plane out beyond the structural grid into the natural setting. Routed notches in the columns locate the position of the $2 \times 8$ inch lumber beams on either side of the structural posts. The beams which sit in the column's notch are expressed as a singular unit not an attachment of parts. Two bolts through the assembly secure the beams to the column. On top of the beams the floor joists span between the length of one ten foot bay and are finished either with exterior decking or interior wood floor. The floor assembly is sheathed underneath the joists so that the expression of the structural beams from the sloped site below continue through any built mass which sits on top of it. The consideration of assembly and detail in the dwelling's structure poetically expresses the natural forces acting upon the elements of the building and the dwelling's sensibility in forming a cohesive and eloquent whole from its many parts. The ease and naturalness in which the structural elements come together creates a foundational essence that helps establish a union between built form and context.

In the design of the dwelling's space and enclosure, the sensation of atmosphere that is derived from the perception of an object being of its environment became the driving force behind the built form. Considering this, the focus of the design turned to creating a building that would make the landscape intelligible, how one moves through the land, views, and understands it. Within the framework of the structural grid the building takes shape as a thin linear bar emphasizing the natural ridge on which it sits. Approaching the building from the wooden forest 

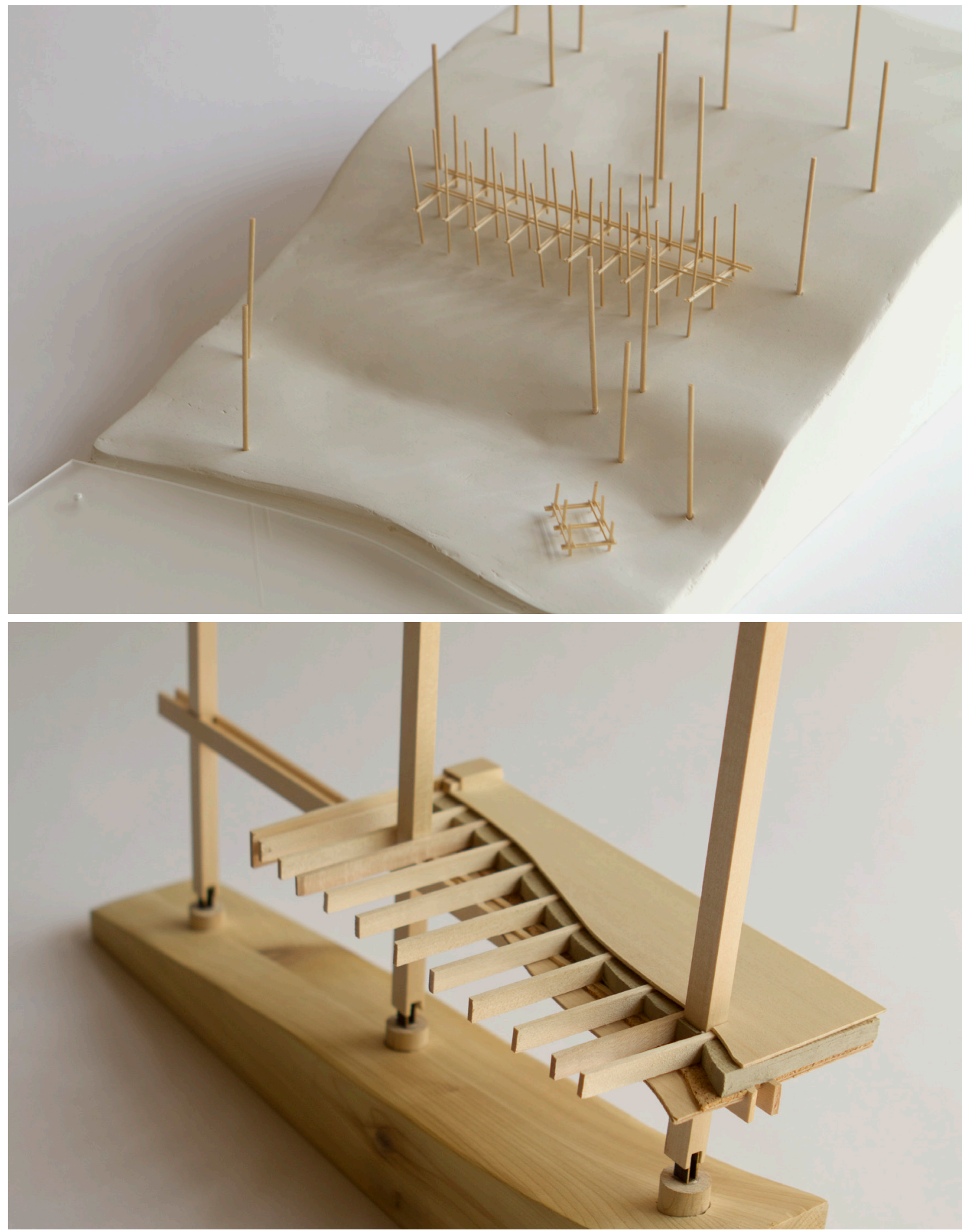
at the rear of the site, the structure of the dwelling is concealed within its walls. Articulated from this viewpoint are the lines of the facade and roof which express the horizontality of the landscape as perceived during one's decent down the slope. In contrast, approaching the front of the building from the lake below, the dwelling's wood structure expresses the visual sensation of verticality created by the steep upward slope and climbing trees that form the natural setting. Slicing through the dwelling's mass is an open path, continuing the uninterrupted progression of nature and human movement up and down the site [Figures 53-55]. To move through the dwelling is also to simultaneously move through the landscape.

The building's form is characterized by the dwelling's cladding. Two-inch strips of vertical charred cedar wood wrap around the building's surfaces visible from the lake front. At the back of the dwelling the same charred wood is used but instead of being placed vertically it is fastened horizontally. Due to the difference between the natural and charred wood, the mass of the dwelling becomes distinct from the building's structure, entry path, and roof. This material contrast emphasizes the distinction of the space for living from the supporting functional elements. As previously mentioned the character of the charred cladding brings with it an ephemeral quality. The expression of the building mass will change with touch, weather, and seasonal cycles. In doing so, the impression of time and place will be imprinted upon the character of the building's facade adding to the perceptible atmosphere of the dwelling. This development of identity will undoubtedly be reflected in the occupation of the interior space clad by the charred wood.

Moving into the dwelling begins before one enters the interior space of the building. Crossing a bridge structure spanning the gap between the sloped topography and dwelling, the steps down to the floor level bring one through a transitional exterior / interior space. Arriving at the entrance platform one may continue through the building and down the slope to the sauna and lake front beyond [Figures 62-63]. At this entry platform the tectonic expression of the building's structure is evident [Figures 56-58] and understood before moving to the dwelling's sheltered entry [Figures 65-66]. In this extended procession through the transitional interior / exterior space to the dwelling and past to the lake front an anticipation is built. This anticipation helps to bring forward a conscious moment where the materialization of the dwelling and landscape are expected but not yet perceived.

In a manner similar to the entrance condition, the main door of the dwelling [Figures 59-61] blurs the threshold between the building's interior and exterior. As one places their hand within the door and around the woven leather handle, one has 
confronted a liminal state. For a brief moment one is neither inside or outside the dwelling but in both conditions at the same time. This encounter with the primary entrance and door allows one to consider their own presence and temporal existence as their body and mind confront these spatial conditions.

The interior of the dwelling in section is bifurcated into two spatial conditions. The back of the dwelling is characterized by a low ceiling where intimate program areas, such as bedrooms, and the circulation of the building is located [Figures 68-69]. Clearstory windows above the low ceiling spaces draw one's focus and movement towards the social spaces at the front of the dwelling and out to the lake beyond, placing emphasis on the natural context that the dwelling becomes a part of. Glazing on the south facade of the building, where program areas such as the kitchen, living area, and exterior deck are located, aim to capture the heat energy of the sun in order to create a warm spatial boundary within the dwelling. This warm zone is associated with communal program and would be desirable during the colder months of the year. The temperature of this condition can be controlled through the opening of the clearstory windows and glazing on the north side of the dwelling to promote cross ventilation and the exchange of heat. The spatial gradient that heat creates within the dwelling allows one to consider their body in relation to where they are within the structure and thus makes one conscious of their being in a particular space.

Enclosed within the volume of the dwelling is an interior / exterior deck. This space is sheltered from the natural elements by the charred wood facade and the building's roof. Large operable openings visually expand the deck space to the exterior setting and allow the natural elements in [Figure 70]. Blurring the threshold between constructed and natural space, the enclosing of the deck area and the process of revealing the exterior becomes a conscious act, making one aware of oneself and the environment one is entering. The dwelling's bedrooms line the deck and are visually separated by wood screens. The screens provide a layer of privacy while highlighting the temporal moment through their interaction with light [Figures 71-73].

Moving from the main dwelling area to the studio occurs through an exterior walkway that aligns with the interior circulation. This walkway spans the sheltered cover of the dwelling's rear exit past the volume of the studio. The walkway, in extending beyond the studio's volume, emphasizes the experience of movement between each enclosure and the connection of the building to the landscape beyond [Figures 64, 67]. Within the studio space, the north wall is fully glazed but is screened 
by the continuation of the dwelling's facade on the outside of the column face, allowing exterior light to gently filter into the space, and adds a layer of perceived shelter to the work area.

For the dwelling on Little Morgan Bay Road the sensation of atmosphere emerges through its architecture and its perceived belonging to the natural surroundings. This combination engenders the dwelling with the ability to provoke a conscious sensation of the present temporal moment. This is achieved in a process of design that continuously considers the effect of built characteristics and forces of energy, and the resulting object of these two interactions with one's corporeal self and the surrounding environment. Considering this at all scales of design, from the detail, to the human proportion, and finally to the built form's relationship to the site, helps in developing a layered experience where all aspects of the architecture contribute to the sensation of atmosphere and are built upon each other. This layered development and consideration of atmospheric sensations engendered in the architecture of the dwelling at Little Morgan Bay help to evoke the rich immaterial quality of atmosphere. 


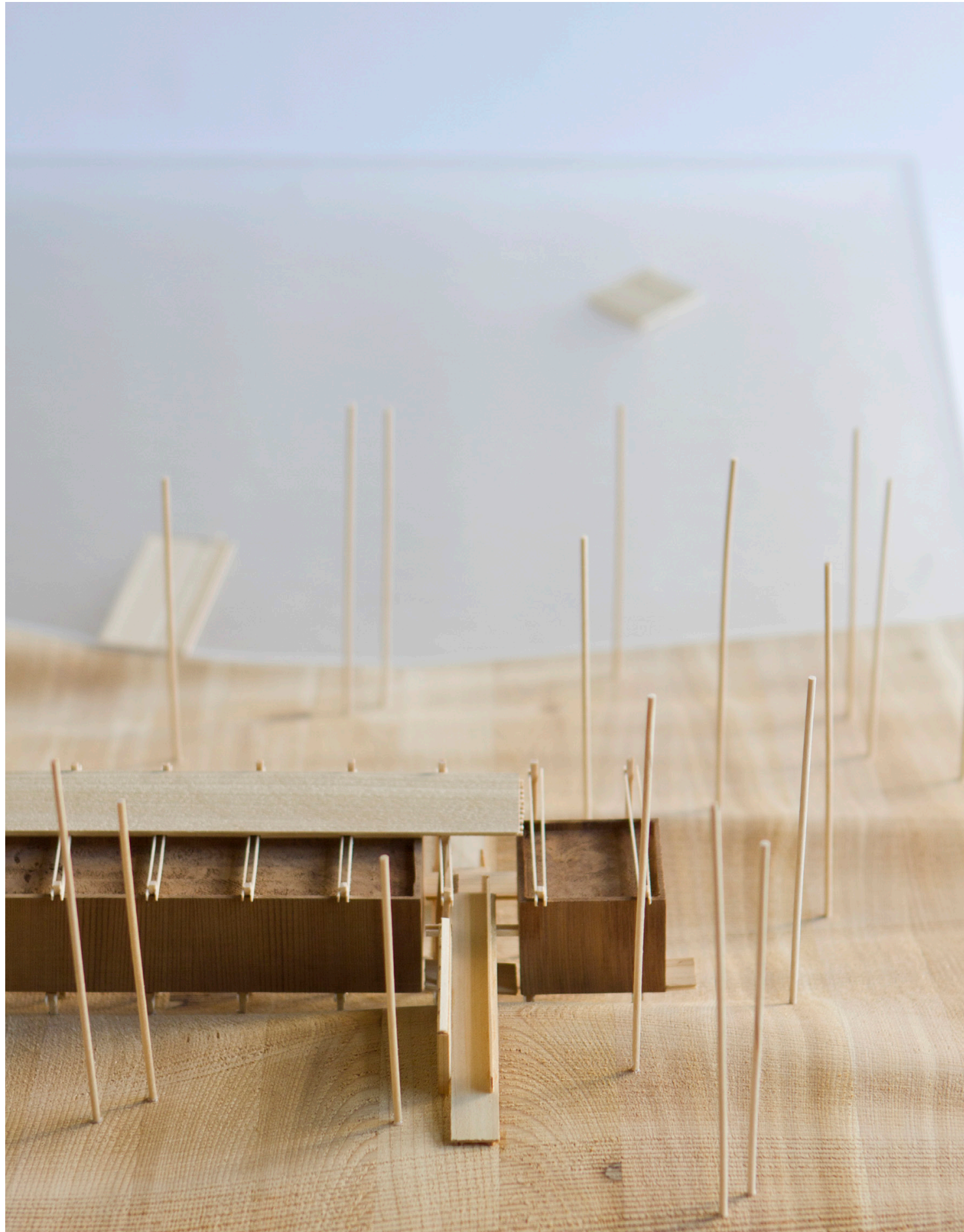




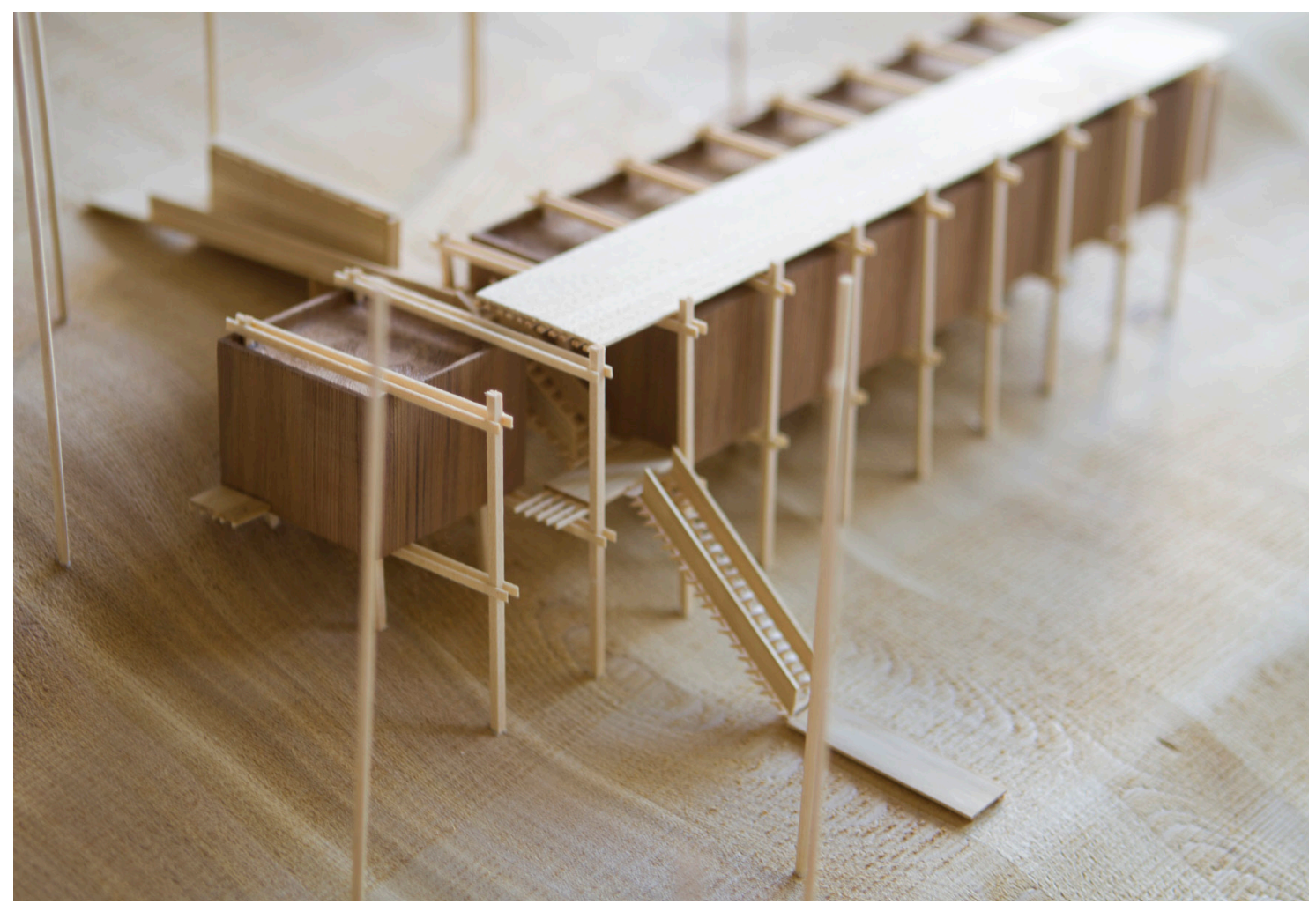

Figure No. 54 


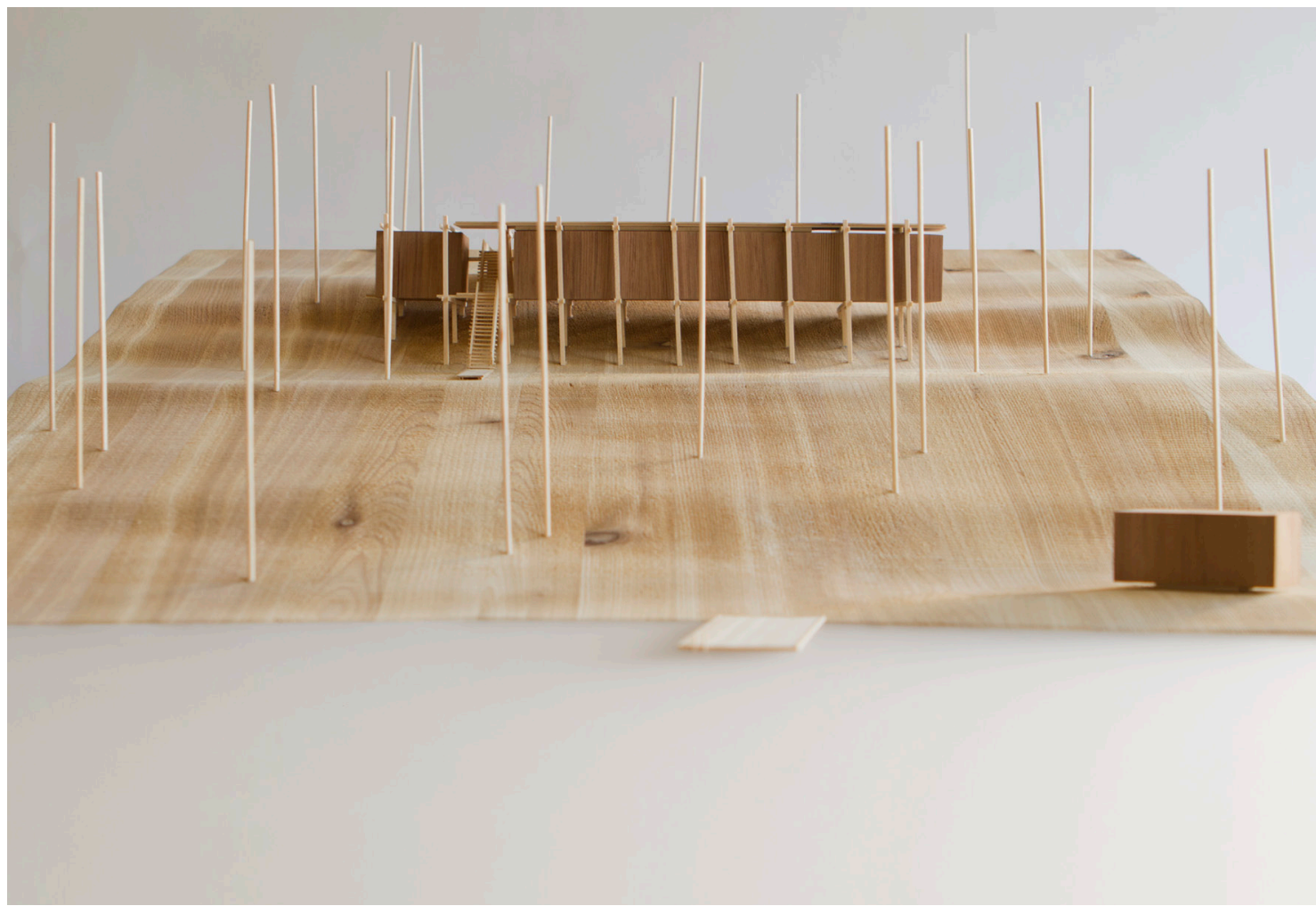

Figure No. 55

1:100 Site Massing

Lake View 

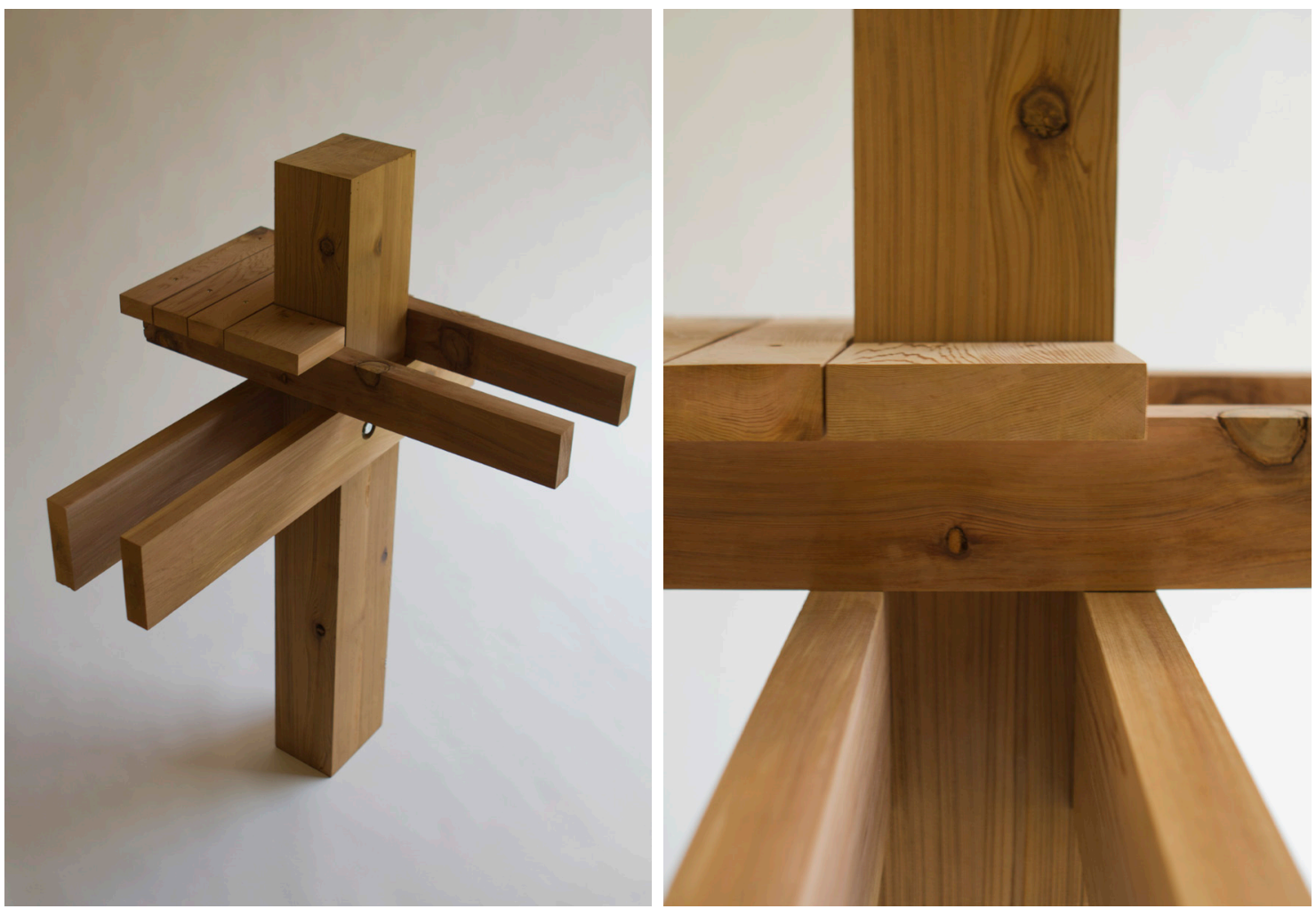

Figure No. 56

I:I Detail Model Column, Beam, and Decking Structural Assembly

Figure No. 57

I:I Detail Model

Decking and Beam Intersection 


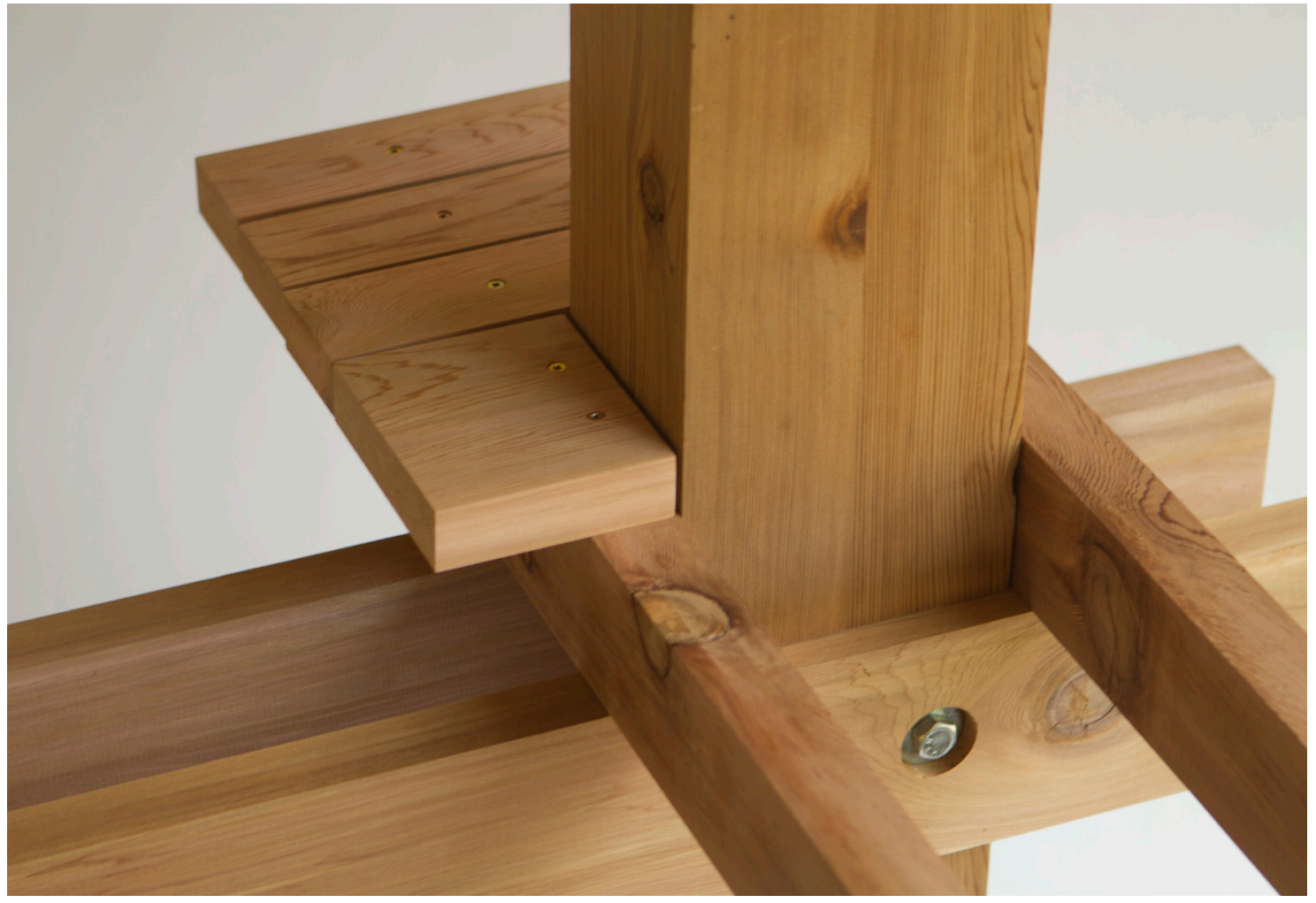

Figure No. 58

I:I Detail Model

Column and Beam

Connection 

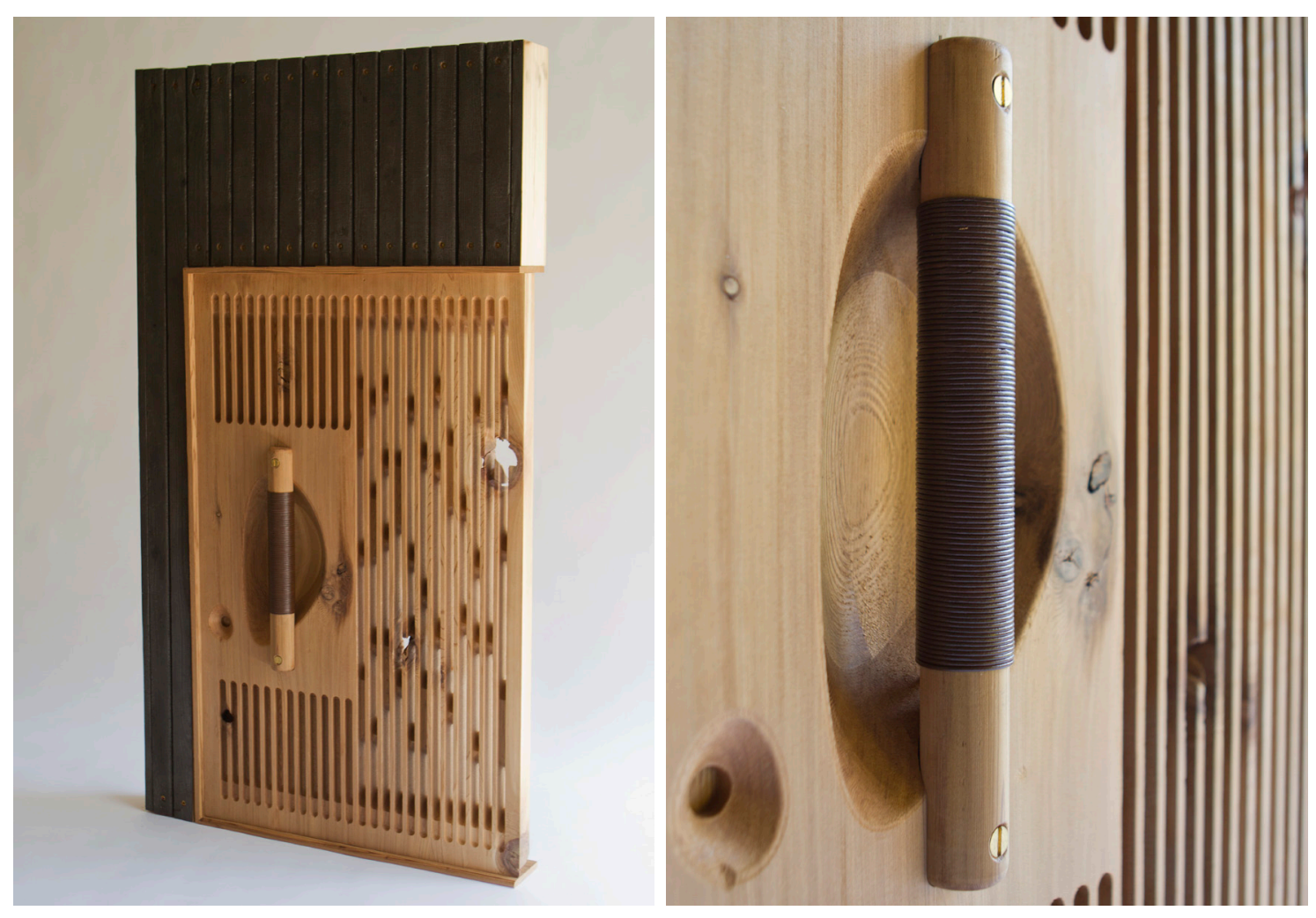

Figure No. 59

I:I Detail Model

Entrance Door and

Exterior Cladding

Figure No. 60

I:I Detail Model

Entrance Door and 


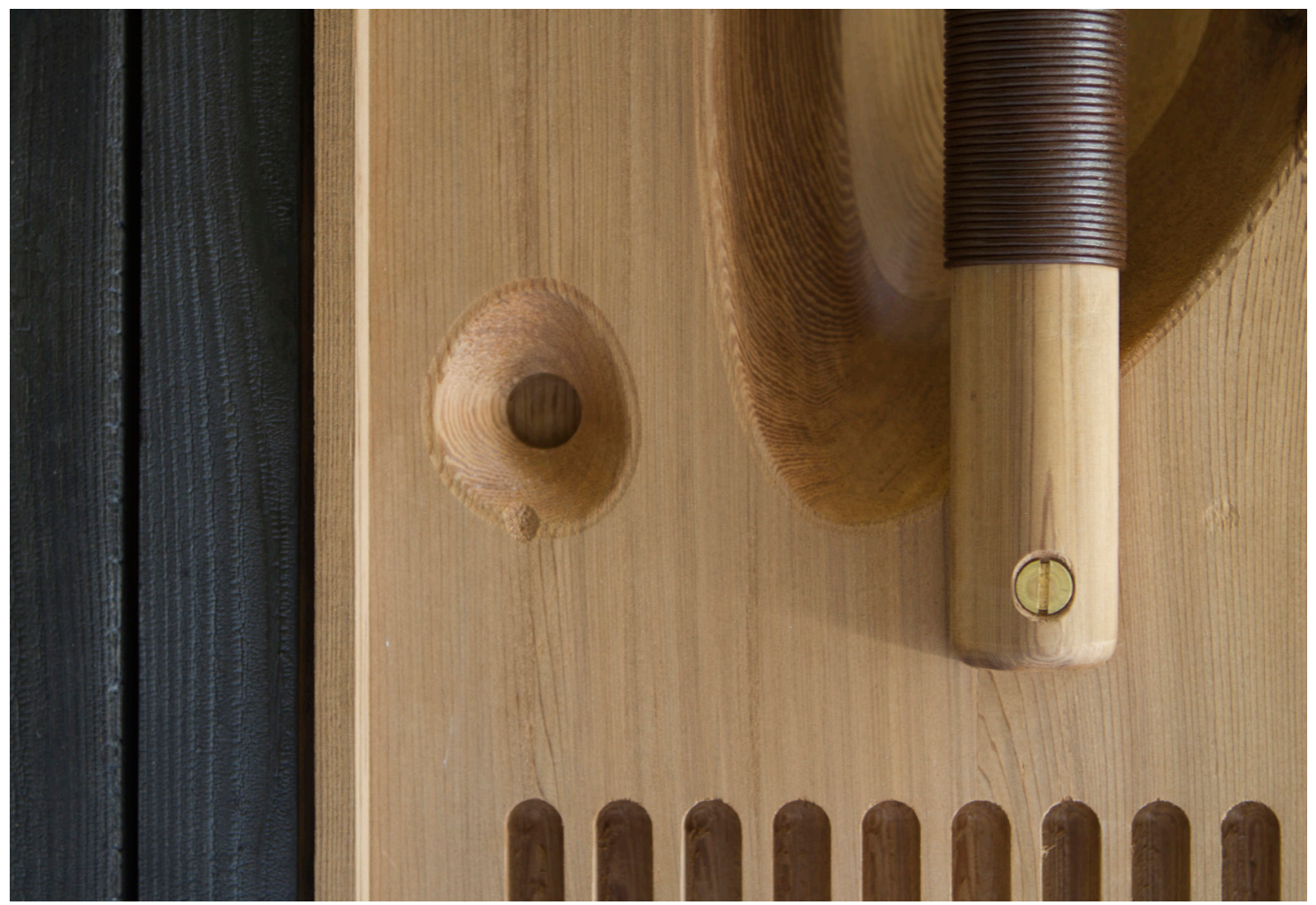

Figure No. 61

I:I Detail Model

Exterior Cladding and

Door Lock 


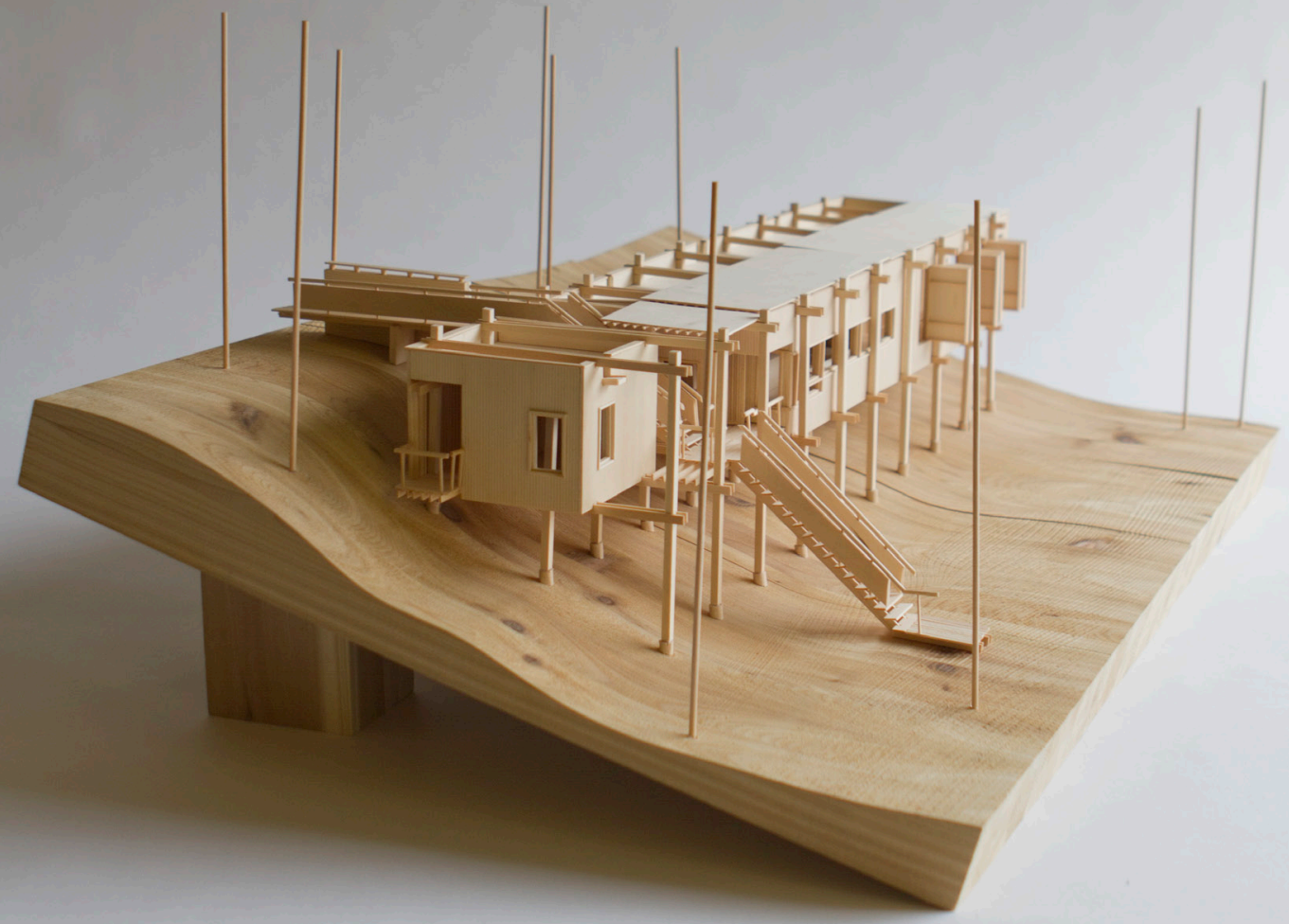




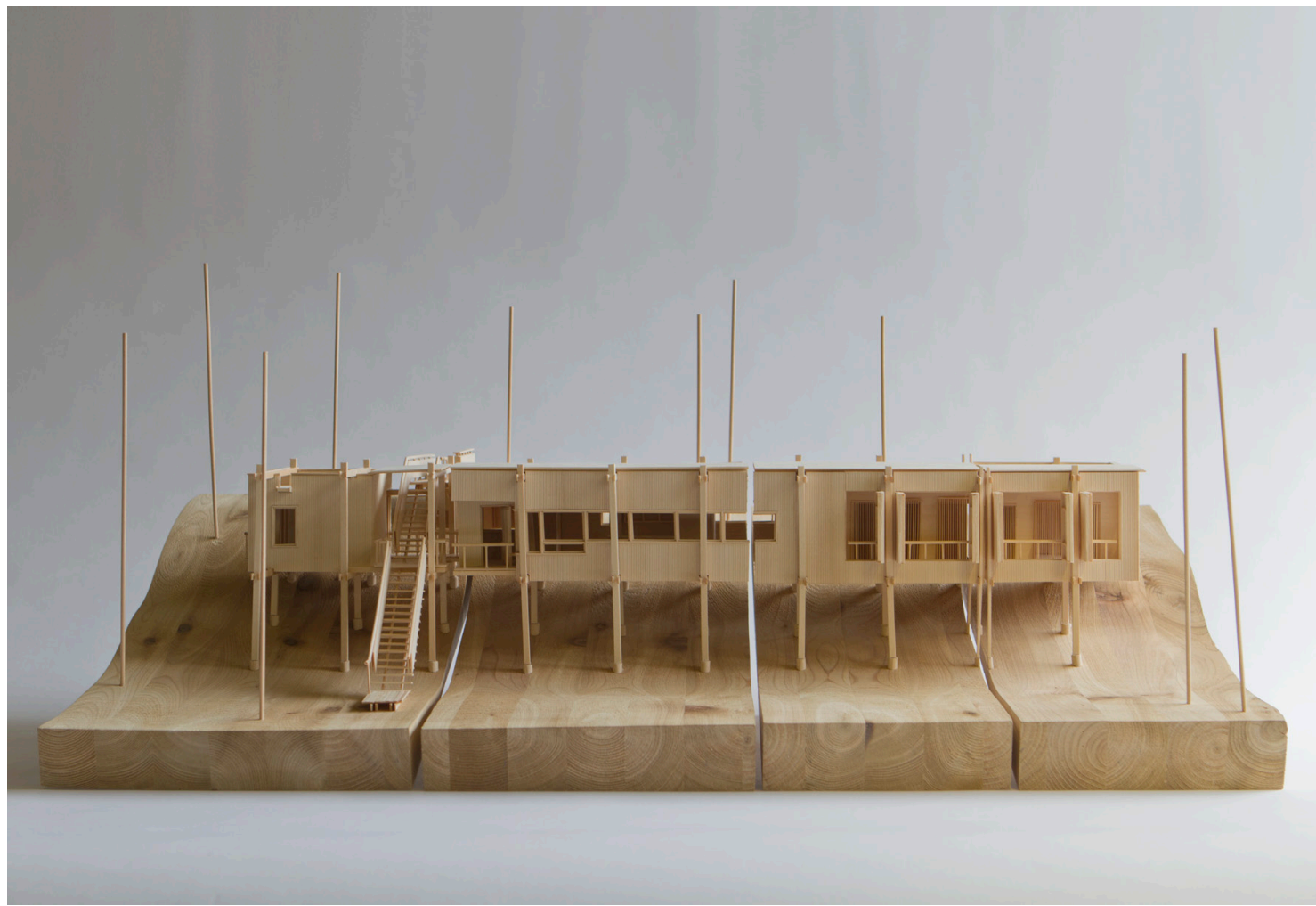

Figure No. 62

I:50 Sectional Model

Figure No. 63

I:50 Sectional Model

View North 

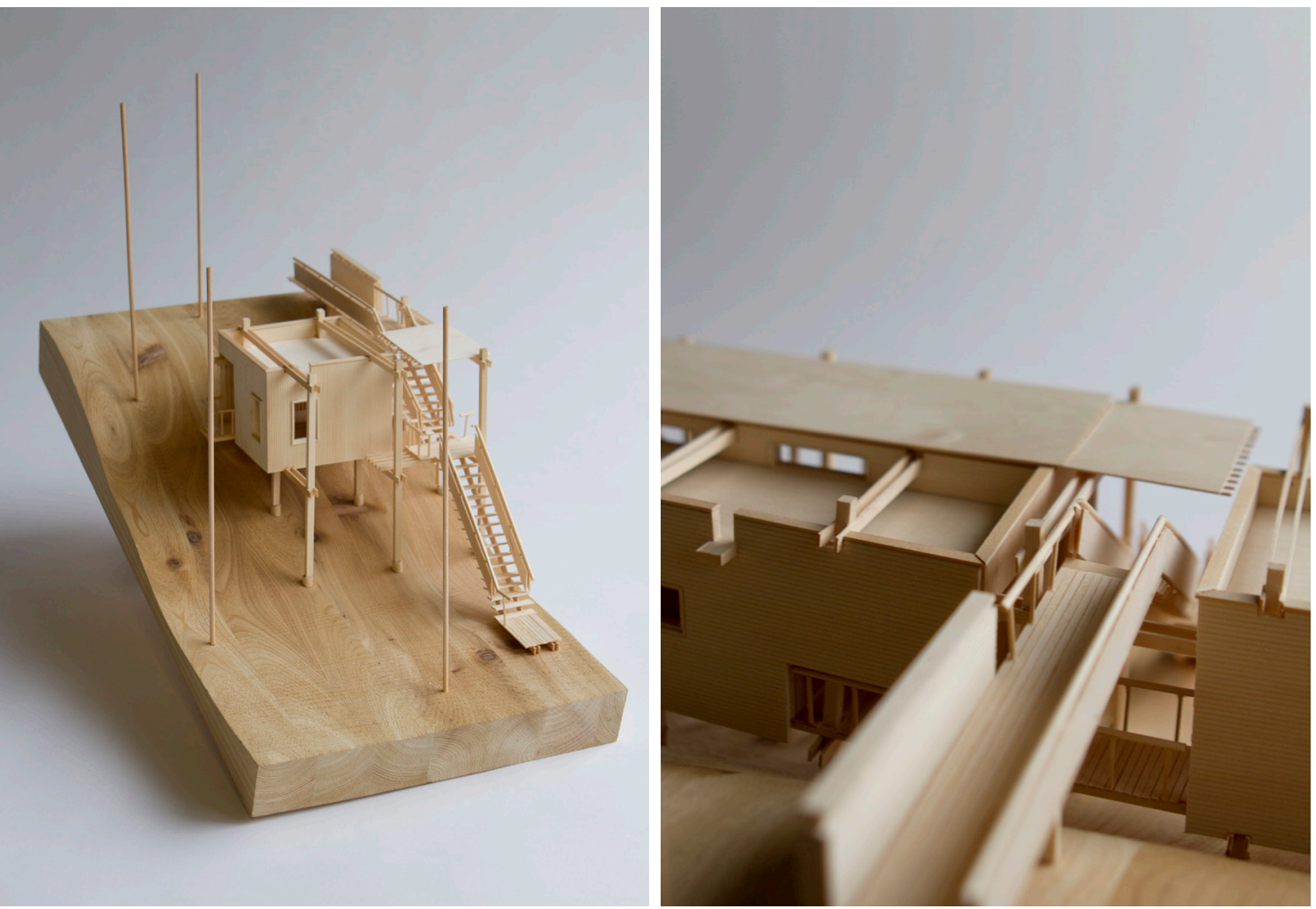

Figure No. 64

I:50 Sectional Model

Section I

Figure No. 65

I:50 Sectional Model

Section 1 


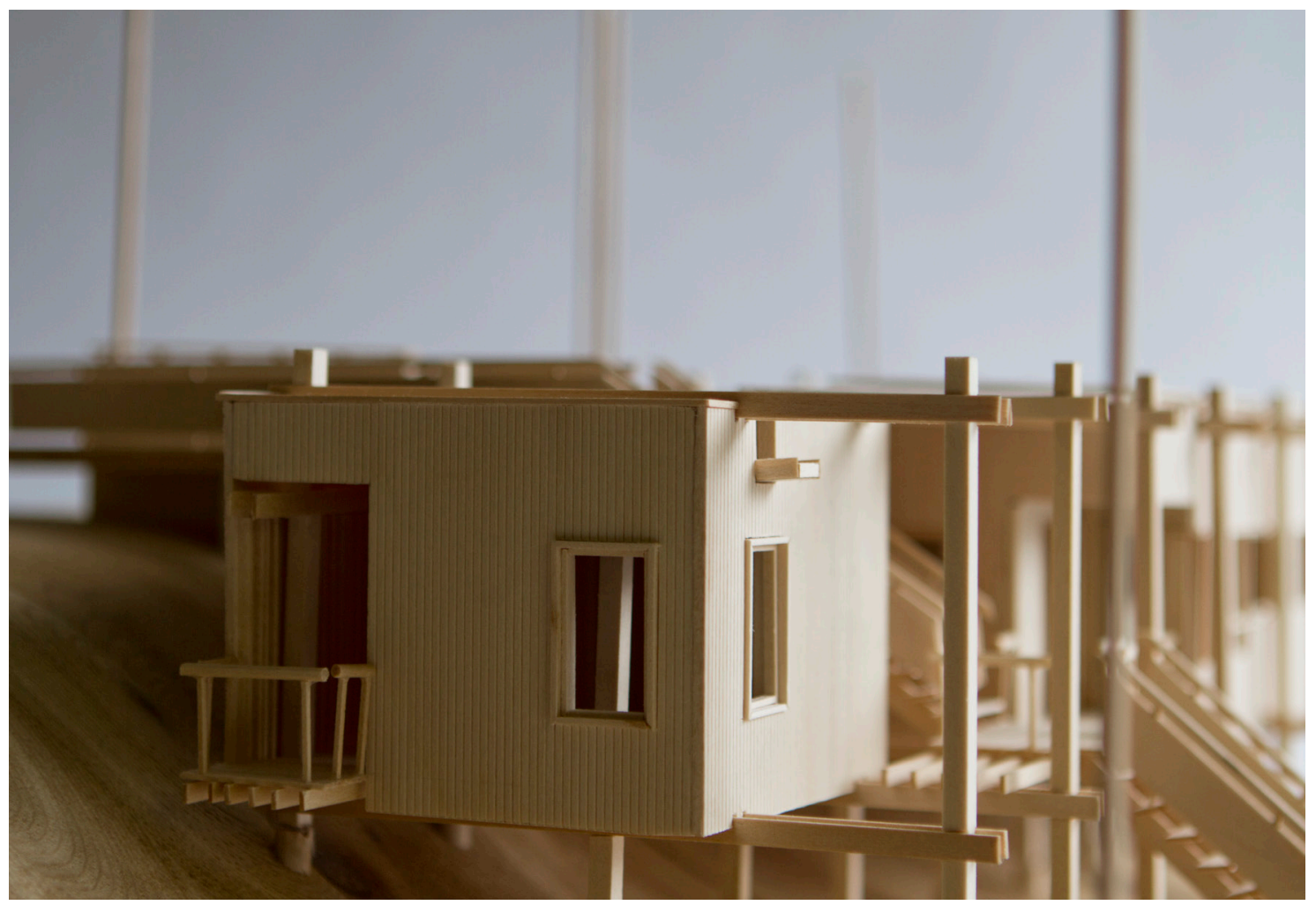

Figure No. 66

I:50 Sectional Model

Section I 

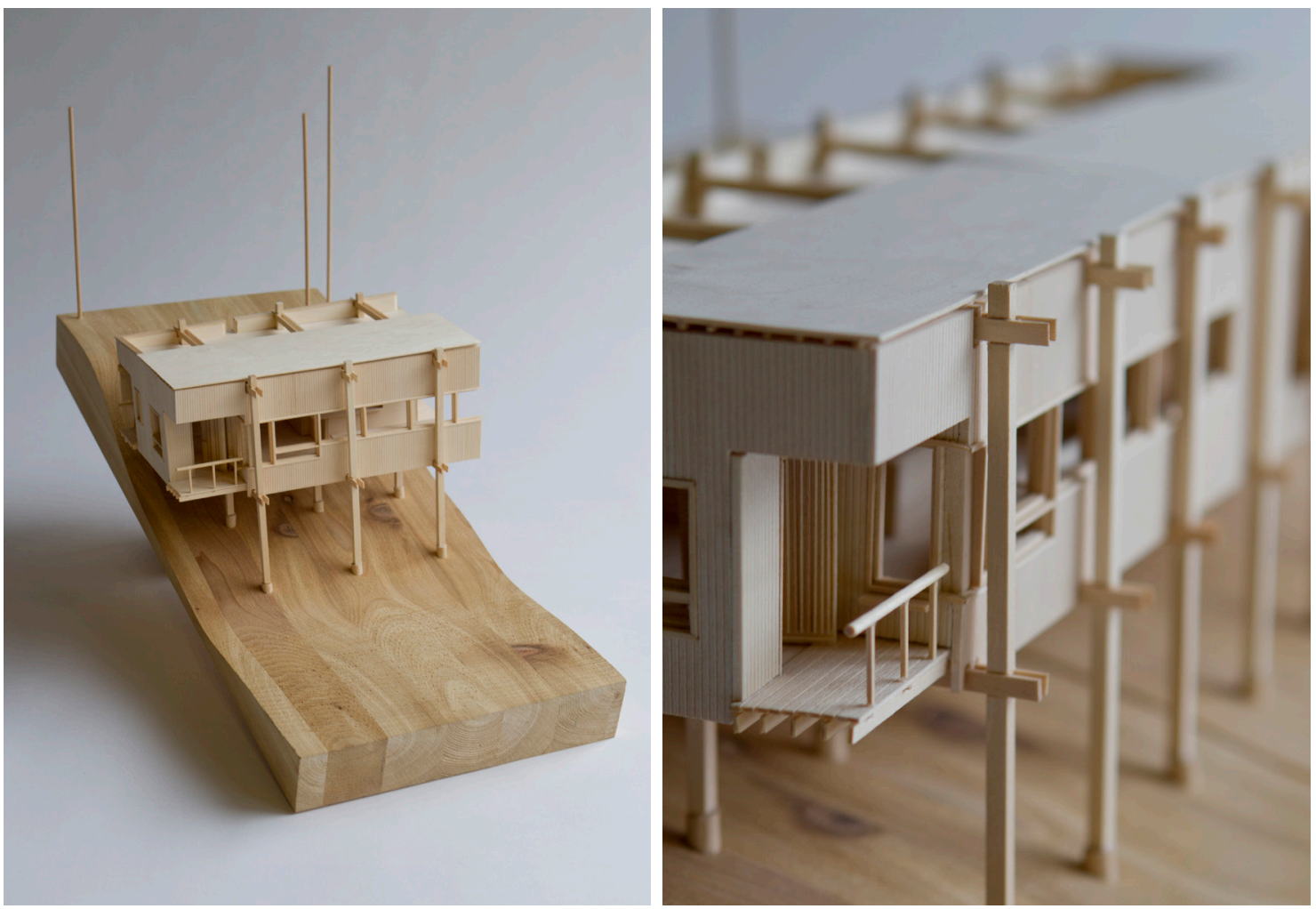

Figure No. 67

I:50 Sectional Model

Section 2

Figure No. 68

I:50 Sectional Model

Section 2 


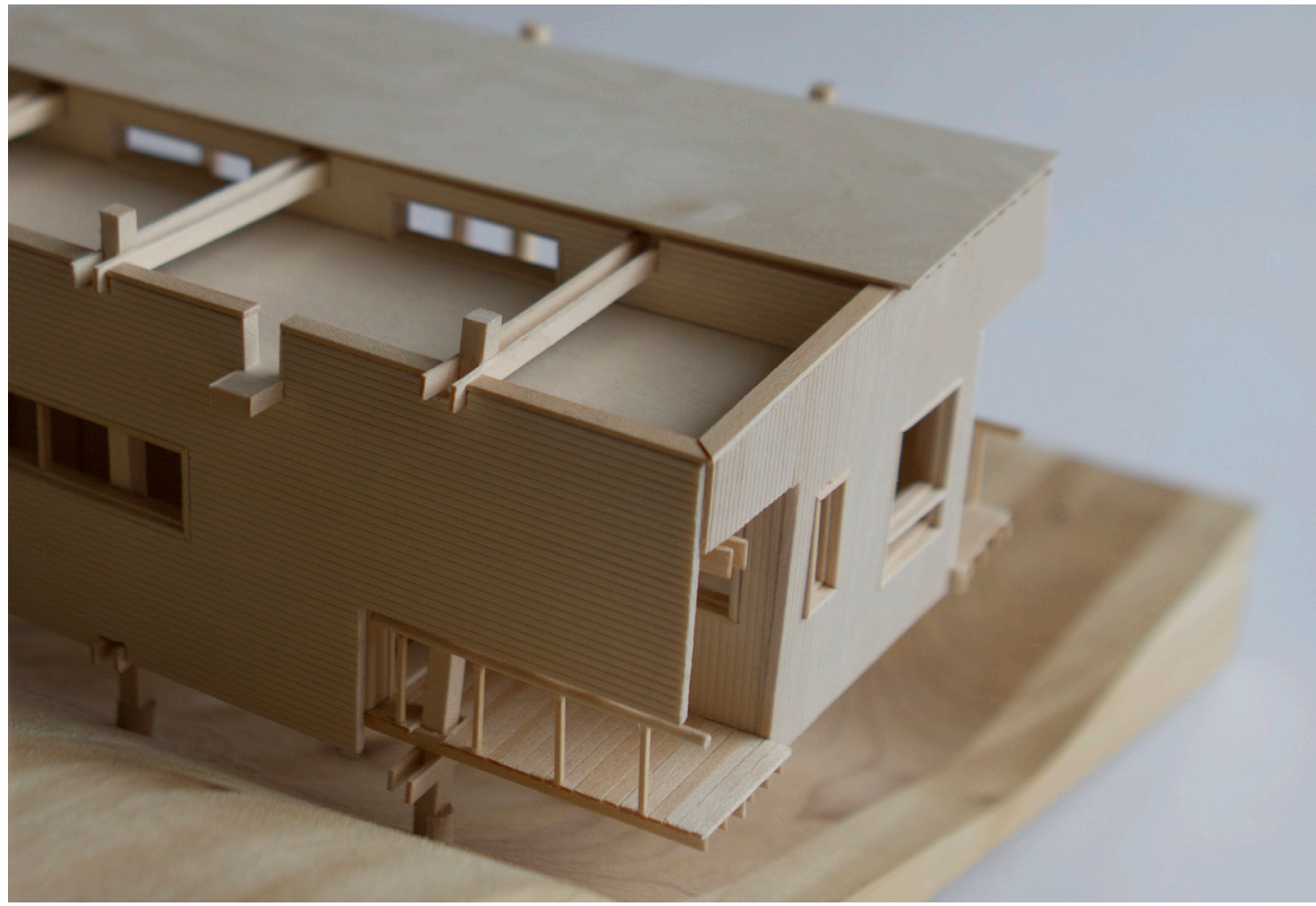

Figure No. 69

I:50 Sectional Model

Section 2

Exterior Bridge To Studio 

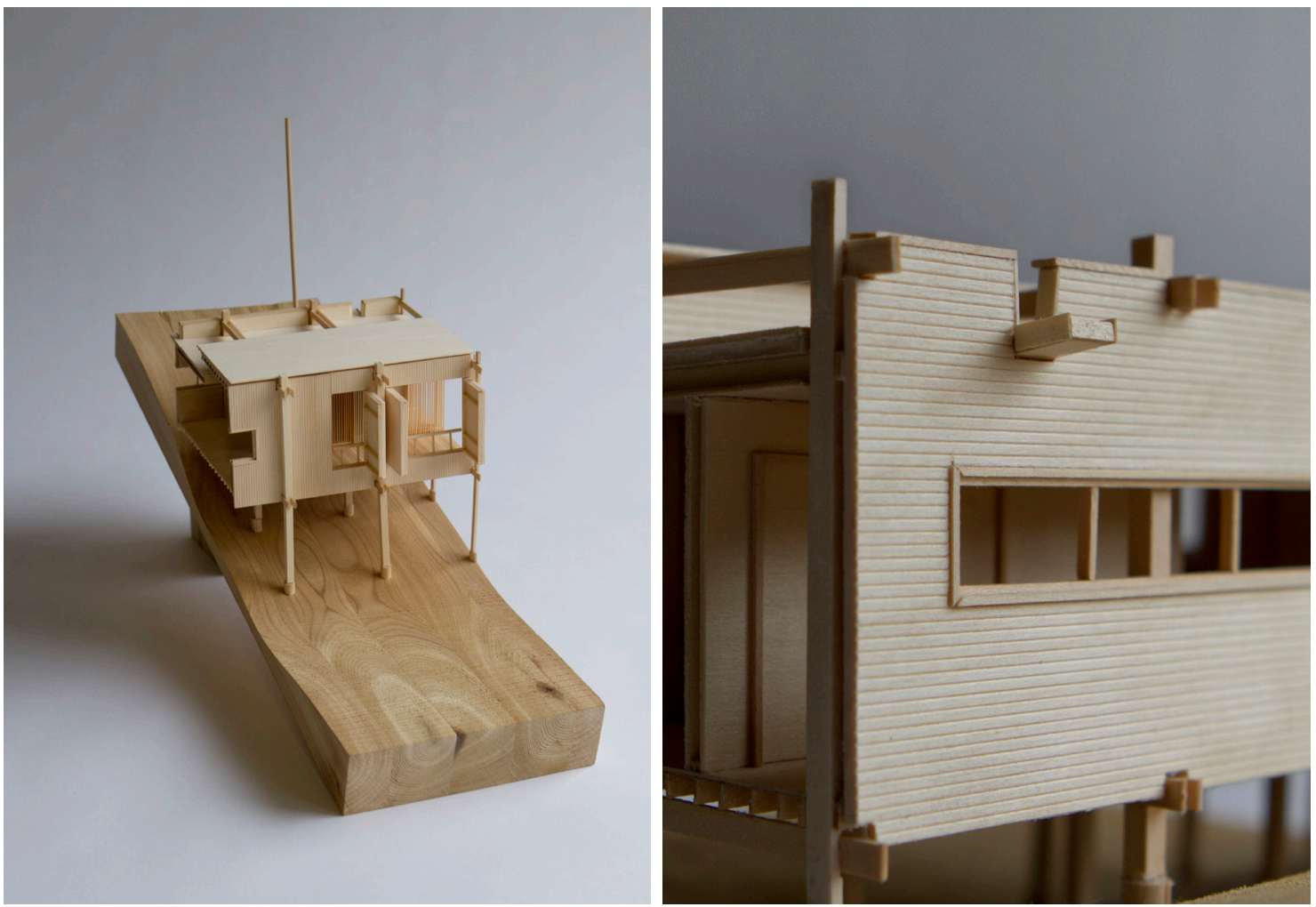

Figure No. 70

I:50 Sectional Model

Section 3

Figure No. 7I

I:50 Sectional Model

Section 3 


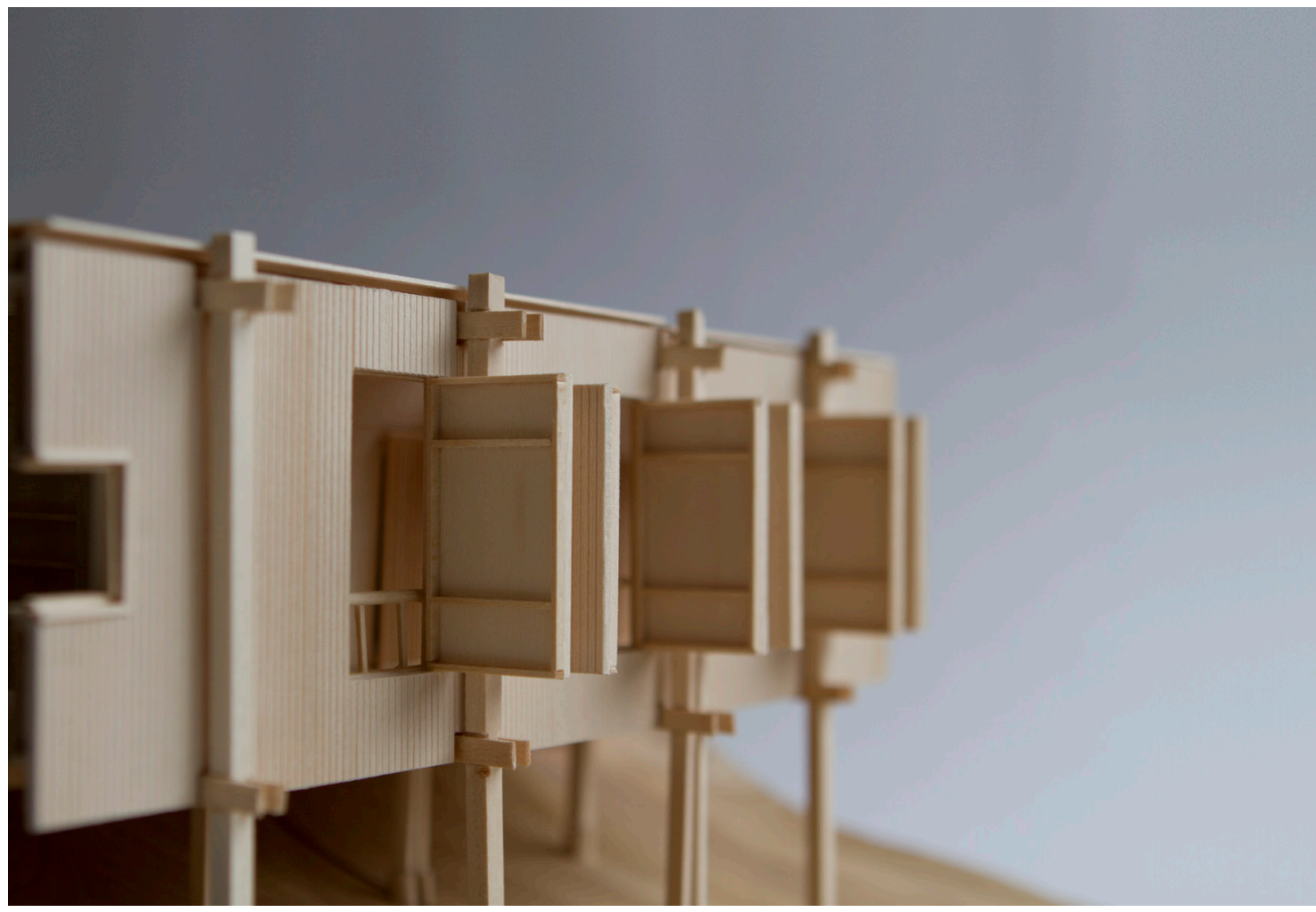

Figure No. 72

I:50 Sectional Model

Section 3

Operable Envelope 

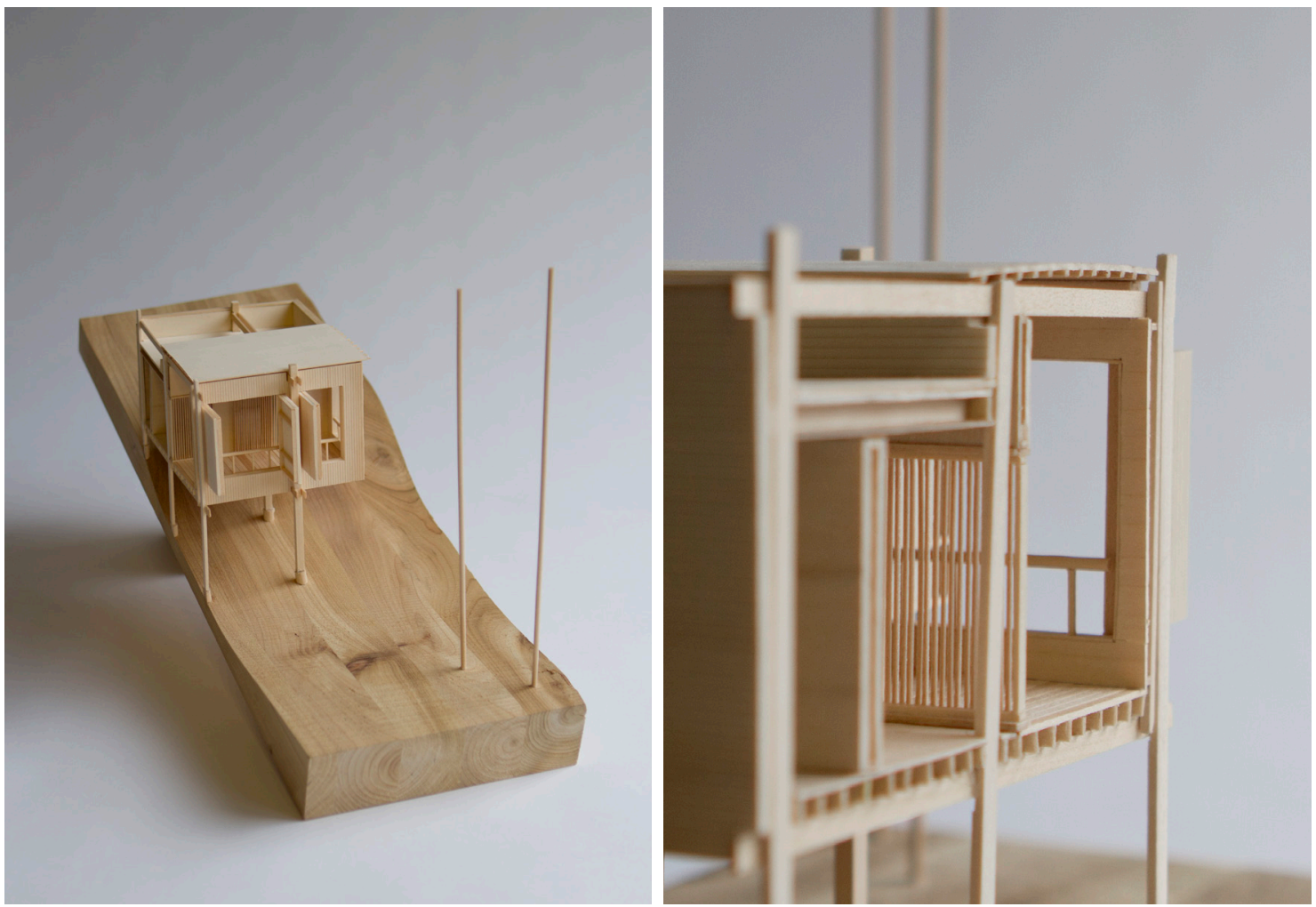

Figure No. 73

I:50 Sectional Model

Section 4

Figure No. 74

I:50 Sectional Model

Section 4 


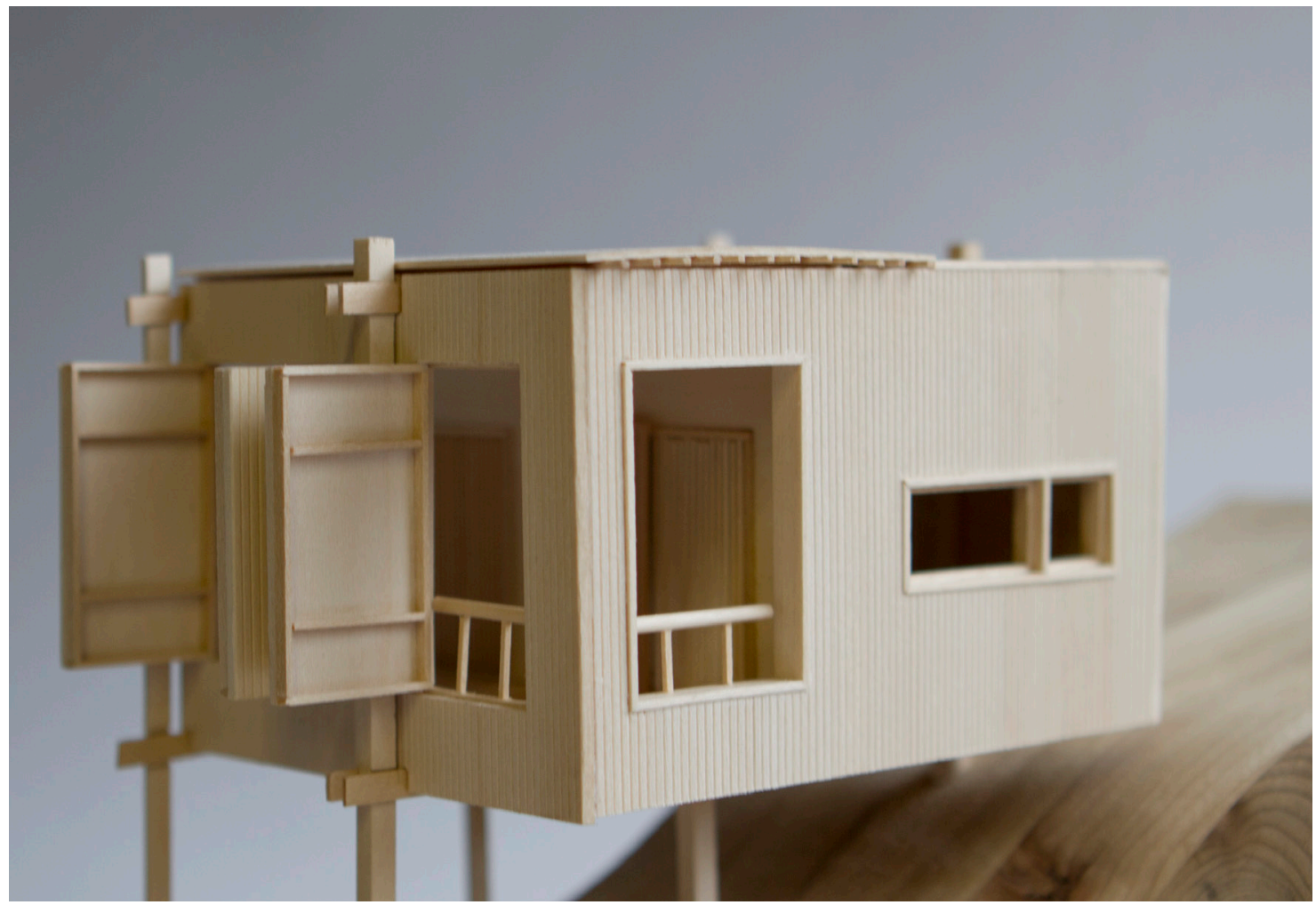

Figure No. 75

I:50 Sectional Model

Section 4

Exterior Deck 



\section{8}

\section{Atmosphere, Architecture, and Design}

The emergence of atmosphere in the dwelling is built upon two fundamental relationships between the building's sensorial design considerations and its interplay with the surrounding context. In aiming to capture the sensation of atmosphere, which is identified with a feeling of one being in, and the dwelling belonging to its environment, the design focused on accentuating experiences relating to one's recognition of the temporal world, the corporeal body, and the natural characteristic of the dwelling site. In doing so the dwelling's architecture becomes one of atmosphere. It is designed from a consideration to evoke a feeling of being within the world.

This approach to architecture changes the typical design process that many contemporary architects employ. To create an architecture of atmosphere the focus of the design process shifts from a consideration of architectural form to a concern for people in space, as the body and mind become the measure of atmospheric quality. This change in focus produces a method of designing architecture that first starts with an interest in the space of architecture and haptic qualities of a building that one engages with. In this mode, the form of architecture is a result of spatial development that connects the body to the building's context and roots itself in the character of place. Architectural form then is not a novel expression of design processes or ideologies, but rather it is how the building comes to explain itself and its context.

In the attempt to create an architecture of atmosphere, the design of a building is always in question as to whether or not is has achieved its atmospheric desire. An atmospheric architecture could be simply judged on its ability to permeate 
a sensation of atmosphere, but this perception is always a subjective experience. Rather, in considering how one judges the success of creating an architecture of atmosphere, the way in which philosopher Martin Heidegger, in his text "Poetically Man Dwells", approaches the evaluation of an authentic building can be appropriated. As Adam Sharr explains in his text on the philosopher:

"[Heidegger] categorised building and dwelling as good or bad according to whether or not it fitted his conception of poetry and poetic making; according to whether or not, in the terms of his philosophy, it was involved in creative attempts to make sense of the world by helping humans to measure the conditions of their existence." ${ }^{\prime 2}$

In a similar way to Heidegger's evaluation of authentic building, an architecture of atmosphere can be judged on whether it has in the consideration of design attempted to make one to feel present in the world and has endeavoured to develop a building that belongs to the world. This judgement is not exclusive to Heidegger since an architecture of atmosphere must always help one to measure the condition of their own existence. Atmosphere is an existential experience. As a result, an architecture of atmosphere must embody this experience while at the same time engendering it. 


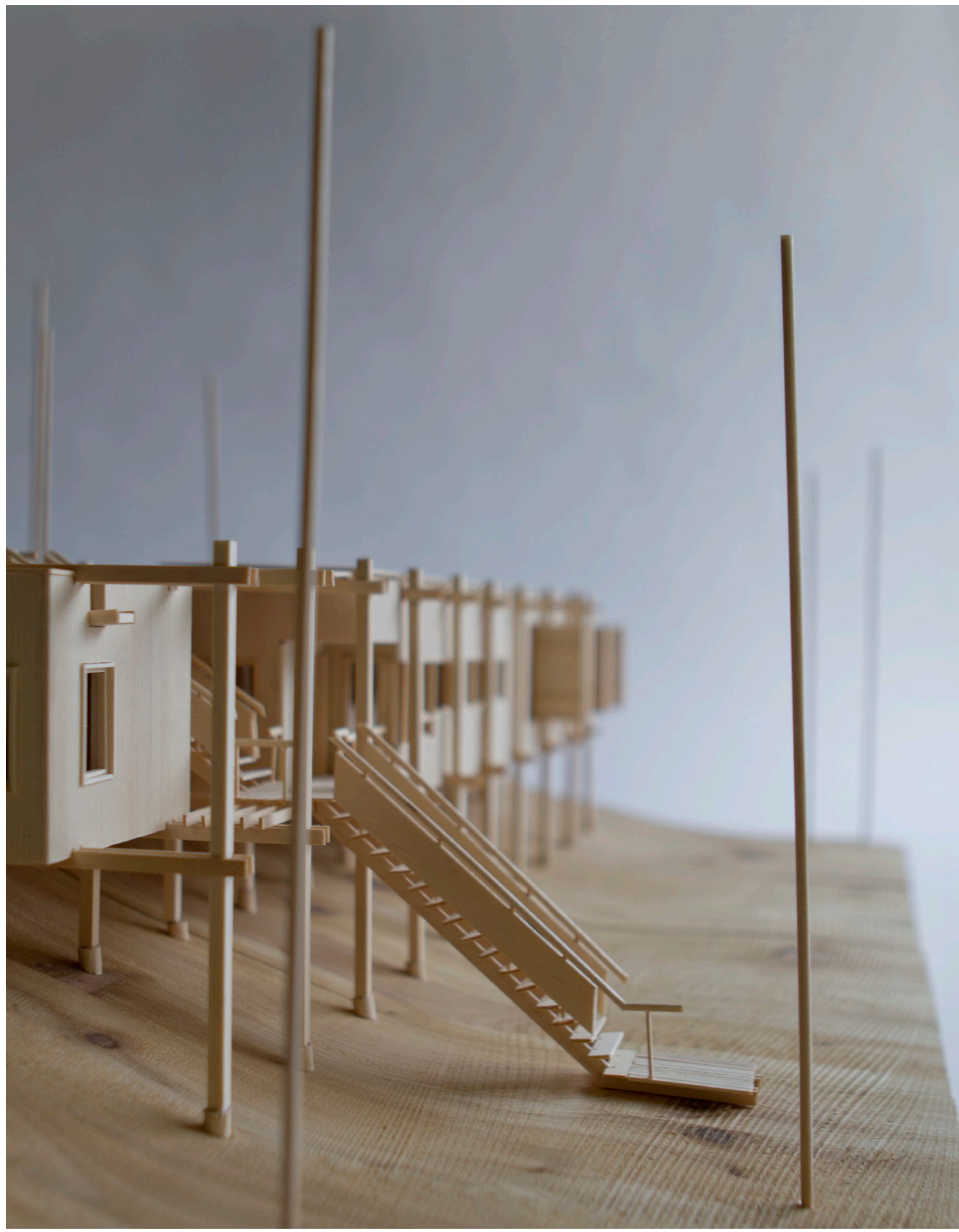





\section{Post-Script}

In concluding this thesis project, one last question emerged. While there are many facets of architectural design that could have been studied, and which are relevant to the state of architecture today, what does this focus on examining the atmosphere of architecture say about our current human state and the contemporary architectural condition? Although my own curiosity and desire to understand atmosphere drew me to the study of this phenomena, my interest in it also developed from an existential question of what is the purpose and meaning of architecture.

I believe that the work in this thesis echo the sentiments of Juhani Pallasmaa who states: "To me, most contemporary architecture is fairly empty of meaning...". ${ }^{63}$ There seems to be in the present condition of architectural design and thought a fascination and focus on the novel expression of architecture and the innovative processes by which it is designed and built. While I am not in opposition to innovation, technology, and progress, the focus on the spectacle that they bring to architecture creates meaningless buildings that do not help people to orientate themselves in the world. The struggle between progress and how we exist in the world is one that has been for many decades noted with each advancement we make. French theorist Guy Debord noted in 1967 that, "In societies where modern conditions of production prevail, life is presented as an immense accumulation of spectacles. Everything that was directly lived is now merely represented in the distance" ${ }^{64}$ This sentiment is no more true than in relation to the architecture of now. Our lived experience, the feeling of being which our contemporary architecture strips away is why an architecture of atmosphere is relevant today. This study of atmosphere suggests that we need something which roots us back to feeling the world and ourselves in it. Architecture can be that something. 



\section{Appendices}

The appendices of this thesis contain drawings and studies that did not find a place within the main body of this work's text. They did however, contribute greatly to the exploration and understanding of atmosphere. Orthographic and perspective drawings aided in clarifying design ideas and documented the spatial conditions of the architecture. Additionally, initial drawn studies were undertaken to explore the characteristics of atmosphere and were conducted before a program or site for this thesis were determined. These drawings focused purely on the architectonic properties relating to one's perception of atmosphere and were the initial processes which helped focus the work on designing an architecture of atmosphere. 

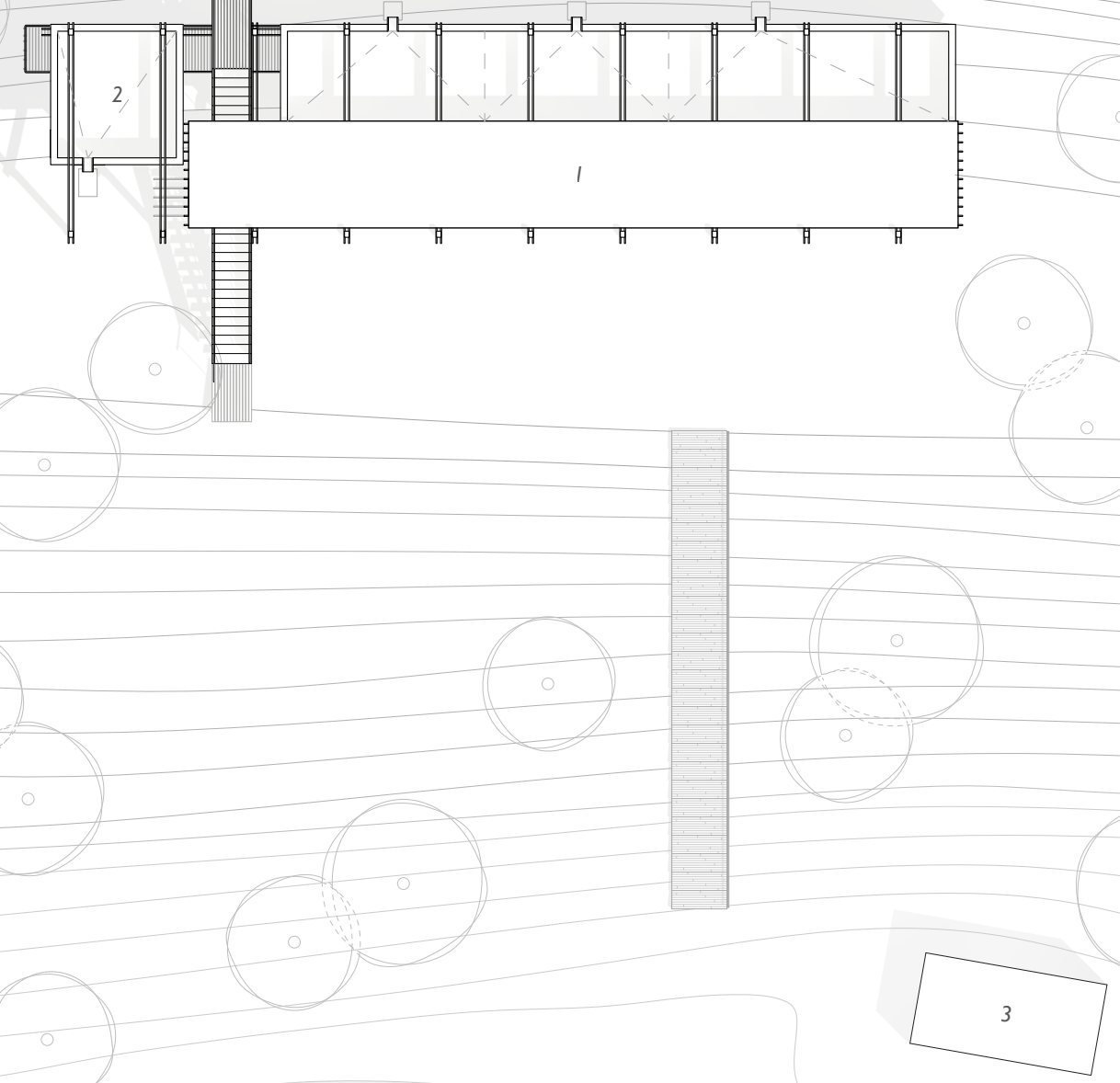


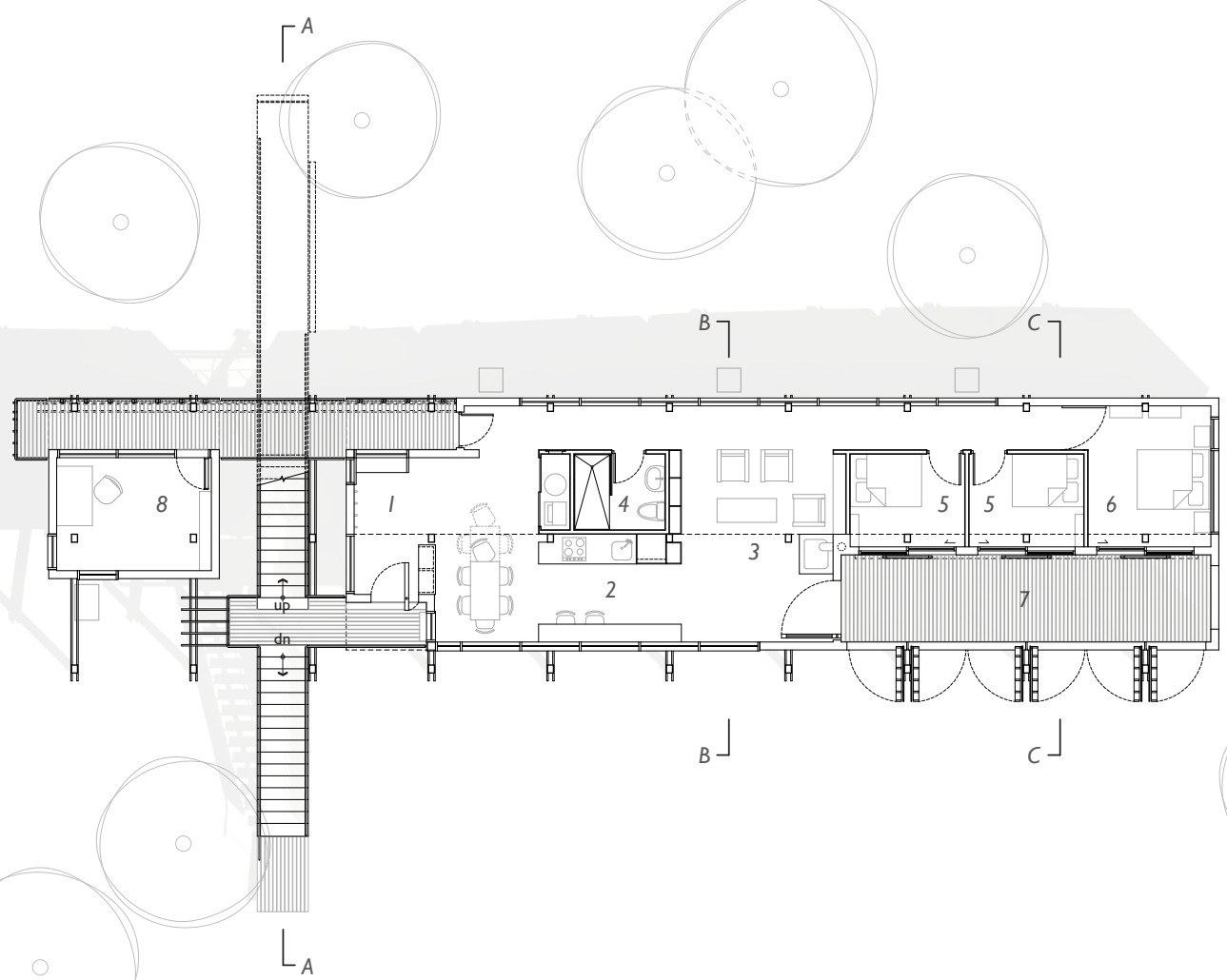

Entry - I Kitchen - 2 Living Area - 3 Bathroom - 4 Guest Rooms - 5 Main Bedroom - 6 Exterior Deck - 7

Studio - 8

Figure No. Al

Site Plan

Scale 1:300

Figure No. A2

Floor Plan

Scale 1:250

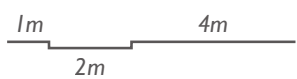




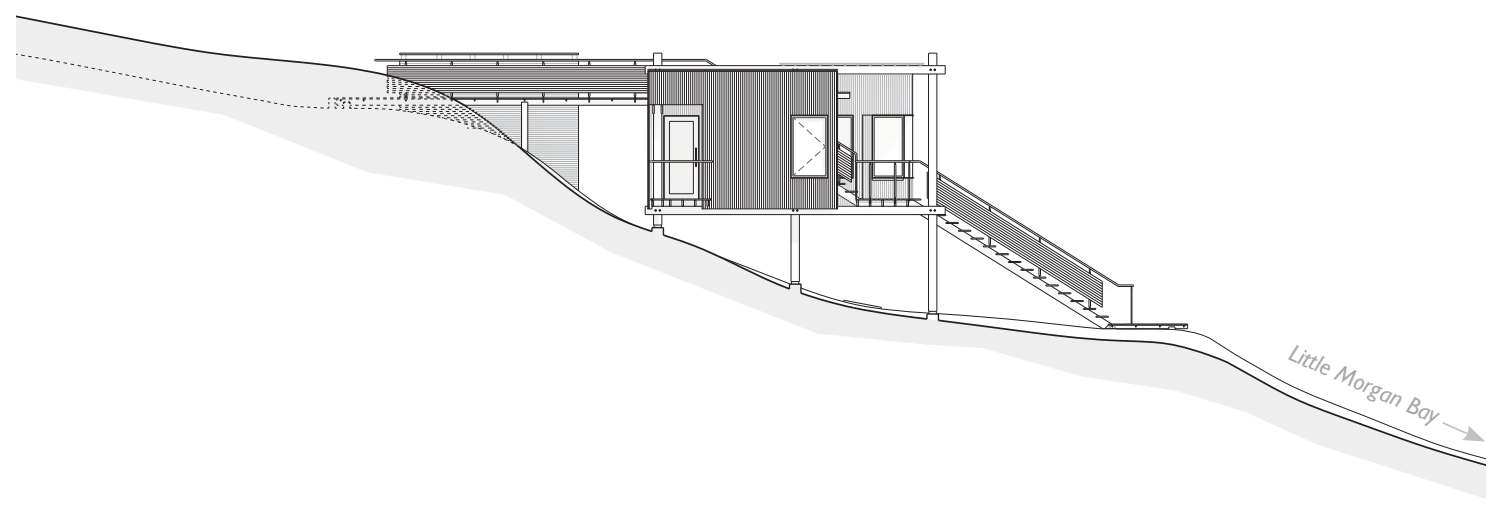

Figure No. A3 West Elevation Scale 1:250

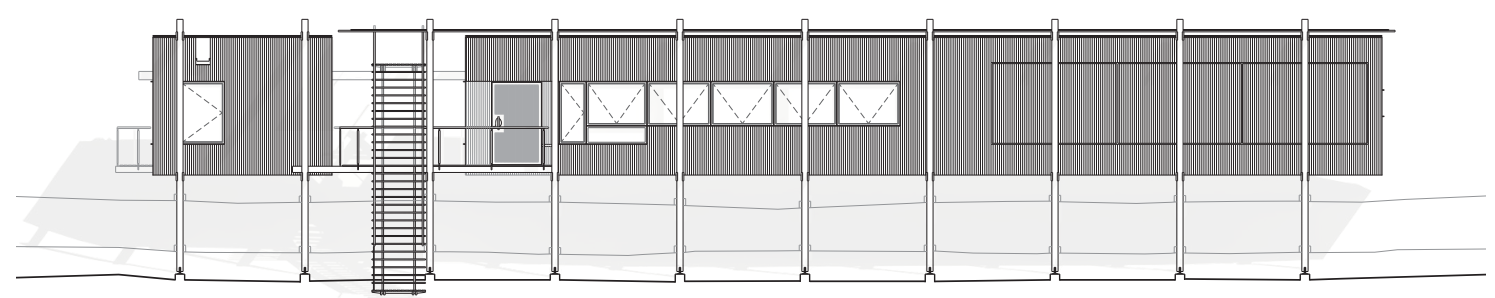

Figure No. A4 


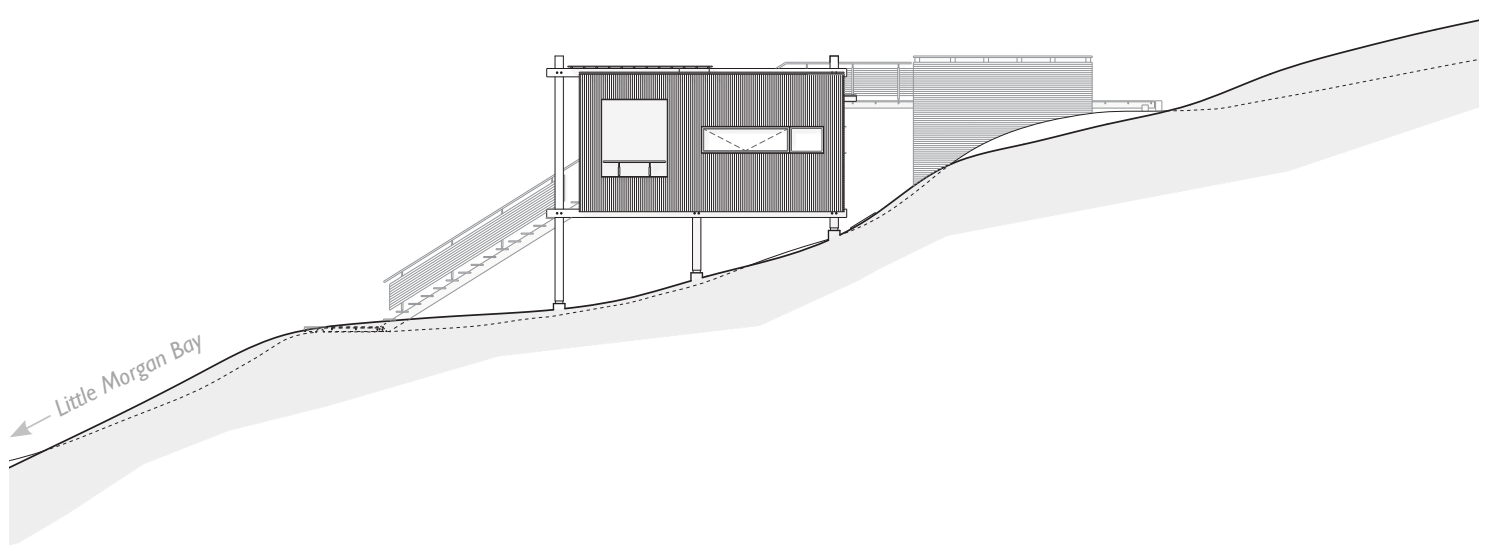

Figure No. A5

East Elevation

Scale I:250

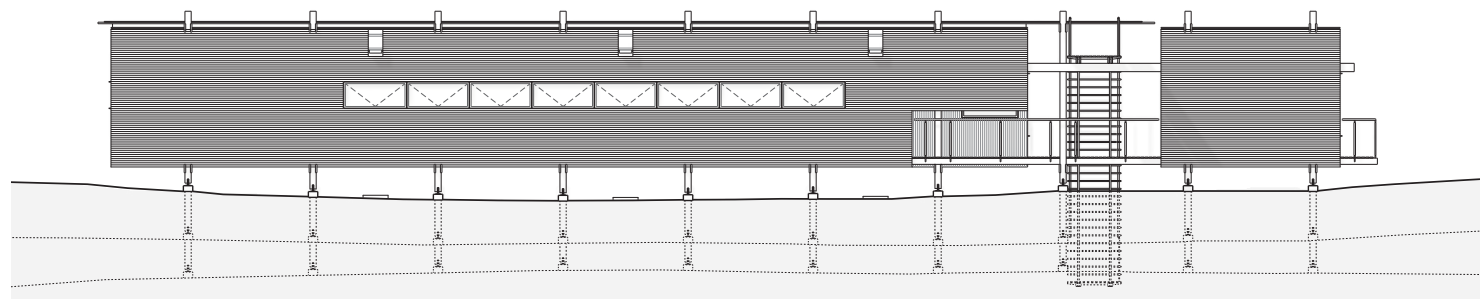

Figure No. A6

North Elevation

Scale I:250 
$102 \mid$ APPENDIXA

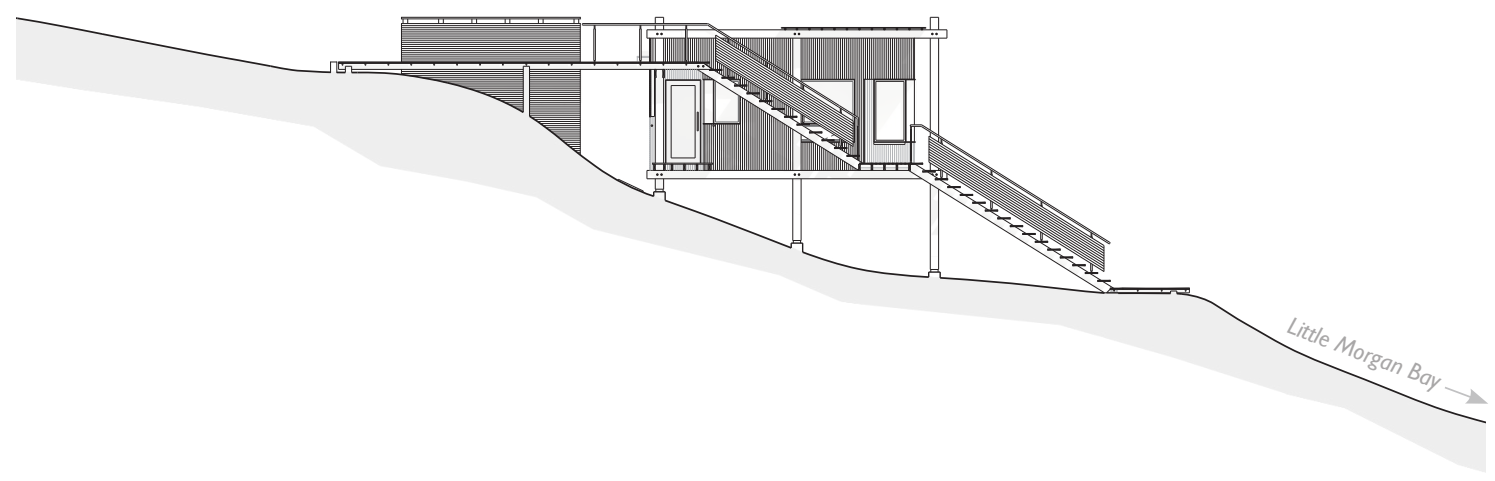

Figure No. A7

Section A-A

Scale I:250 


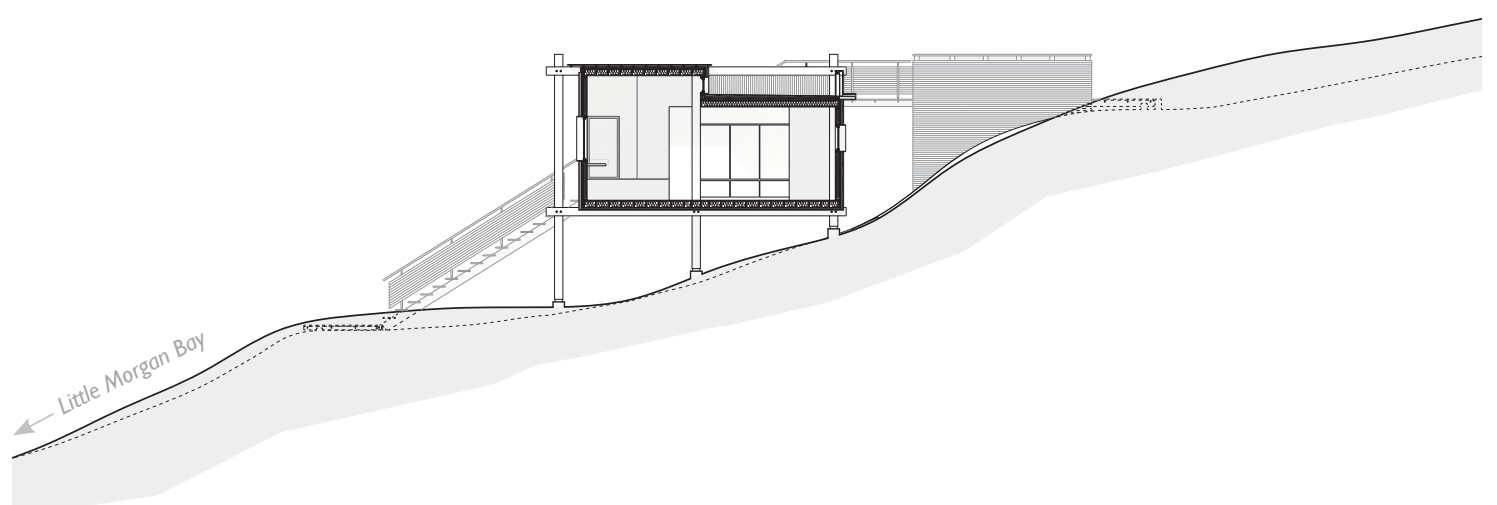

Figure No. A8

Section B-B

Scale 1:250

Figure No. A9

Section C-C

Scale I:250 


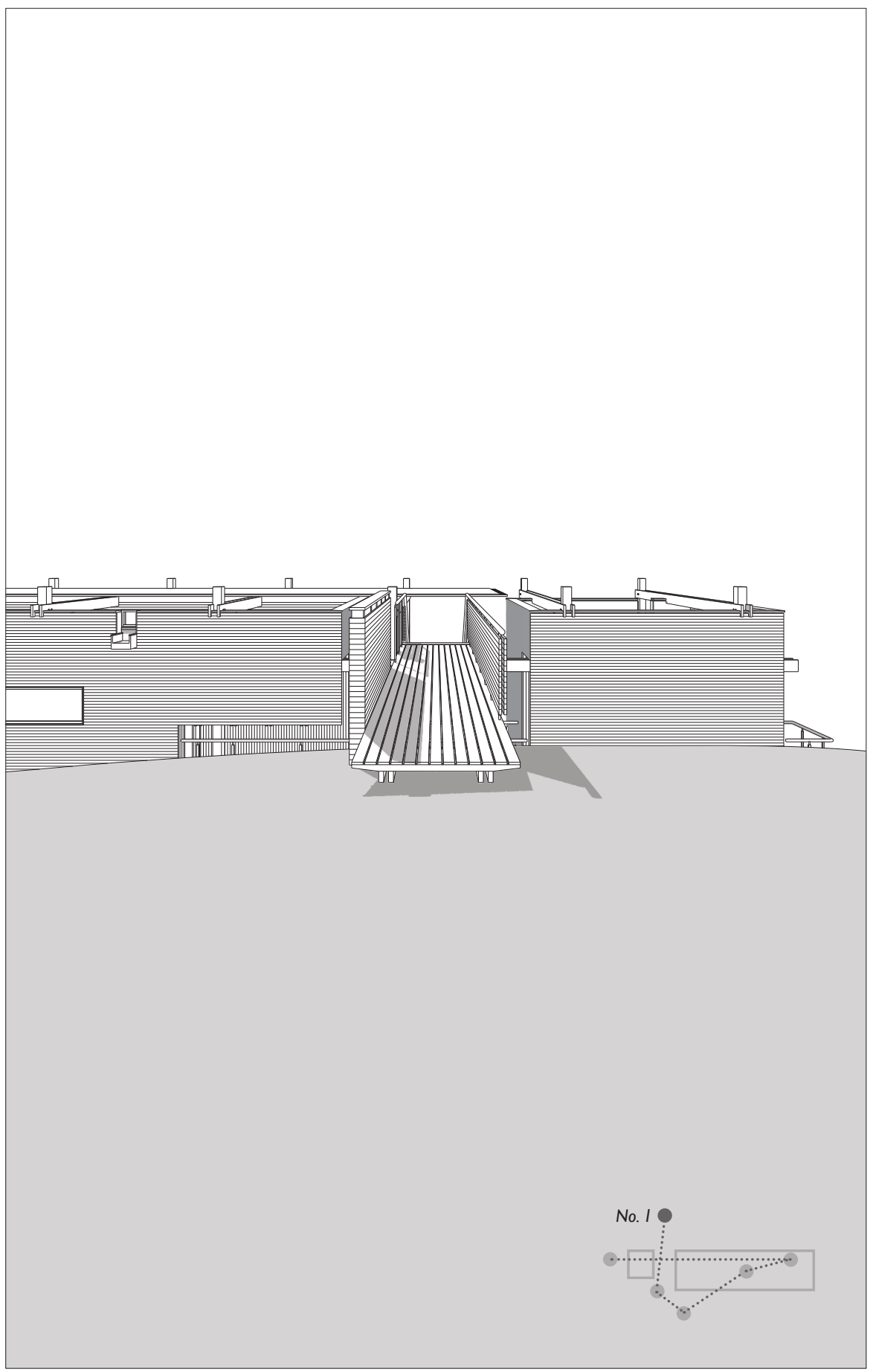

Figure No. BI

Perspective Drawing No. I 
Figure No. B2

Perspective

Drawing No. 2

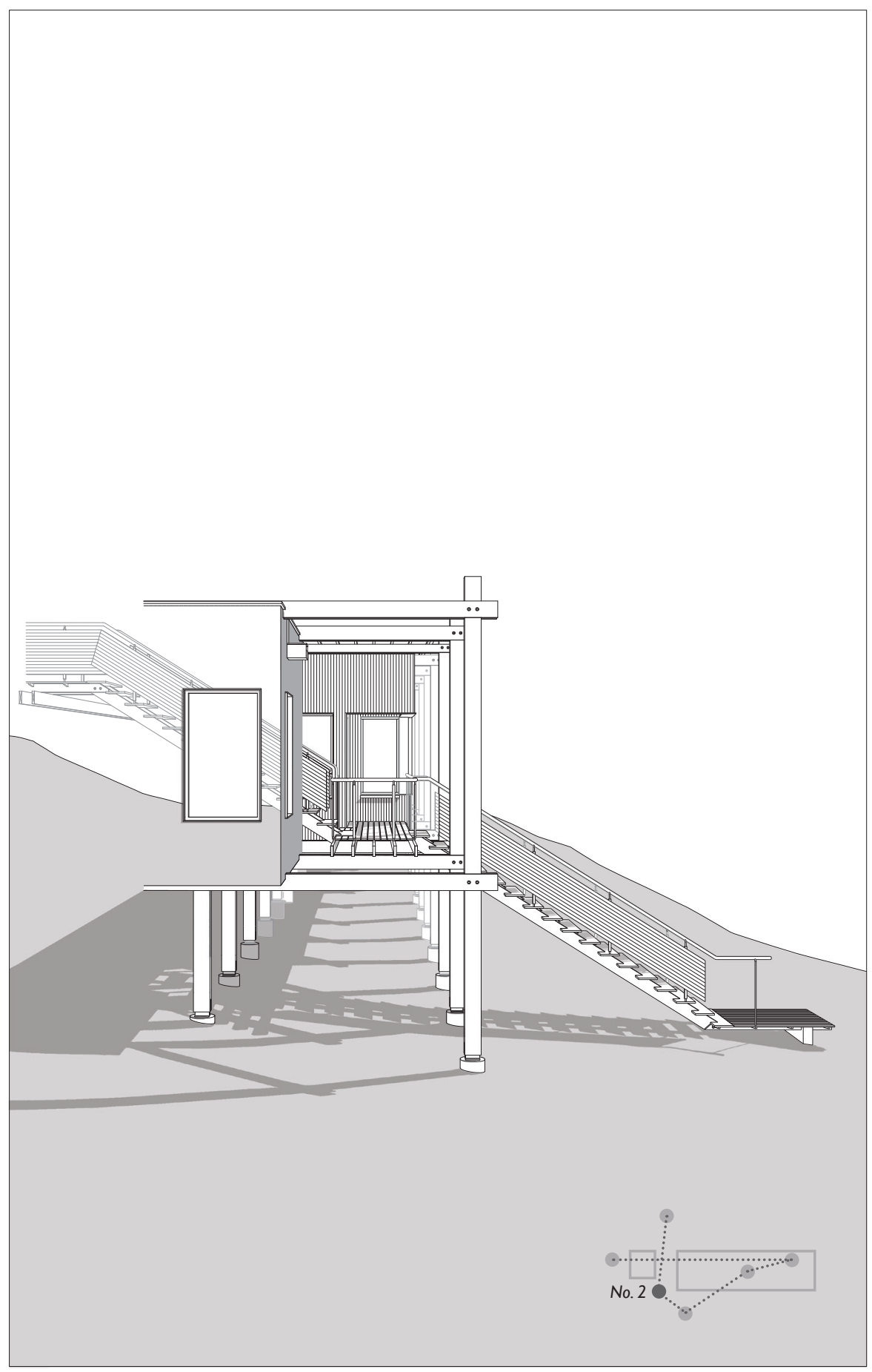




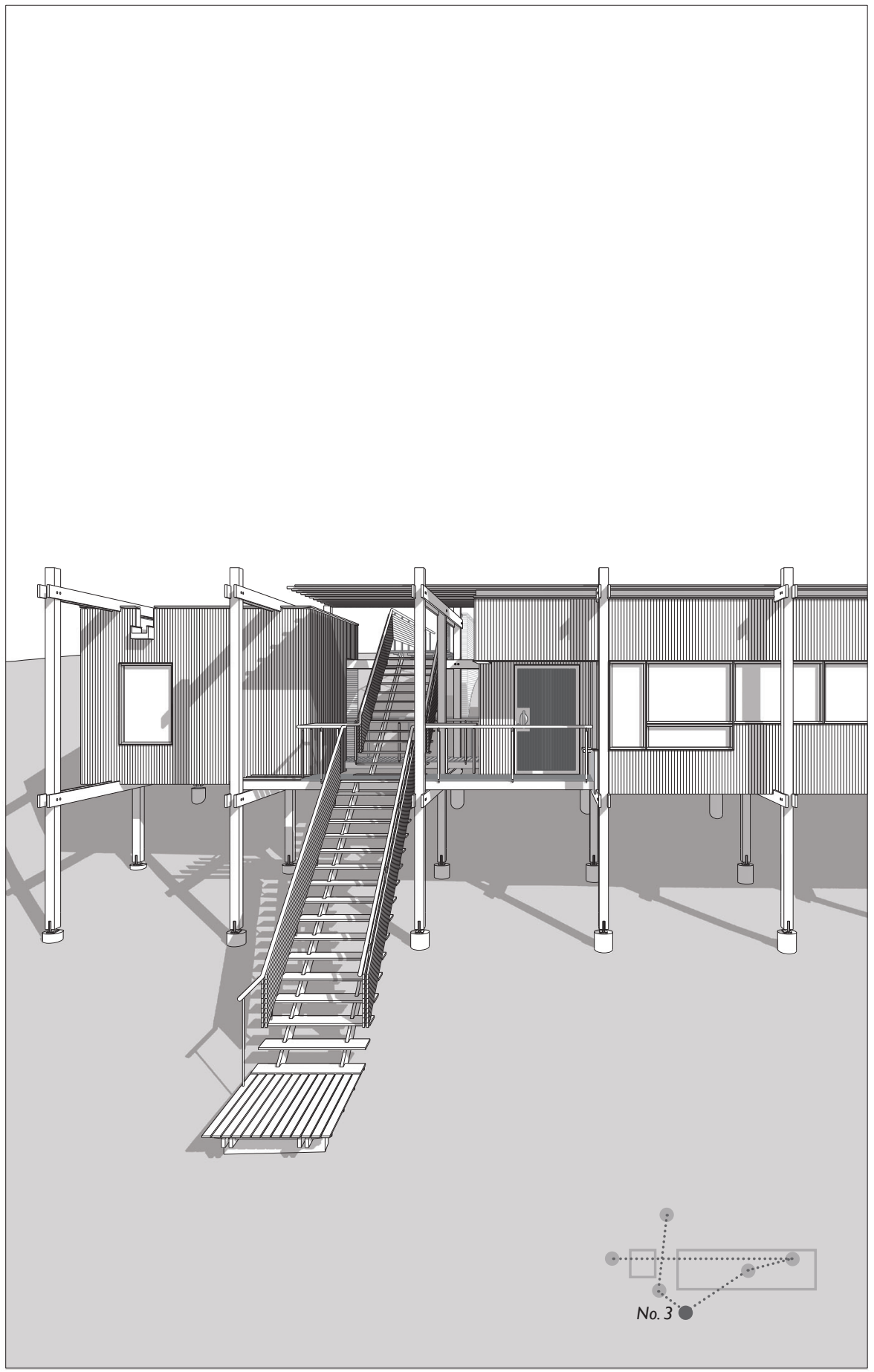

Figure No. B3 Perspective Drawing No. 3 
Figure No. B4

Perspective Section A

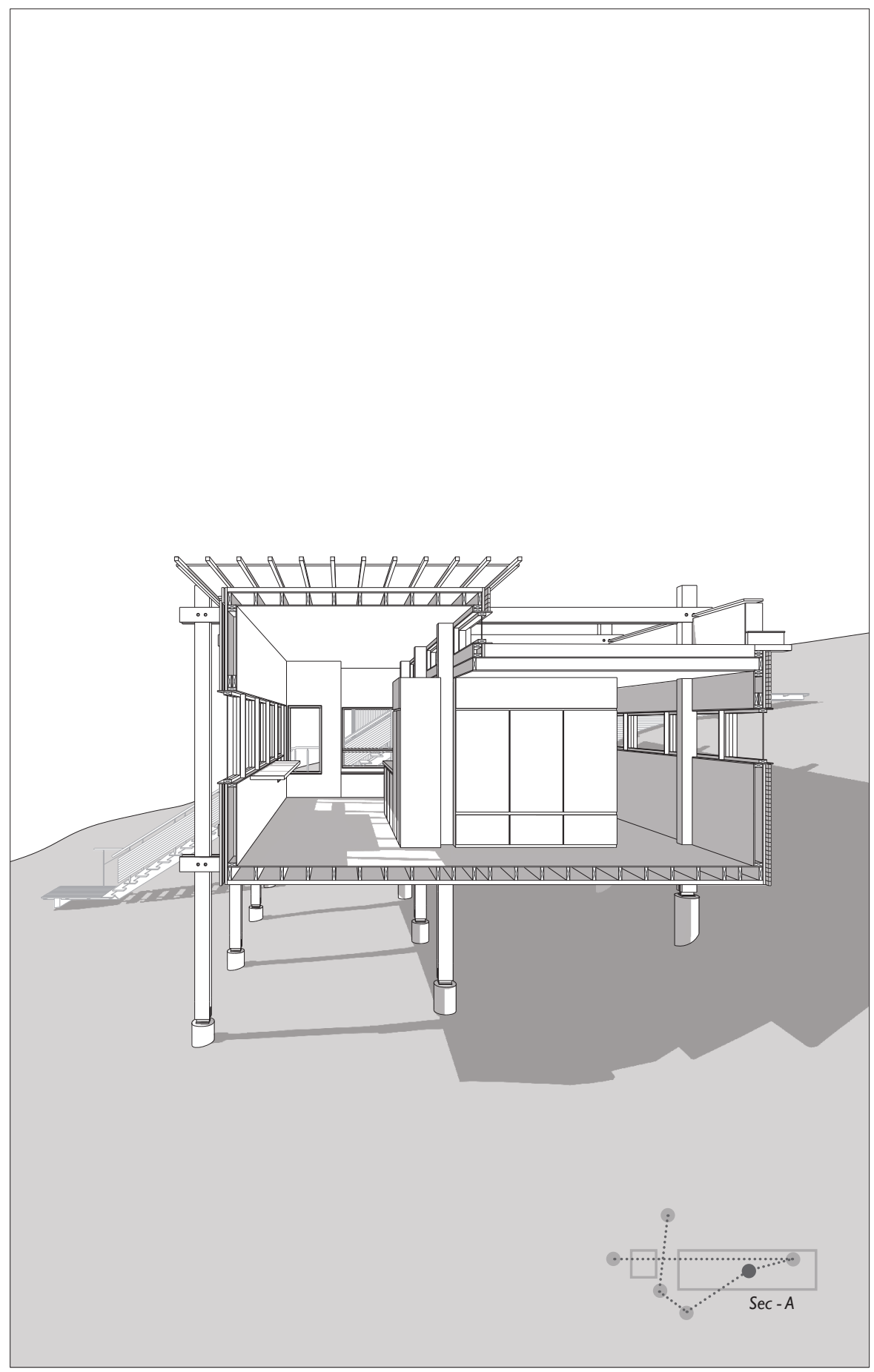




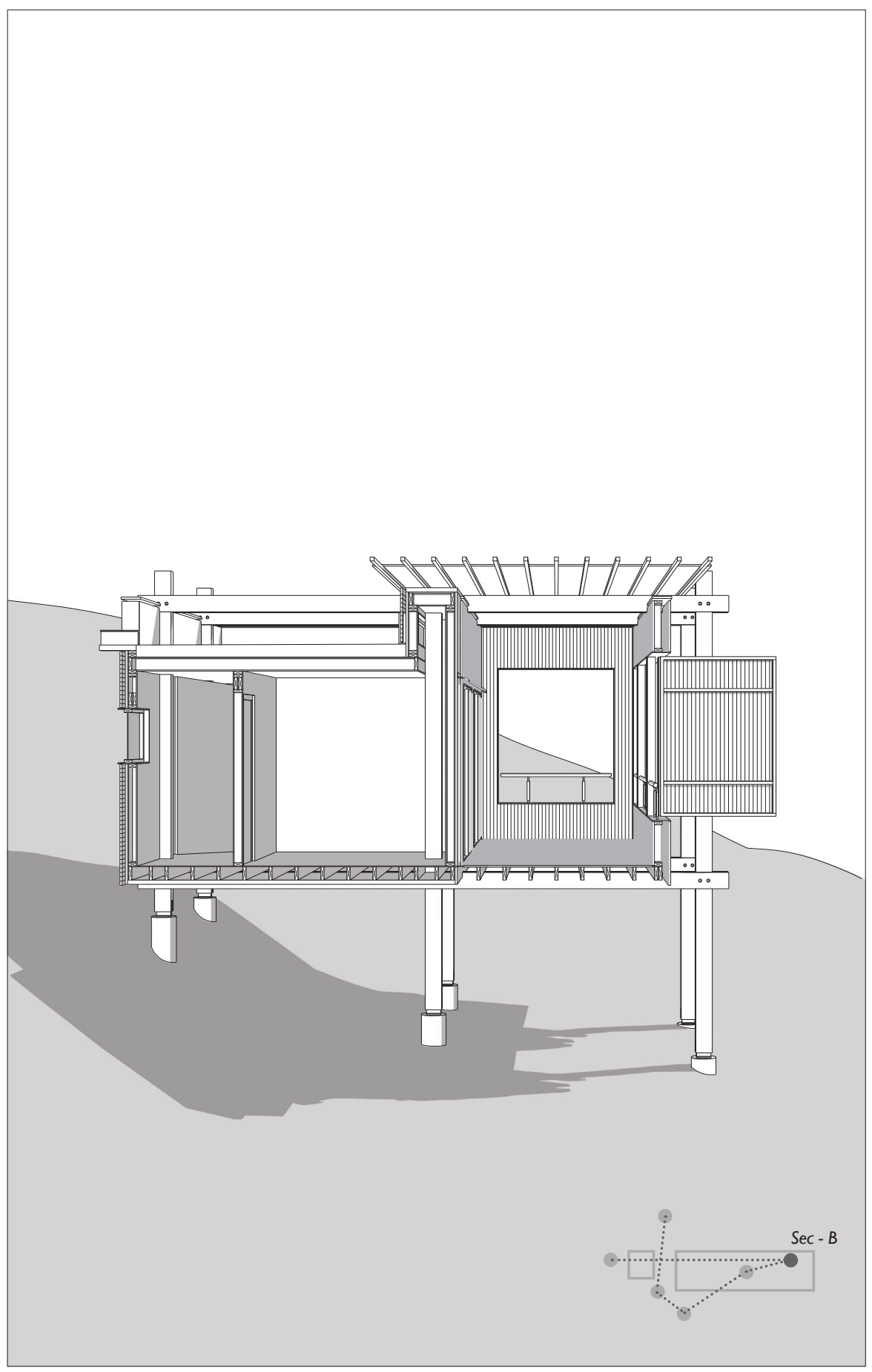

Figure No. B5

Perspective

Section B 
Figure No. B6

Perspective

Drawing No. 4

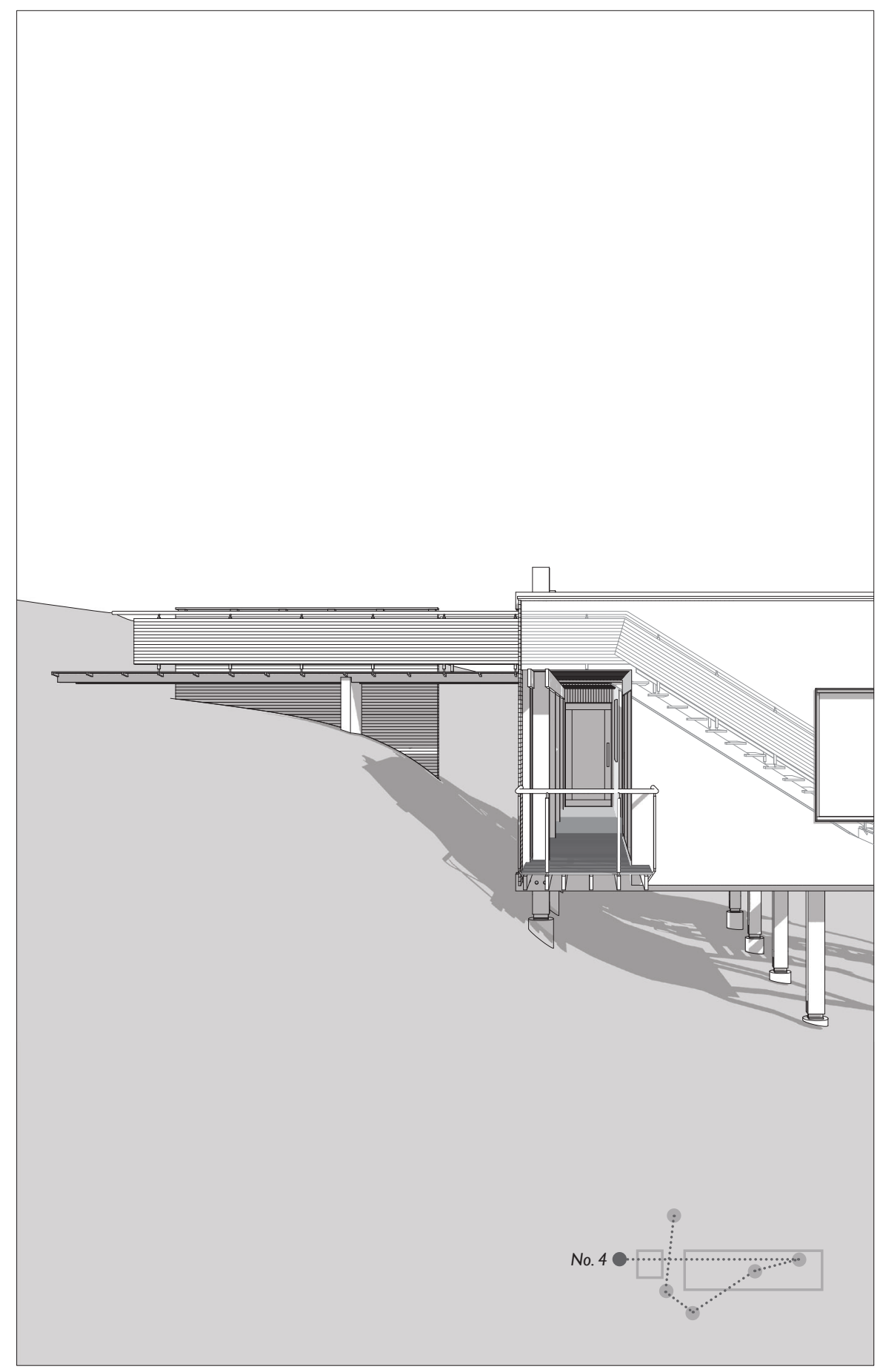


$110 \mid$ APPENDIX C

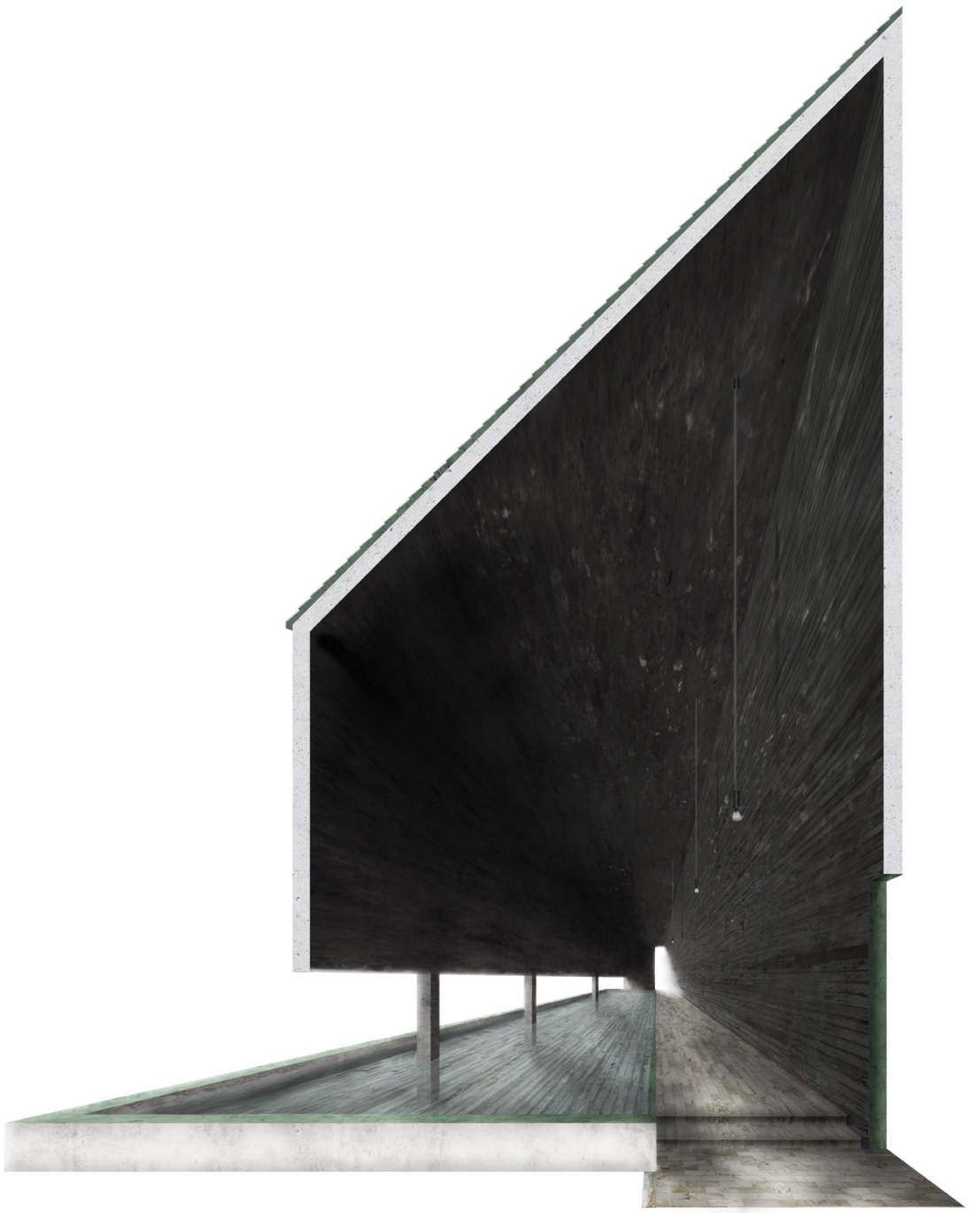

Figure No. Cl

Preliminary Drawing Study Spatial Study No. I 


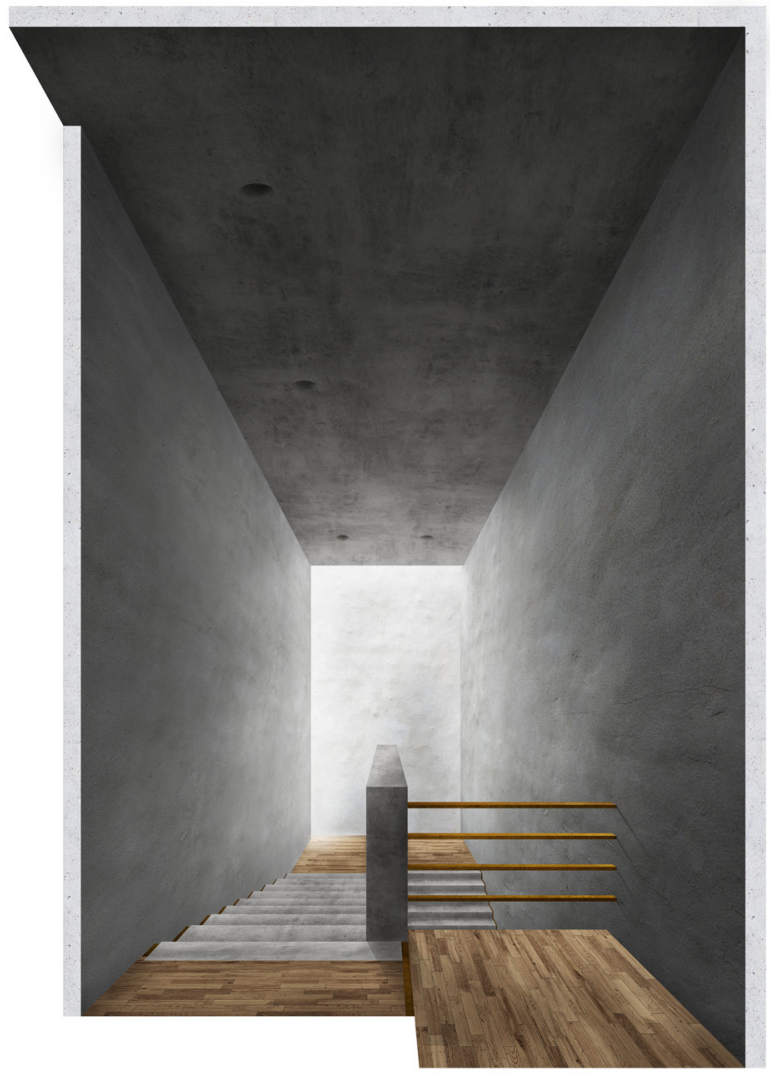

Figure No. C2

Preliminary Drawing Study

Spatial Study No. 2 


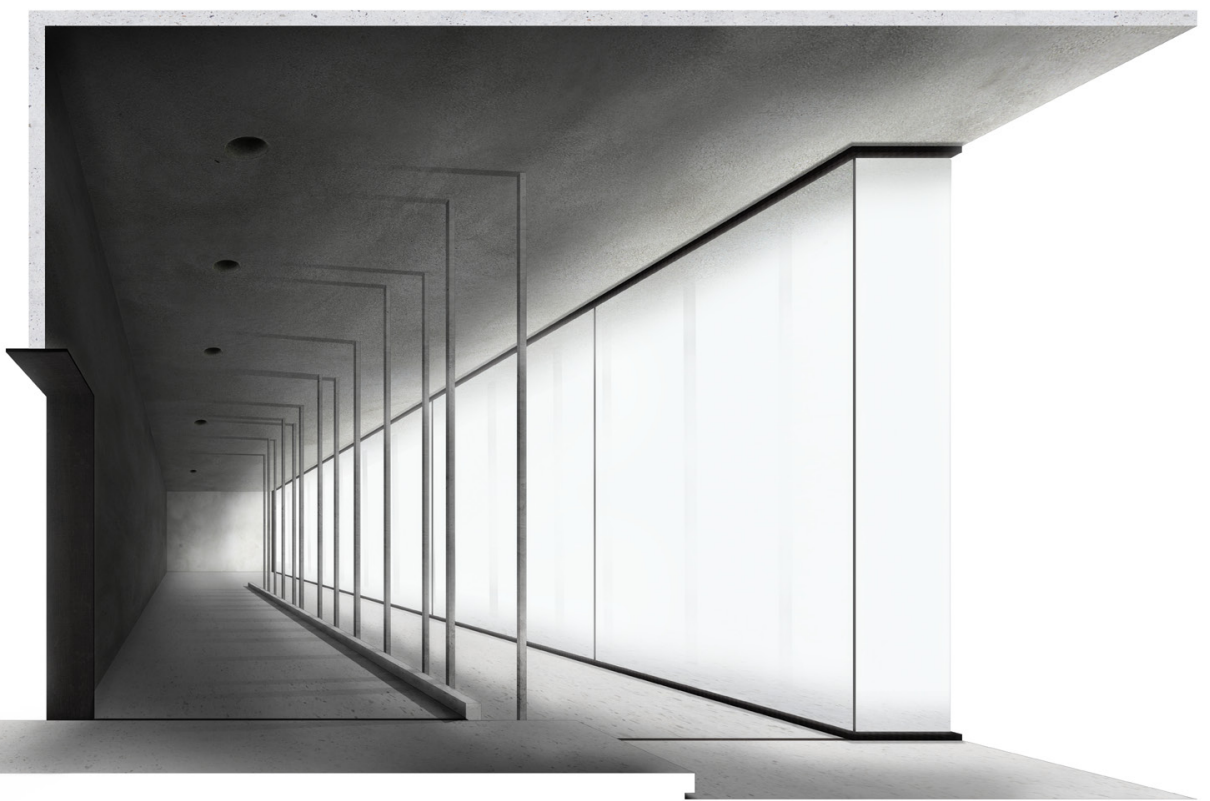

Figure No. C3

Preliminary Drawing Study Spatial Study No. 3 


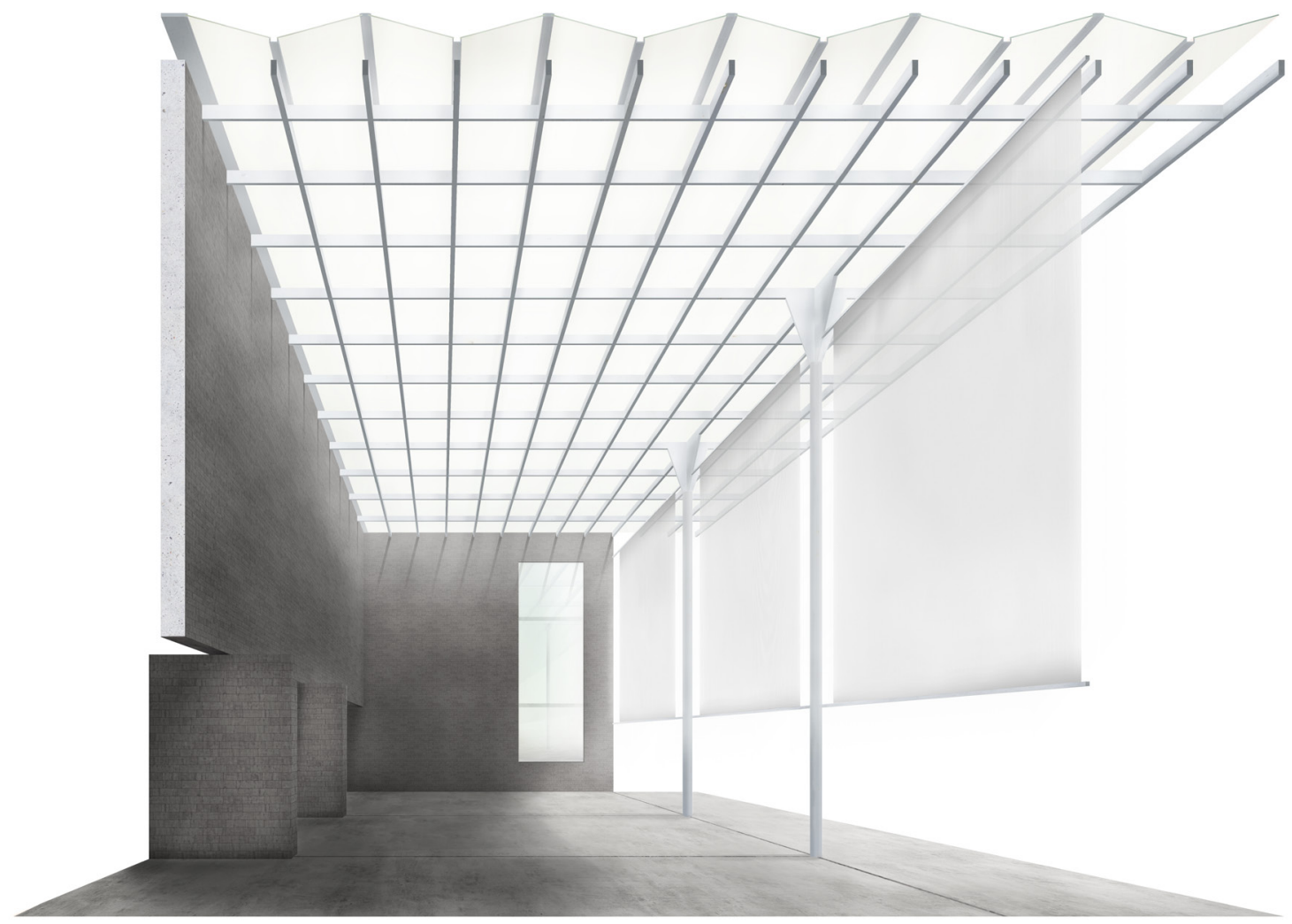

Figure No. C4

Preliminary Drawing Study

Spatial Study No. 4 



\section{Endnotes}

1. Suriano, Matthew Anthony. "What is Architecture: ASC 103 The Built Context." (Toronto, December 2, 2008).

2. Borges, Jorge Lusi. This Craft of Verse. (Cambridge: Harvard University Press, 2000), 18.

3. Reiser, Jesse, and Umemoto Nanako. Atlas of Novel Tectonics. (New York: Princeton Architectural Press, 2006), 11.

4. Wigley, Mark. “The Architecture of Atmosphere.” (Daidalos, 1998: 18-27), 27.

5. Cayne, Bernard S, and Lexicon Publications. The New Lexicon Webster's Dictionary Of The English Language. (New York: Lexicon Publications Inc., 1998), 59.

6. Addington, Michelle, and Daniel Schodek. Smart Materials and New Technologies: For Architecture and Design Professions. (New York: Elsevier, 2005), 7.

7. Ibid.

8. National Gallery of Canada. "Mark Ruwedel: 1945 -". Accessed June 25, 2015. http:/ / www.gallery.ca/en/see/collections/artist.php?iartistid $=4808$.

9. Merleau-Ponty, Maurice. "The Film and the New Psychology." In Sense and NonSense, by Maurice Merleau-Ponty, 48-59. (Evanston: Northwestern University Press, 1964), 48.

10. Zumthor, Peter. Atmospheres: Architectural Environments - Surrounding Objects. (Basel: Birkhäuser, 2006), 13.

11. Ibid. 
12. Bohme, Gernot. "Urban Atmospheres: Charting New Directions for Architecture and Urban Planning." In Architectural Atmospheres: On the Experience and Politics of Architecture, by Christian Borch, 42-59. (Basel: Birkhauser, 2014), 43.

13. Bohme, Gernot. "Atmosphere as the Subject Matter of Architecture.” In Herzog \& De Meuron: Natural History, by Philip Ursprung, 398-406. (Baden: Lars Muller Publishers, 2002), 402.

14. Bohme, Gernot. "Encountering Atmospheres: A Reflection on the Concept of Atmosphere in the Work of Juhani Pallasmaa and Peter Zumthor." (OASE Journal for Architecture, 2013: 93-100), 97-99.

15. Borch, Christian. "The Politics of Atmospheres: Architecture, Power, and the Senses." In Architectural Atmospheres: On the Experience and Politics of Architecture, by Christian Borch, 60-89. (Basel: Birkhauser, 2015), 80.

16. Russell, Bertrand. History of Western Philosophy. (London: Routledge Classics, 2004), 52 .

17. Ibid.

18. Plato. Republic. Translated by G.M.A. Grube and Revised by C.D.C. Reeve. (Indianapolis: Hackett Publishing Company, 1992), 187-188.

19. Ibid., 188-189.

20. Ibid., 187-188.

21. Hill, Jonathan. Immaterial Architecture. (New York: Routledge, 2006), 2. 
22. Bohme, "Urban Atmospheres: Charting New Directions for Architecture and Urban Planning”, 45.

23. Speaks, Michael. "Intelligence after Theory." (Perspecta 38, 2006: 101-106), 104.

24. Speaks, "Intelligence after Theory", 103; Stan, Allen. Points + Lines: Diagrams and Projects for the City. (New York City: Princeton Architectural Press, 1999), 49.

25. Ibid.; Ibid., 49-50.

26. Speaks, "Intelligence after Theory", 104.

27. Pallasmaa, Juhani. "Space, Place, and Atmosphere: Peripheral Perception in Existential Experience." In Architectural Atmospheres: On the Experience and Politics of Architecture, by Christian Borch, 18-41. (Basel: Birkhauser, 2014), 22.

28. Ibid., 22-24.

29. Bohme, "Atmosphere as the Subject Matter of Architecture", 402.

30. Borch, Christian. "Introduction: Why Atmospheres?” In Architectural Atmospheres: On The Experience and Politics of Architecture, by Christian Borch, 6-17. (Basel: Birkhauser, 2015), 8.

31. Bohme, Gernot. "Atmosphere as Mindful Physical Presence in Space.” (OASE Journal for Arcbitecture, 2013: 21-32), 29.

32. Bohme, "Urban Atmospheres: Charting New Directions for Architecture and Urban Planning", 43. 
33. Shaw, Philip. The Sublime: The New Critical Idiom. (New York City: Routledge, 2006), 48.

34. Ibid, 49 .

35. Bohme, "Atmosphere as the Subject Matter of Architecture", 402.

36. Mitcham, Carl. "Dasein Versus Design: The Problematics of Turning Making Into Thinking." (International Journal of Technology and Design Education, 2001: 27-36), 28-29.

37. Bohme, "Encountering Atmospheres: A reflection on the Concept of Atmosphere in the Work of Juhani Pallasmaa and Peter Zumthor", 99.

38. Borch, "The Politics of Atmospheres: Architecture, Power, and the Senses", 80.

39. Burger, John. Ways Of Seeing. (London: Penguin Books, 1997), 8.

40. Ursprung, Philip. "Beauty and Atmosphere: Portfolio." In Herzog and De Meuron: Natural History, by Philip Ursprung, 354-385. (Baden: Lars Muller Publishers, 2002), 365.

41. Pallasmaa, Juhani, Klaske Havik, Tielens Gus. "Atmosphere, Compassion and Embodied Experience.”(OASE Journal for Architecture, 2013: 33-52), 43.

42. Ibid, 45 .

43. Zumthor, Atmospheres: Architectural Environments - Surrounding Objects, 5.

44. Ibid., 11. 
45. Wigley, "The Architecture of Atmosphere”, 18.

46. Gregotti, Vittorio. "The Exercise Of Detailing." In Theorizing A New Agenda For Architecture: An Anthology of Architectural Thory 1956-1995, by Kate Nesbitt, 494-497. (New York: Princeton Architectural Press, 1996), 496.

47. Wigley, "The Architecture of Atmosphere", 24.

48. Zumthor, Atmosphere: Architectural Environments - Surrounding Objects, 51.

49. Perez-Gomez, Alberto. "The Space of Architecture: Meaning as Presence and Representation.” In Questions Of Perception: Phenomenology Of Architecture, by Steven Holl, Juhani Pallasmaa and Alberto Perez-Gomez, 7-26. (Tokyo: A+U Publishing Co., 2006), 8.

50. Bohme, "Encountering Atmospheres: A Reflection on the Concept of Atmosphere in the Work of Juhani Pallasmaa and Peter Zumthor", 97.

51. Bohme, "Atmosphere as Mindful Physical Presence in Space", 23.

52. Pallasmaa, Juhani. The Eyes Of The Skin. (Chichester: John Wiley \& Sons Ltd, 2011), 56 .

53. Zumthor, Atmosphere: Architectural Environments - Surrounding Objects, 33-35.

54. Lally, Sean. The Air From Other Planets: A Brief History Of Architecture To Come. (Zurich: Lars Muller Publishers, 2014), 23-24.

55. Addington and Schodek, Smart Materials and New Technologies: For Architecture and Design Professions, 7. 
56. Sloterdijk, Peter. Terror From The Air. (Lost Angeles: Semiotext(e), 2009), 18.

57. Lally, The Air From Other Planets: A Brief History Of Architecture To Come, 51.

58. Addington, Michelle. "The Phenomena of the Non-Visual." in Softspace: From a Representation of Form to a Simulation of Space, by Sean Lally and Jessica Young, 38-51. (New York: Routledge, 2009), 39.

59. Hill, Immaterial Architecture, 160.

60. Mostafavi, Mohsen, and David Leatherbarrow. On Weathering: The Life Of Buildings In Time. (Cambridge: The MIT Press, 1993), 16.

61. Pallasmaa, The Eyes Of The Skin: Architecture and the Senses, 41.

62. Sharr, Adam. Heidegger for Architects. (New York: Routledge, 2007), 88.

63. Pallasmaa, Havik, and Gus, "Atmosphere, Compassion and Embodied Experience", 45.

64. Debord, Guy. The Society of The Spectacle. (New York: Zone Books, 1994), 6. 


\section{Bibliography}

Addington, Michelle. "The Phenomena of the Non-Visual." In Softspace: From a Representaion of Form to a Simulation of Space, by Sean Lally and Jessica Young, 38-51. New York: Routledge, 2009.

Addington, Michelle, and Daniel Schodek. Smart Materials and New Technologies: For Architecture and Design Professions. New York: Elsevier, 2005.

Bohme, Gernot. "Atmosphere as Mindful Physical Presence in Space." OASE Journal for Architecture, 2013: 21-32.

Bohme, Gernot. "Atmosphere as the Subject Matter of Architecture.” In Herzog \& De Meuron: Natural History, by Philip Ursprung, 398-406. Baden: Lars Muller Publishers, 2002.

Bohme, Gernot. "Encountering Atmospheres: A Reflection on the Concept of Atmosphere in the Work of Juhani Pallasmaa and Peter Zumthor." OASE Journal for Architecture, 2013: 93-100.

Bohme, Gernot. "Urban Atmospheres: Charting New Directions for Architecture and Urban Planning." In Architectural Atmospheres: On the Experience and Politics of Architecture, by Christian Borch, 42-59. Basel: Birkhauser, 2014.

Borch, Christian. "Introduction: Why Atmospheres?” In Architectural Atmospheres: On The Experience and Politics of Architecture, by Christian Borch, 6-17. Basel: Birkhauser, 2015 .

Borch, Christian. "The Politics of Atmospheres: Architecture, Power, and the Senses." In Architectural Atmospheres: On the Experience and Politics of Architecture, by Christian Borch, 60-89. Basel: Birkhauser, 2015. 
Borges, Jorge Lusi. This Craft of Verse. Cambridge: Harvard University Press, 2000.

Burger, John. Ways Of Seeing. London: Penguin Books, 1997.

Cayne, Bernard S, and Lexicon Publications. The New Lexicon Webster's Dictionary Of The English Language. New York: Lexicon Publications Inc., 1988.

Debord, Guy. The Society of The Spectacle. New York: Zone Books, 1994.

Gregotti, Vittorio. "The Exercise Of Detailing." In Theorizing A New Agenda For Architecture: An Anthology of Architectural Theory 1956-1995, by Kate Nesbitt, 494-497. New York: Princeton Architectural Press, 1996.

Hill, Jonathan. Immaterial Architecture. New York: Routledge, 2006.

Lally, Sean. The Air From Other Planets: A Brief History Of Architecture To Come. Zurich: Lars Muller Publishers, 2014.

Merleau-Ponty, Maurice. “The Film and the New Psychology.” In Sense and Non-Sense, by Maurice Merleau-Ponty, 48-59. Evanston: Northwestern University Press, 1964.

Mitcham, Carl. "Dasein Versus Design: The Problematics of Turning Making Into Thinking." International Journal of Technology and Design Education, 2001: 27-36.

Mostafavi, Mohsen, and David Leatherbarrow. On Weathering: The Life Of Builings In Time. Cambridge: The MIT Press, 1993.

National Gallery of Canada. Mark Ruwedel: 1945 -. June 25, 2015. http://www. gallery.ca/en/see/collections/artist.php?iartistid $=4808$ (accessed June 25, 2015). 
Pallasmaa, Juhani. "Space, Place, and Atmoshere: Peripheral Perception in Existential Experience." In Architectural Atmospheres: On the Experience and Politics of Architecture, by Christian Borch, 18-41. Basel: Birkhauser, 2014.

Pallasmaa, Juhani. The Eyes Of The Skin. Chichester: John Wiley \& Sons Ltd, 2011.

Pallasmaa, Juhani, Klaske Havik, and Gus Tielens. "Atmosphere, Compassion and Embodied Experience.” OASE Journal for Architecture, 2013: 33-52.

Perez-Gomez, Alberto. "The Space of Architecture: Meaning as Presence and Representation.” In Questions Of Perception: Phenomenology Of Architecture, by Steven Holl, Juhani Pallasmaa and Alberto Perez-Gomez, 7-26. Tokyo: A+U Publishing Co., 2006.

Plato. "Republic.” By Translated by G.M.A. Grube and Revised by C.D.C. Reeve. Indianapolis: Hackett Publishing Company, 1992.

Reiser, Jesse, and Umemoto Nanako. Atlas of Novel Tectonics. New York: Princeton Architectural Press, 2006.

Russell, Bertrand. History of Western Philosophy. London: Routledge Classics, 2004.

Sharr, Adam. Heidegger for Architects. New York: Routledge, 2007.

Shaw, Philip. The Sublime: The New Critical Idiom. New York City: Routledge, 2006.

Sloterdijk, Peter. Terror From The Air. Los Angeles: Semiotext(e), 2009.

Speaks, Michael. “Intelligence after Theory.” Perspecta 38, 2006: 101-106. 
Stan, Allen. Points + Lines: Diagrams and Projects for the City. New York City: Princeton Architectural Press, 1999.

Ursprung, Philip. "Beauty and Atmosphere: Portfolio." In Herzog \& De Meuron: Natural Hisotry, by Philip Ursprung, 354-385. Baden: Lars Muller Publishers, 2002.

Wigley, Mark. “The Architecture of Atmosphere.” Daidalos, 1998: 18-27.

Zumthor, Peter. Atmospheres: architectural environments - surrounding objects. Basel: Birkhäuser, 2006. 